\title{
Rastreamento de câncer de pele em um município de colonização pomerana do Estado do Espírito Santo, $1997-2002$
}

\section{Rita de Cássia Cunha Rocha}

Dissertação apresentada ao Programa de Pós-Graduação em Saúde Pública para obtenção do título de Mestre em Saúde Pública.

Área de concentração: Epidemiologia

Orientador: Prof. Dr. Délsio Natal

São Paulo

2005

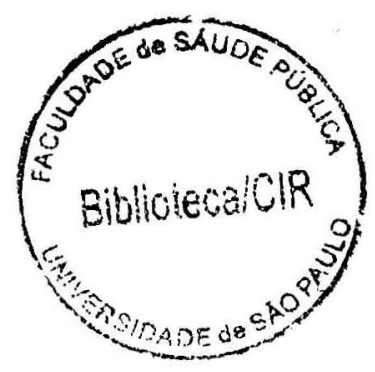


Autorizo, exclusivamente para fins acadêmicos e científicos, a reprodução total ou parcial desta tese, por processos fotocopiadores, com citação da fonte.

Rita de Cássia Cunha Rocha.

18 de fevereiro de 2005. 


\section{AGRADECIMENTOS}

Ao Prof. Dr. Carlos Cley Coelho pela sua sensibilidade em reconhecer que pomeranos merecem atenção especial e também por proporciona-me a rica experiência de fazer parte da equipe médica do programa em estudo.

Ao Dr. Roberto Pagung em persistir em manter a eqüidade para os lavradores pomeranos.

Ao Arlindo Lagass, agente de saúde que contribuiu para a inserção do pomerano na comunidade espírito-santense.

À Prof ${ }^{a}$ Dra. Lygia Busch Iversson, incentivadora e colaboradora no conhecimento dos hábitos dos lavradores pomeranos.

Ao Prof. Delsio Natal, amigo e orientador da minha dissertação.

Ao Prof. João A. Sossai pela dedicação a todos os mestrandos.

À Prof $f^{a}$ Maria Cecília Goi Porto Alves pelas suas considerações relevantes.

À Associação Martin Lutero ; à Secretaria de Estado da Saúde do Espírito Santo; à Universidade Federal do Espírito Santo e às Secretarias Municipais de Saúde de Afonso Cláudio, Itarana, Itaguaçu, Domingos Martins, Baixo Guandu, Vila Pavão, Vila Valério, Laranja da Terra, Pancas, São Roque do Canaã e Santa Maria de Jetibá, parceiros do convênio de cooperação técnica para viabilização do "Programa de Assistência Dermatológica ao Lavrador Pomerano no Interior do Estado".

À Secretaria Municipal de Saúde de Santa Maria de Jetibá que contribuiu para o estudo de forma especial.

À equipe técnica e à equipe organizadora do programa, parceiros na caminhada. 
Agradeço à Secretaria de Estado da Saúde do Espírito Santo que financiou o referido curso de mestrado. 


\section{RESUMO}

Rocha RCC. Rastreamento de câncer de pele em município de colonização pomerana do Estado do Espírito Santo, 1997-2002. São Paulo; 2005.[ Tese de Mestrado- Faculdade de Saúde pública da Universidade de São Paulo ].

Fundamentos: O "Programa de Assistência Dermatológica aos Lavradores Pomeranos no Interior do Estado do Espírito Santo" cobre 11 municípios do interior do Estado do Espírito Santo com o objetivo de diagnosticar e tratar precocemente os casos. Escolheuse estudar o município de Santa Maria de Jetibá, por apresentar, num estudo estatístico no ano de 2000, o maior número de casos de câncer de pele dentre estes municípios. Os pomeranos chegaram a Santa Maria de Jetibá nos anos de 1872 e 1873, formando a maior colônia existente no Estado. São lavradores, expondo-se ao sol por horas seguidas desde a infância, quando iniciam a atividade no campo. Apresentam pele tipo 1 ou 2 que, somado às condições tropicais do seu território e insuficientes medidas de proteção solar individual ou coletiva, favorecem ser reconhecidos como grupo de risco para câncer de pele. Objetivo: Analisar a contribuição de um programa de rastreamento de câncer de pele como estratégia de prevenção secundária, no período de 1997 a 2002 com enfoque no munićpio de Santa Maria de Jetibá. Métodos: Analisados 345 pacientes que demandaram atendimento de consulta dermatológica no programa, resultando na análise de 432 lesões com diagnóstico clínico de câncer de pele. Dessas, 318 lesões foram confirmadas histopatologicamente como câncer de pele, ocorridas em 237 pacientes. Foram descritos as variáveis segundo sexo, idade, atividade principal, número de lesões, origem étnica, tipo de pele, número de horas de exposição ao sol no dia, horário de exposição ao sol no dia, uso de protetor contra o sol, história de câncer de pele na família, história de outros cânceres de pele na família, número de casos por local de atendimento, local da lesão, tipo de câncer de pele e tipo de tratamento. Resultado: Do total de 318 lesões confirmadas histopatològicamente como câncer de pele, $80,8 \%$ foram Carcinoma Basocelular, 10,7 \% Carcinoma espinocelular, 2,5 Melanoma, 3,1 \% Carcinoma espinocelular in situ, 0,9\% Melanoma in situ e 1,9\% Carcinoma Misto. Dos pacientes com câncer de pele confirmado pelo exame histopatológico, $86,2 \%$ da área 
urbana e $98,2 \%$ da área rural eram lavradores. A origem étnica pomerana/alemã aparece com percentuais importantes sendo 91, 1\% materna e 92, 5\% paterna Apresenta-se um percentual alto de $85,6 \%$ no município com tipo de pele 1 e 2 . Dentre outras importantes variáveis, destaca-se o início da atividade na lavoura que tem um percentual expressivo de 88,2 de acometimento na faixa etária maior ou igual a nove anos até 15 anos de idade, encontrado no ano de 2002.

Conclusão: $O$ rastreamento do câncer de pele como experiência no Espírito Santo mostrou-se efetivo como estratégia de prevenção secundária, ou seja, no diagnóstico precoce dos casos a cada ano, principalmente pelo seu alto grau de acerto clínico $(82,4$ \%) e sua resolutividade no tratamento das lesões de câncer de pele, tendo como etapa anterior o diagnóstico e tratamento das lesões pré-câncer. A prevenção de ocorrência de casos de câncer de pele inclui, como uma das recomendações ao município, a divulgação do índice de radiação ultravioleta diária e a dose eritematosa mínima à população e o aconselhamento sobre proteção solar às crianças e aos adolescentes.

Descritores: rastreamento de câncer de pele, lavradores pomeranos, proteção solar. 


\begin{abstract}
Rocha RCC. Skin cancer screening in pomerana settling county in State of Espírito Santo, 1997 -2002. São Paulo; 2005 [Master's Thesis- School of Public Health University of São Paulo Brasil].
\end{abstract}

Foundation: The "Program of Dermatological Assistance to Pomeranos Ploughmen in Espirito Santo state" covers 11 municipalities from the back lands of Espírito Santo with early occurrences diagnosis and treatment. It was chosen to study Santa Maria de Jetiba county, because it presents in a statistic study in the year of 2000 the greatest number of skin cancer among these counties. Pomeranos arrived in Santa Maria de Jetiba in the years of 1872 and 1873, forming the biggest existing colony in the State. They are ploughmen that are exposed to sun for successive hours since infancy, when they begin the countryside activity. They present skin type 1 or 2 , sun-sensitive skin that combined to tropical conditions of their territory and insufficient individual or collective solar protection resources, favor to recognize them as a skin cancer risk group. Objetive: Analyze the contribution of a skin cancer screening program as strategy of secondary prevention, in the period of 19972002 with approach in Santa Maria de Jetibá county. Methods: Analyzed 345 patients who had demanded attendance of dermatological consultation in the program, resulting in the analysis of 432 injuries with clinical diagnosis of skin cancer. Of these, 318 injuries had been confirmed histologically as skin cancer, occurrenced in 237 patients. The variable according to sex, age, main activity, number of injuries, ethinic origin, type of skin, number of hours of exposition to the sun in the day, schedule of exposition to the sun in the day, use of protection against the sun, history of cancer skin in the family, history of other cancers skin in the family, number of cases for attendance place, place of the injury, type of skin cancer and type of treatment. Results: Of the total 318 injuries confirmed histologically as skin cancer, $80,8 \%$ had been basal cell carcinoma, $10,7 \%$ squamous cell carcinoma, 2,5 cutaneous malignant melanoma, 3.1\% squamous cell carcinoma in situ, 0,9 $\%$ cutaneous malignant melanoma in situ and $1,9 \%$ mixter carcinoma. Of the patients with skin cancer confirmed histologically, $86,2 \%$ of urban area and $98,2 \%$ of rural area were 
ploughmen. The ethnic origin pomerana/german appears with important percentages being 92,5 paternal and 91,1 maternal. A high percentage of $85,6 \%$ is presented in the city with type of skin 1 and 2; Among other important variable, the beginning of the farming activity has a high percentage of 88,2 in between kids on their nine years of age up to 15 years old; Conclusion: The skin cancer screening as experience in Espírito Santo State revealed effective as strategy of secondary prevention, or either, in the precocious diagnosis of the cases each year, by its high degree of clinical achievements $(82,4 \%)$ and its effect treatment of the injuries of skin cancer and having as previous stage the diagnosis and treatment of pre-skin cancer injuries. The prevention of the cases occurrences, including recommendation of the daily ultraviolet minimum "eritematosa" dose and public awareness, as also a children and teenagers counseling program in the local area of health and education for solar protection.

Descriptors: skin cancer screening, pomeranos ploughmen, solar protection. 


\section{ÍNDICE}

I-INTRODUÇÃO

II-REVISÃO DA LITERATURA 16

$\begin{array}{ll}1 \text { - O câncer no mundo e no Brasil. } & 16\end{array}$

2- A epidemiologia do câncer de pele no mundo e no Brasil. 21

3- Melanoma: Classificação de Clark e Breslow. 31

4- Radiação ultravioleta. 33

5- Dermastocopia. $\quad 40$

6-Câncer de Pele no Espírito Santo $\quad 41$

6.1-A epidemiologia do câncer de pele não melanoma 41

6.2-A epidemiologia do câncer de pele melanoma 41

7-Os pomeranos: $\quad 42$

7.1-A Pomerânia $\quad 42$

7.2-A vinda dos pomeranos para o Brasil. 43

7.3-A chegada dos pomeranos no Espírito Santo. 44

7.4-A cultura: língua, costumes e hábitos. 45

$\begin{array}{ll}\text { III-OBJETIVOS } & 48\end{array}$

$\begin{array}{ll}\text { 1-Objetivo geral } & 48\end{array}$

2-Objetivo específico $\quad 48$

IV-MATERIAL E MÉTODO $\quad 49$

1-Área de estudo $\quad 49$

2-População 51

3-Instrumentos e Procedimentos $\quad 51$ 
6-Limitação do estudo.

7-Aspectos éticos

V-RESULTADOS

VI- DISCUSSÃO

$\begin{array}{ll}\text { VII-CONCLUSÕES } & 92\end{array}$

$\begin{array}{ll}\text { VIII-RECOMENDAÇÕES } & 93\end{array}$

$\begin{array}{ll}\text { IX-REFERÊNCIAS } & 94\end{array}$

ANEXOS

Anexo 1-Convênio do "Projeto de Extensão Assistência Dermatológica aos Lavradores Pomeranos no Estado do Espírito Santo" celebrado em 1998.

Anexo 2-Convênio da efetivação do "Programa de Assistência Dermatológica aos Lavradores Pomeranos no Estado do Espírito Santo"cclcbrado cm 2003.

Anexo 3-Mapa do Plano Diretor de Regionalização do Espírito Santo

Anexo 4-Atlas da Mata Atlântica no Brasil

Anexo 5-Atlas da Mata Atlântica em Santa Maria de Jetibá 


\section{I-INTRODUÇÃO}

O câncer de pele é o que incide mais no Brasil devido ao aparecimento frequiente de casos de câncer de pele não melanoma. Segundo estimativa do Instituto Nacional do Câncer (INCA), no ano de 2003 seriam diagnosticados 82.000 novos casos de câncer de pele não melanoma em brasileiros resultando em 1.125 b́bitos no mesmo período.

O câncer de pele melanoma, tipo grave devido à alta possibilidade de metástase $\mathrm{e}$ elevada mortalidade, representa $4 \%$ dos tipos de câncer de pele. A exposição a determinados fatores ambientais e a determinação genética de uma população são fatores de risco ao aparecimento de câncer de pele. A exposição excessiva à radiação ultravioleta é o principal carcinogênico para câncer de pele (LIMA e SANTOS 2004).

O Espírito Santo teve estimado, pelo INCA, 1150 casos de câncer de pele não melanoma e 90 casos de câncer de pele melanoma em 2003 (INCA 2003).

Favorecendo ao citado acima, o Estado tem na sua colonização imigrantes pomeranos, alemães, italianos, dentre muitos de origem européia, tendo na sua constituição física pele clara, sensível à radiação solar, e um número considerável de lavradores expostos ao sol, por longo período diário, o que torna o câncer de pele importante nas políticas públicas.

Além de conhecer os fatores de riscos para medidas de prevenção, tem-se que trabalhar com registros de informações, utilizando-se o número real de casos existentes já que estimativas não são fidedignas para um estudo de uma determinada população. 
Assim, o Ministério da Saúde reconhecendo o câncer e sua importância epidemiológica, em 1999 implanta no Brasil um Sistema de Avaliação e Vigilância do Câncer e Seus Fatores de Risco, estimulando os estados a conduzirem esse processo. A coordenação nacional é exercida pelo Instituto Nacional do Câncer (INCA). A Secretaria de Estado da Saúde do Espírito Santo (SES-ES) tem uma coordenação estadual do referido Programa.

As principais ações estão voltadas para a prevenção primária da doença, no intuito de evitar ou diminuir a exposição aos fatores de risco ambientais visto que não se dispõe ainda de meios científicos para mudar a ocorrência do aparecimento do câncer geneticamente determinado. O tabagismo é um fator de risco com programa de controle bem estruturado e com estratégias bem conhecidas. Esse gerou modelo como programa de vigilância epidemiológica. O Ministério da Saúde/INCA e as Secretarias Estaduais de Saúde implantaram o programa de controle do tabagismo e prevenção primária de câncer respaldados na magnitude desse problema, que é traduzida por uma prevalência de 30,6 milhões de fumantes no país, programa este com difusão municipal. Outros fatores de risco para cânceres importantes são o consumo excessivo do álcool, a exposição a irradiações, entre essas a solar, dieta inadequada, substâncias químicas oriundas da exposição ocupacional, comportamentos sexuais de risco, aumentando a chance de exposição a vírus carcinogênicos sexualmente transmissíveis, uso de medicamentos como estrogênio (há controvérsias) e fatores reprodutivos com alterações hormonais (INCA 1998).

Para a implantação de um Programa de Epidemiologia e Vigilância do Câncer, principalmente no âmbito estadual, tem-se que construir um sistema de informação capaz de gerar tomada de decisões pela análise e disseminação de informações sobre câncer. As principais fontes de dados de incidência são os Registros de Câncer de Base Populacional (RCBP) e os Registros de Câncer de Base Hospitalar (RCH), em relação a dados de mortalidade têm-se o Sistema de Mortalidade (SIM) e os Inquéritos Populacionais em relação a dados de prevalência de um fator de risco, todos inseridos na SES-ES. 
A prevenção e controle do câncer de pele cstão estruturalmente localizados na Coordenação Estadual de Epidemiologia e Avaliação do Câncer da SES-ES. Como o câncer de pele não é de notificação compulsória não se dispõe de um banco de dados específico. Atualmente trabalha-se com os dados das fichas clínico-epidemiológicas do "Programa de Assistência Dermatológica aos Lavradores Pomeranos no Interior do Estado do Espírito Santo". Este programa é desenvolvido em municípios do interior do estado desde o ano de 1987, uma iniciativa do médico dermatologista Prof. Dr.Carlos Cley Coelho, professor da Universidade Federal do Espírito Santo e do agente de saúde Arlindo Lagass da Associação Albergue Martin Lutero.

COELHO (2002) relata que foi a reportagem do jornalista capixaba Rogério Medeiros, do câncer de pele nos pomeranos e o desmatamento no Espírito Santo, o despertar sobre um problema que aparentemente não ocorria, pois quase nenhum pomerano era visto no ambulatório de dermatologia do Hospital Universitário Dr. Cassiano Antônio de Moraes (HUCAM) da Universidade Federal do Espírito Santo antes do ano de 1986. A partir deste ano relata que se surpreendeu ao deparar com grande número de imigrantes pomeranos trazidos ao ambulatório por um agente de saúde que falava o português por eles. As lideranças da Igreja Luterana resolveram construir um albergue para facilitar a vinda dos pomeranos do interior para Vitória e agendar consultas médicas em hospitais públicos, principalmente no HUCAM, devido aos altos preços das consultas particulares. Descreve, ainda, que quase não se fazia nada pelos pacientes que chegavam no seu ambulatório de dermatologia, pois o câncer de pele estava em estado bem avançado, resultando no encaminhamento ao Hospital Santa Rita de Cássia, hospital estadual de alta complexidade, para tratamento mais adequado. Porém nem sempre conseguiam atendimento e voltavam para o interior numa situação mais grave. Diante dessa situação, o Prof. Dr. Carlos Cley Coelho, segundo seu próprio relato, propõe a Pró-Reitoria de Extensão da Universidade Federal do Espírito Santo um projeto para diminuir o alto índice de câncer de pele nos pomeranos com um trabalho de educação preventiva nas comunidades do interior. Iniciou, com dez alunos da Universidade Federal do Espírito Santo, as viagens para vinte municípios do interior, dentre eles, as de Santa Maria de Jetibá, Laranja da Terra, Afonso Cláudio, Itaguaçu, Itarana, Baixo Guandu 
expectativa de vida, considerando a possível vulnerabilidade à sobrevida pelo câncer melanoma.

Com o olhar também na organização de serviços de saúde percebe-se que a média e alta complexidade da atenção oncológica no Estado deverão ser contempladas em consonância com o Plano Diretor de Regionalização do Espírito Santo (PDR-ES), definindo as referências por microrregiões de saúde principalmente até a mais complexa em oferta de diagnóstico e tratamento, referências estadual.

Assim, algumas considerações devem ser indagadas:

1. Como fica o "Programa de Assistência Dermatológica aos Lavradores Pomeranos no Interior do Estado do Espírito Santo" neste novo desenho da rede de atenção oncológica do SUS-ES, diferenciando o seu papel com de competência municipal? 2. E como será o desenho do fluxo de atendimento do paciente com suspeita de câncer de pele? 3. Como o Estado e os municípios tratarão grupos especiais ou de risco de certa patologia?

Propõe-se que as informações contidas nas fichas clínico-epidemiológicas sejam instrumentos utilizados pelos médicos da atenção primária para conhecimento daquela comunidade no seguimento de casos ou mesmo para avaliação dos serviços municipais no enfretamento do problema identificado. A implantação de prontuário médico compartilhado é uma forma de proposta para que as informações das consultas especializadas cheguem aos médicos da atenção primária e aos pacientes. Ainda convive-se com situações em que o paciente não tem retorno do resultado histopatológico, não podendo afirmar que câncer de pele está na sua história pregressa. O mecanismo de interação entre os especialistas e os médicos da atenção primária, deverá incluir o fluxo da resposta do diagnóstico histopatológico.

O desenho da rede de atenção oncológica prevê fluxos bem definidos e garantia de encaminhamento do nível de atenção primária até os Centros de Alta Complexidade em Oncologia (CACON). 
prevenir a incidência de câncer de pele, comum nessa população, freqüentemente submetida à intensa radiação solar, em virtude de seu trabalho essencialmente agrícola. Foram assinados onze convênios com cada município, inclusive com o município de Santa Maria de Jetibá, mantendo sua classificação entre os municípios prioritários para a prevenção e controle do câncer de pele (ANEXO 1).

No mês de junho do ano de 2003, a Secretaria Estadual de Saúde renovou, por mais cinco anos, o convênio para efetivação do "Programa de Assistência Dermatológica aos Lavradores Pomeranos no Interior do Estado do Espírito Santo", precisamente em 11 municípios, em parceria com a Associação Albergue Martin Lutero, Universidade Federal do Espírito Santo e com as Secretarias Municipais de Saúde aonde ocorrem os atendimentos (ANEXO 2).

O programa faz uma visita anual por localidade em finais de semana, cumprindo uma carga horária de oito horas no sábado e quatro horas no domingo. Há um cronograma anual para viabilizar a divulgação da presença da equipe do programa à população feita pelas paróquias luteranas locais e secretarias municipais de saúde e contando, às vezes, com deslocamento de pessoas dos distritos vizinhos através de ônibus fretado por essas instituições. Como a demanda é espontânea, ocorre, em algumas viagens, um número excessivo de consultas aos pacientes, fazendo a equipe trabalhar mais do que as horas previstas.

São essas as localidades cobertas pelo programa:

1-Distrito de Palmeira de Santa Joana localizado no município de Itaguaçu;

2- Sede do município de Itarana;

3- Distrito de Lagoa Serra Pelada localizado no município de Afonso Cláudio;

4- Sede do município de Vila Valério; 
5- Distrito de Crisciúma localizado no município de Laranja da Terra;

6-Distrito de Garrafão e na sede do município de Santa Maria de Jetibá;

7- Sede do município de Baixo Guandu;

8- Sede do município de Vila Pavão;

9- Distrito de Laginha de Pancas localizado no município de Pancas;

10- Distrito de Paraju e na sede do município de Domingos Martins;

11- Sede do município de São Roque do Canaã.

ROCHA (2002) descreve como é a atuação do Programa do nos dias de atendimento no interior do Estado que se inicia aos sábados a $8 \mathrm{~h} 30$ com uma média de vinte estudantes de medicina da Universidade Federal de Medicina do Espírito Santo (UFES), disponibilizados em mesas individualizadas na sala destinada à consulta clínica. É o primeiro contato com a queixa do paciente. Após escreverem o histórico do paciente no prontuário da unidade de saúde ou do arquivo local do programa, examinam toda extensão do tegumento cutâneo sendo sempre valorizado os locais de maior exposição solar. Há um rastreamento das lesões névicas sugestivas de melanoma e das lesões pré-cancerígenas com o levantamento da hipótese diagnóstica clínica realizada pelo estudante. Como o programa é de extensão universitária, todos pacientes examinados pelos estudantes serão encaminhados para um dos três dermatologistas que irá falar do quadro dermatológico do paciente, ensinando sinais e sintomas de qualquer lesão ali surgida, firmando assim o diagnóstico clínico e a conduta terapêutica a ser seguida pelo acadêmico de medicina. É o momento de aprendizagem e da elucidação diagnóstica. 
Nestas comunidades durante os dois dias de trabalho, o programa atende por localidade uma média de 400 pacientes sendo que aproximadamente 10\% das dermatoses têm o diagnóstico clínico de câncer de pele.

Todo o diagnóstico de câncer de pele é encaminhado para a sala de cirurgia, anexa a sala do atendimento clínico, composta em média por 10 estudantes de medicina que já passaram pela cadeira de cirurgia da UFES. Após avaliação cirúrgica, realizada por um dos dois cirurgiões da equipe do programa, ocorre a exerése da lesão com a hipótese clínica de câncer de pele. É o momento da cura, onde se destaca a resolutividade deste programa de rastreamento: diagnóstico feito com cirurgia realizada. Exceções ocorrem, pois alguns pacientes podem possuir lesões que mereçam encaminhamento para centros mais especializados devido ao tamanho da lesão ou mesmo a possível gravidade clínica de necessidade de radioterapia. Toda lesão retirada cirurgicamente é encaminhada para exame histopatológico no Hospital Universitário Dr. Antônio Cassiano de Moraes (HUCAM) para a confirmação do caso de câncer de pele.

Continuando ROCHA (2002), ressalta o preenchimento de uma ficha clínicoepidemiológica para todo paciente com o diagnóstico clínico de câncer de pele, antes do seu encaminhamento para a cirurgia. Esta ficha é resultado da avaliação realizada por uma médica sanitarista e uma enfermeira que destaca principalmente o estilo de vida, a etnia, a principal atividade desenvolvida pelo paciente e sua história familiar de câncer de pele ou /e outros cânceres que não pele. Neste momento enfatiza-se a prevenção do câncer de pele para o paciente e toda sua família.

A ficha clínico-epidemiológica foi implantada em 1996 para o levantamento de variáveis importantes como hábitos de determinada população vulnerável ao aparecimento de casos de câncer de pele. A SES-ES foi assessorada pela Prof . Lygia Busch Iversson da Universidade de São Paulo (USP).

A SES-ES planilhou todas as informações da ficha clínica adotada anteriormente pelo programa, ou seja, do período de 1990 a 1995 . Foi organizada equipe para a 
coleta dessas informações sob a supervisão de duas médicas sanitaristas. Posteriormente, com a coordenação da Dra. Elizabete Santos Madeira, houve uma computação geral dos dados destes pacientes atendidos no período de 1990 a 1995 bem como a consolidação dos dados da ficha clínico-epidemiológica dos anos de 1996 e 1997. Porém como os resultados histopatológicos não foram todos acessados, houve prejuízo em não se divulgar isoladamente as informações sobre os hábitos destas comunidades.

Atualmente, a SES-ES vem trabalhando na consolidação dos dados de câncer de pele deste referido programa para um estudo descritivo do câncer de pele no Estado até o ano de 2003, a partir do ano de 1997 quando houve uma maior adesão à implantação da ficha clínico -epidemiológica.

A implantação de fichas clínico-epidemiológicas no "Programa de Assistência Dermatológica aos Lavradores Pomeranos de Câncer no Interior do estado do Espírito Santo" permite conhecer qual o tipo de câncer de pele que mais incide naquela determinada população e sua frequiência por faixa etária e sexo. Além disso, leva a conhecer seus hábitos, suas atividades profissionais, sua descendência familiar e sua história pregressa familiar em relação ao câncer. Presume-se que todas estas informações contidas nas fichas clínico-epidemiológicas são de muito valor aos municípios, na avaliação das condições de saúde local, sendo efetivo na intervenção para interrupção de determinantes de uma certa doença.

A Prof ${ }^{\text {a }}$ Lygia sugeriu que a SES-ES deveria propor, às autoridades municipais e à própria comunidade pomerana, intervenções locais para mudança de hábitos principalmente ao referente ao trabalho na lavoura em lugares descobertos, expostos ao sol por longas horas diárias. O que se conseguiu foi introduzir além das respostas às perguntas sobre os fatores de risco e seus cuidados diários na lavoura as recomendações sobre o uso de chapéu de abas largas, camisa com manga, calça comprida e uso de protetor solar se a condição financeira permitisse. A SES-ES distribuiu protetores solares, por um período aproximadamente de dois anos, à população coberta pelo programa de assistência dermatologica e por intermédio do 
Programa Estadual Saber Saúde esteve nas escolas municipais, educando alunos sobre os fatores de risco para câncer, nos anos de 2003 e 2004, em que os folders com o slogan "Excesso só se for de Proteção" enfatizam os cuidados com a exposição solar, seus horários mais apropriados e os principais sinais na pele que podem vir a ser um caso de câncer de pele.

No ano de 2004 a SES-ES, com financiamento do Ministério da Saúde/INCA, confeccionou bonés legionários c está fazendo a distribuição $\mathrm{cm}$ todos os locais de atendimento do "Programa de Assistência Dermatológica aos Lavradores Pomeranos no Interior do Estado do Espírito Santo" e estimulando as comunidades a reproduzirem essa confecção, bem como distribuindo folders educativos.

Em relação às informações colhidas nas fichas clínico-epidemiológicas, o Prof. Dr. Carlos Cley Coelho, sentindo a demora da construção do banco de dados da SESES, solicitou a Prof ${ }^{a}$ Eliane Zandonade da Universidade Federal do Espírito Santo análises estatísticas das uma amostra destas fichas (não se tem relato do método de amostragem utilizado) e dos resultados histopatológicos dos pacientes atendidos no interior pelo programa, resultando em três relatórios:

1. No relatório de Análise Estatística para um estudo descritivo sobre o câncer de pele ZANDONADE (2000), analisou estatisticamente 824 fichas clínicoepidemiológicas de 12 postos de atendimento do programa de rastreamento (Marechal Floriano, Palmeira de Santa Joana, Lagoa Serra Pelada, Vila Valério, Crisciúma, Alto Jatiboca, Garrafão, Baixo Guandu, Vila Pavão, Santa Maria de Jetibá, Lajinha de Pancas e Domingos Martins) no período de 1996 a 1998. As variáveis estudadas foram tipo histopatológico, sexo e sítio da lesão. Foi observado que Palmeira de Santa Joana é a localidade de maior número de casos de câncer de pele neste período. Foram 117 casos equivalente a $14,2 \%$ do total estudado. Santa Maria de Jetibá teve 76 casos atendidos, ou seja, 9,2\% da amostra. A localidade de Garrafão que pertence também ao município de Santa Maria de Jetibá foi computado separadamente tendo uma frequiência de 56 casos no mesmo período, o que pode distorcer um posterior estudo descritivo. Encontrado também nesta análise estatística 
que o posto de Santa Maria de Jetibá foi o que apresentou o maior número de lesão do tipo carcinoma espinocelular, equivalente a $17,70 \%$ no ano de 1998 . Somados os dois postos que estão localizados no município de Santa Maria de Jetibá têm-se 132 casos de câncer de pele neste período de estudo o que pode levar a suspeita de que Santa Maria de Jetibá tem o câncer de pele como uma doença importante se comparada com os demais municípios do Estado, incluídos no programa de assistência dermatológica.

2. Neste mesmo ano de 2000, na mesma data de 30 de agosto, a Prof Zandonade apresenta outro relatório de análise estatística para um estudo descritivo sobre o câncer de pele melanoma ao Prof. Dr.Carlos Cley Coelho solicitante do referido estudo. São estudados os mesmos postos de atendimento do estudo anterior, no mesmo período com uma amostra agora de 1097 fichas clínico-epidemiológicas. É demonstrado que o maior número de casos ocorreu no ano de 1998. Foram 15 casos de melanoma equivalente a $39,5 \%$ do total estudado (38 casos). O maior número de casos de melanoma ocorreu em Santa Maria de Jetibá e Vila Pavão com seis casos em cada posto.

3. Mais um relatório estatístico é solicitado pelo Prof. Dr.Carlos Cley Coelho a Prof." Eliane Zandonade para analisar 1097 fichas clínico-epidemiológicas nestes mesmo postos de atendimento para identificação dos casos de câncer não melanoma (CBC) neste mesmo período. Foi demonstrado que 647 casos foram de $\mathrm{CBC}$ relativo a $38,2 \%$ da amostra. Santa Maria de Jetibá apresentou 52 casos de CBC equivalente a $8,0 \%$ deste total. Mais uma vez foi computado separadamente os casos ocorridos em Garrafão que teve 47 casos de CBC, ou seja, 7,3\% dos casos. Palmeira de Santa Joana, distrito do município de Itaguaçu, apresentou 96 casos de $\mathrm{CBC}$ representando 14,8\% do total dos CBC. O total de número de casos no município de Santa Maria de Jetibá é de 99 casos de CBC somando-se o número de casos da sede do município e de Garrafăo. Assim visualiza-se que Santa Maria de Jetibá é um município importante em número de casos de $\mathrm{CBC}$. 
Recentemente, no ano de 2004, a SES-ES participou de uma assessoria do Ministério da Saúde em que técnicos do INCA e da SES-ES iniciaram uma avaliação da assistência oncológica no estado e com base na epidemiologia priorizaram cinco cânceres para estudo imediato de uma rede de atenção à saúde, resolutiva em todos os níveis do Sistema Único de Saúde (SUS) sendo que mais uma vez o câncer de pele é reconhecido como problema de saúde pública na população espírito-santense, junto aos cânceres de colo, mama, pulmão, próstata e estômago. Esta decisão mobilizou técnicos da Coordenação Estadual de Avaliação e Epidemiologia do Câncer e Seus Fatores de Risco, do Núcleo Estadual de Epidemiologia, da Coordenadoria de Controle e Avaliação e Coordenação Estadual da Atenção Primária da SES-ES, refletindo em uma análise conjunta da epidemiologia e da prestação de serviços.

No primeiro momento de diagnóstico desta rede, percebeu-se que a sua organização inicia-se na atenção primária, para solucionar a dificuldade do acesso, devolvendo à população a integralidade na assistência. $O$ município aparece como local de extrema importância como acesso de determinada população à atenção a saúde para redução da morbi-mortalidade.

De acordo com Taylor (1995) citado por STARFIELD (2002, p.552), a experiência em países desenvolvidos e em desenvolvimento indica que a mudança contínua de comportamento é melhor promovida pela participação da família e da comunidade, do que pela abordagem usual que estimula a dependência, dizendo às pessoas o que é de seu maior interesse.

Diante do levantamento de hábitos na população atendida pelo "Programa de Assistência Dermatológica aos Lavradores Pomeranos no Interior do Estado do Espírito Santo", que traduzem fatores de risco importantes no aparecimento de casos, este trabalho propõe intervenções culturalmente aceitas, levando em conta que a comunidade é agente ativo nesta proposta. 
Em 1996, com a implantação das fichas clínicas-epidemiológicas no programa, os técnicos da SES-ES realizaram entrevistas com pessoas destas comunidades, conscientes da importância das informações na caracterização populacional. Porém, as fitas com as gravações desapareceram. Tal fato leva-se à percepção que naquela época não existia um consenso para este estudo da comunidade pomerana.

Sente-se que, atualmente, os técnicos com formação em saúde pública ganharam espaço no programa e que existe a possibilidade de melhor direcionamento deste estudo, principalmente porque a coordenação da Associação Albergue Martin Lutero, também adquire uma nova postura na sua inserção com a equipe técnica do programa. Esse não pode ser mais um programa somente de assistência dermatológica, em que diagnóstico clínico e tratamento cirúrgico se bastam. Por isso, a equipe técnica sentiu necessidade de reforçar um nome para o programa que refletisse mais o seu principal objetivo que é de rastrear câncer de pele no atendimento dermatológico a uma população sob risco e em 2004, mesmo com um convênio oficializando, mais uma vez, o nome de "Programa de Assistência Dermatológica aos Lavradores Pomeranos no Interior do Estado do Espírito Santo" começa a incorporar no seu dia a dia o nome de "Programa de Rastreamento de Câncer de Pele nos Lavradores Pomeranos do Interior do Espírito Santo" que melhor condiz com o objetivo de diagnosticar precocemente câncer de pele.

Propõe-se neste trabalho uma atenção mais integral ao paciente, aqui identificada como medidas preventivas adequadas a um grupo de risco, como:

1. Educação em saúde nas escolas públicas com divulgação ampla das medidas de proteção ao sol às crianças, futuros lavradores, para impedimento do efeito cumulativo do sol.

2. Educação em saúde aos adultos principalmente ao aparecimento de lesões précancerígenas ou mesmo sinais do câncer de pele, para detecção precoce de casos, seja pela alta incidência do carcinoma basocelular ou pela letalidade do melanoma maligno.

3. A inserção na comunidade para conhecer melhor a condição de vida dos pomeranos resultando em mudanças de seus hábitos para reflexo na qualidade $e$ 
expectativa de vida, considerando a possível vulnerabilidade à sobrevida pelo câncer melanoma.

Com o olhar também na organização de serviços de saúde percebe-se que a média e alta complexidade da atenção oncológica no Estado deverão ser contempladas em consonância com o Plano Diretor de Regionalização do Espírito Santo (PDR-ES), definindo as referências por microrregiões de saúde principalmente até a mais complexa em oferta de diagnóstico e tratamento, referências estadual.

Assim, algumas considerações devem ser indagadas:

1. Como fica o "Programa de Assistência Dermatológica aos Lavradores Pomeranos no Interior do Estado do Espírito Santo" neste novo desenho da rede de atenção oncológica do SUS-ES, diferenciando o seu papel com de competência municipal? 2. E como será o desenho do fluxo de atendimento do paciente com suspeita de câncer de pele? 3. Como o Estado e os municípios tratarão grupos especiais ou de risco de certa patologia?

Propõe-se que as informações contidas nas fichas clínico-epidemiológicas sejam instrumentos utilizados pelos médicos da atenção primária para conhecimento daquela comunidade no seguimento de casos ou mesmo para avaliação dos serviços municipais no enfretamento do problema identificado. A implantação de prontuário médico compartilhado é uma forma de proposta para que as informações das consultas especializadas cheguem aos médicos da atenção primária e aos pacientes. Ainda convive-se com situações em que o paciente não tem retorno do resultado histopatológico, não podendo afirmar que câncer de pele está na sua história pregressa. O mecanismo de interação entre os especialistas e os médicos da atenção primária, deverá incluir o fluxo da resposta do diagnóstico histopatológico.

O desenho da rede de atenção oncológica prevê fluxos bem definidos e garantia de encaminhamento do nível de atenção primária até os Centros de Alta Complexidade em Oncologia (CACON). 
Atualmente alguns municípios do Estado contratam especialistas, no caso dermatologistas, para o atendimento de pacientes abrangendo às vezes mais dois municípios, numa forma de consórcio, para resolução de problemas de saúde idênticos ou semelhantes. Ao concluir-se o levantamento do número de casos de melanoma ocorridos no Espírito Santo decorrente ao diagnóstico realizado pelo "Programa de Assistência Dermatológica aos Lavradores Pomeranos no Interior do Estado do Espírito Santo", no período de 1989 a 2002, contatou-se que o número foi reduzido significantemente, chegando a nenhum diagnóstico no ano 2000 o que levou uma dedução, ainda sem uma análise epidemiológica, que estes especialistas estariam realizando o diagnóstico de pacientes nestas áreas consideradas de risco. Isto refletiu que não se partilha as informações, e que não foi considerado o monitoramento do aparecimento do melanoma como importante em intervenções para melhora da expectativa de vida. Falta a SES-ES regular o Sistema de Informações de Saúde, conhecendo todas as fontes de dados sobre qualquer doença ou agravo. Neste caso, falta a pesquisa em hospitais de referência estadual em oncologia, como é o Hospital Santa Rita de Cássia, visto que o Registro Hospitalar de Câncer não está trabalhando com os dados de 2004. Também, falta a parceria com - Grupo Brasileiro Multidisciplinar e Multicêntrico para o do Melanoma (GBM), para cruzamento de dados e fontes.

Com a implantação do PDR-ES, a organização de serviços de saúde se dará de forma microrregionalizada. Os Centros Regionais de Especialização irão responder a organização de serviços para um conjunto de municípios que formam determinada microrregião, mantendo-se algumas referências estaduais, como o Centro Estadual de Dermatologia Sanitária.

Mantendo a epidemiologia como base para qualquer análise em saúde, a SES-ES reconhece que pomeranos constituem grupos vulneráveis ao câncer de pele e para manter a eqüidade, continuará investindo nas localidades municipais com populações pomeranas prevalentes. 
Por toda descrição estatística (ZANDONADE, 2000), Santa Maria de Jetibá apresenta maiores números absolutos de câncer de pele não melanoma e melonama dentre os municípios acompanhados pelo "Programa de Assistência Dermatológica aos Lavradores Pomeranos no Interior do Estado do Espírito Santo".

Além do exposto, Santa Maria de Jetibá é um município com população na sua quase totalidade toda pomerana e lavradora, o que permitiu um estudo descritivo mais aprimorado sobre a ocorrência de câncer de pele num grupo de risco. 


\section{II-REVISÃO DA LITERATURA:}

\section{1-O câncer no Mundo e no Brasil}

Nas últimas décadas, o câncer vem sendo considerado mundialmente um problema de saúde pública, com frequiência se mantendo em ascensão, sendo a segunda causa de óbito por doença no Brasil, só ultrapassado pelas doenças cardiovasculares, com exceção da região sul do Brasil onde as causas externas são a segunda causa de óbitos. A progressiva ascensão da mortalidade por doenças crônico-degenerativa tem como um dos fatores o envelhecimento da população ocasionando uma exposição ambiental mais prolongada que contribui com a carcinogênese. O Ministério da Saúde (M. S) estimou para o ano de 2000, 284.205 casos novos de câncer no Brasil sendo que desses 113.959 chegariam ao óbito. Foi estimado que o câncer de pulmão $(12,61 / 100.000)$ seria a primeira causa de morte por câncer no sexo masculino, seguido por câncer de estômago $(8,66 / 100.000)$, da próstata $(8,34 / 100.000)$ e do esôfago $(4,83 / 100.000)$. No sexo feminino o câncer de mama $(9,78 / 100.000)$ foi a principal causa de morte por câncer. O óbito por câncer de pulmão $(4,97 / 100.000)$, por colo de útero $(4,25 / 100.000)$, por estômago $(4,24 / 100.000)$ e por cólon e reto $(4,24 / 100.000)$ seguiram em importância de causa de óbito no sexo feminino (MINISTÉRIO DA SAÚDE 2000).

Enquanto estimativa de casos novos para o ano 2000, no Brasil, o sexo masculino apresentou o câncer de pele não melanoma como a primeira causa em incidência $(26,81 / 100.000)$, seguido do câncer de próstata $(18,14 / 100.000)$, pulmão (17,69/100.000) e estômago (16,76/100.000). Já no sexo feminino, o câncer de mama, com uma taxa de incidência de 33,58 casos novos por 100.000 habitantes foi a principal causa estimada para acometimento, seguido pelo câncer de pele não melanoma $(24,17 / 100.000)$, colo de útero $(20,48 / 100.000)$ e estômago $(7,3 / 100.000)$ (MINISTÉRIO DA SAÚDE 2000). 
Ao trabalhar a estimativa do número de casos de câncer para o ano de 2003, o Ministério da Saúde previu 402.190 casos novos com 126.960 óbitos em todo o Brasil, um aumento significativo em três anos, em que pese não se trabalhar com informações precisas e mais fidedignas de um sistema de mortalidade, base para as referidas estimativas.

Verificam-se estimativas para o Brasil em 2003, diferenciando pouco do ano de 2000. Foi estimado para o câncer de pulmão (13,00/100000) colocando-o como primeira causa de óbito no sexo masculino, seguido do câncer de próstata $(9,47 / 100000)$, estômago $(8,45 / 100000)$, esôfago $(4,97 / 100000)$ e cólon e reto $(4,24 / 100000)$. No sexo feminino o câncer de mama foi mantido como a primeira causa de morte $(10,40 / 100000)$, seguido pelo câncer de pulmão $(5,45 / 100000)$, cólon e reto $(4,73 / 100000)$, colo do útero $(4,58 / 100000)$ e estômago $(4,27 / 100000)$ (MINISTÉRIO DA SAÚDE 2003).

Um informe mundial sobre câncer realizada em Genebra no ano de 2003, demonstra que poderá haver um aumento de $50 \%$ na incidência do câncer no mundo, representado por 15 milhões de casos novos no ano 2020 (OMS 2003). Esses dados reforçam a importância de medidas para melhoria da qualidade de vida para evitar, por exemplo, os 6,2 milhões de mortes por tumores malignos ocorridos no mundo em 2000. Este informe encontra-se num manual de 351 páginas publicado pelo Centro Internacional de Investigações sobre o câncer (CIIC), centro este que faz parte da Organização Mundial de Saúde (OMS). Nele, encontram-se, ainda, descrições acerca da incidência mundial e as causas do câncer, os principais tipos de tumores malignos, a detecção precoce e seu tratamento, além de propor medidas de saúde pública para a redução da morbidade e mortalidade do câncer, que se concentram na redução do consumo de tabaco, no regime alimentar e modos de vida saudáveis e implementação de programas de detecção precoce.

No mundo, entre os cinco cânceres mais comuns, com exceção do câncer de pele não melanoma, o de maior incidência, destacam-se os de pulmão, colon e reto, mais estômago, tanto nos homens como nas mulheres, sendo que os cânceres de pulmão e 
estômago são mais comuns nos homens e nas mulheres prevalecem os de mama e câncer cervical (WORLD HEALTH ORGANIZATION 2004).

Nos Estados Unidos (EUA), câncer é a segunda causa de morte, sendo que em 2002 foi estimado que mais de 550.000 iriam a b́bito o que significa que 1.500 óbitos por dia por esta doença de um total de 1.2 milhões de casos novos. Todas as raças são atingidas pela doença, mas a raça negra é a que mais contribui para a taxa de mortalidade por câncer por todos os tipos (CDC 2002).

Numa análise de tendência dos principais cânceres que levam a óbito no Estados Unidos, no período de 1990 a 2000, categorizada por estado, sexo e raça/etnia STEWART et. al (2004) verifica-se que houve um declínio, na mortalidade por câncer, mais expressivo no período de 1994-1998, sendo em homens (-1.8\% / ano) e em mulheres $(-1.3 \% /$ ano) de todas as raças, com estabilização no período de 1998$2000 \mathrm{em}$ homens e mulheres de todas as raças. Constataram que no período entre 1990-2000, a mortalidade por todos os tipos de câncer declinou entre homens negros $(-2.0 \%$ / ano) e mulheres negras $(-0.6 \% /$ ano $)$ e algumas outras raças. Este declínio ocorreu mais cedo, em meados de 1990, nos homens brancos (-1.7\% / ano) e nas mulheres brancas (-1.3\% / ano). Porém, no período de 1998 a 2000, houve um aumento da mortalidade por câncer, nas mulheres com percentual ao ano de 0.3. Os autores identificaram que houve um decréscimo na mortalidade por tipo de câncer que foi de (- $1.7 \%$ /ano) por câncer de pulmão e brônquios entre os homens; de (-2.0 $\%$ / ano) no câncer de colon e reto em homens e ( $-1.7 \%$ /ano) em mulheres e com decréscimo de câncer de próstata de (-2.6\% /ano) e câncer de mama feminina de ($2.3 \%$ /ano). O incremento da mortalidade de câncer em mulheres, no período de 1990 a 2000, ocorreu devido ao câncer de pulmão e brônquios.

No Brasil, a taxa de mortalidade das cinco principais localizações primárias mais freqüentes, ajustadas por idade pela população mundial, por 100.000 homens, entre 1979 e 1999, mostra que a mortalidade por câncer de pulmão é a de maior ocorrência em 1999, demonstrando uma ascendência no período. Nas mulheres, a mortalidade por câncer, também ajustada e no mesmo período tem a mortalidade por câncer de 
mama como a de maior ocorrência, em ascendência, com taxa um pouco acima de 8 óbitos por câncer de mama /100.000 mulheres em 1979, chegando a uma taxa um pouco abaixo 12 óbitos por câncer de mama /100000 mulheres em 1999. Mesmo assim, a mortalidade por câncer de pulmão ascende do ano de 1979 para o ano de 1999, indo de uma taxa de mortalidade por câncer de pulmão de quase 4 óbitos por câncer de pulmão/100.000 mulheres a taxa acima deste valor, respectivamente. Os demais tipos de cânceres mais freqüentes para a taxa de mortalidade no Brasil, neste período de 1979 a 1999, para o sexo masculino, são a mortalidade por câncer de estômago, sendo que há um declínio, mas mantendo-se como segundo tipo de câncer no ano de 1999. Em ordem de maior ocorrência segue o de próstata, esôfago e por último colon e reto neste mesmo ano. No sexo feminino, os principais cânceres que contribuem para a taxa de mortalidade em 1999, ajustadas por idade pela população mundial, entre 1979 e 1999, além da mama e pulmão, primeiro e segundo lugares respectivamente, são colon e reto, colo de útero e por último, estômago (MINISTÉRIO DA SAÚDE 2004-ATLAS DE MORTALIDADE POR CÂNCER NO BRASIL 1997-1999).

Os neoplasmas ocupam o segundo ou terceiro de causa de óbitos na maioria das capitais do Brasil. Dez por cento dos 6́bitos são causados por neoplasmas, exceto em São Paulo, Rio de Janeiro e estados do Sul que apresentam uma porcentagem acima da média nacional (LATORRE 1997).

Em estudo de tendência da mortalidade por câncer de estômago no Brasil e nas capitais brasileiras, para o periodo de 1977 a 1989, LATORRE (1997) identificou uma redução do coeficiente de mortalidade por câncer de estômago (padronizado) de 10,4 6́bitos especifico por 100.000 habitantes em 1978 para 5,2 em 1989 no Brasil.

Na Região Sudeste, esta diminuição dos coeficientes de mortalidade por câncer de estômago padronizado, significou a ocupação no segundo lugar nas causas de mortalidade por câncer em todas as capitais, com exceção de Vitória, onde ocupa o quinto lugar nesta classificação. 
No estudo Aspectos Epidemiológicos do Câncer no Município de São Paulo: Fatores de Risco, o coeficiente de incidência do câncer de estômago, na cidade de São Paulo, foi de 36,6 casos $/ 100.000$ habitantes no sexo masculino e 15,1 casos/100.000 habitantes no sexo feminino, no período de 1997-1999, considerada intermediária na comparação com países como Canadá que apresenta em homens uma incidência de 9,1 casos / 100.000 habitantes do sexo feminino; ItáliaFlorença, com 28,4 casos/100.000 habitantes e 13,6 casos /100.000 habitantes, respectivamente entre homens e mulheres; Reino Unido apresentando no homem 13,1 casos /100.000 habitantes e nas mulheres 4,9 casos/100.000 habitantes e Dinamarca com incidência de 8,2 casos/ 100.000 habitantes nos homens e 3,6 casos/ 100.000 habitantes nas mulheres. No Japão-Hiroshima, a incidência do câncer de estômago é bem elevado com taxas de 83,1 casos/ 100.000 habitantes nos homens e 35,9 casos/ 100.000 habitantes nas mulheres (DEPARTAMENTO DE EPIDEMIOLOGIA DA FACULDADE DE SAÚdE PÚBLICA DA UNIVERSIDADE DE SÃO PAULO 2003).

O Espírito Santo apresentou, no gráfico de taxas de mortalidade das 5 localizações primárias mais lireqüentes em 1999, ajustadas por idade pela população mundial, por 100.000 homens, entre o período de 1979 c 1999, (MINISTÉRIO DA SAÚDE 2004), por ordem de maior ocorrência, pulmão e estômago em primeiro lugar, próstata, esôfago e fígado e entre mulheres, mama, colo de útero, pulmão, estômago e colon e reto.

Na distribuição proporcional do total de mortes por câncer, segundo localização primária do tumor, em homens, para os períodos entre 1979 e 1983 e entre 1995 e 1999, constata-se que, no Espírito Santo, a mortalidade por câncer de estômago, no período de $1979-1983$, representou $24,02 \%$ de todos os cânceres, sendo o primeiro em ocorrência nos homens seguido de mortalidade por câncer de traquéia, brônquios e pulmões, com $12,07 \%$ proporcionalmente, desprezando-se $14,83 \%$ do somatório de mortalidade de câncer em outras localizações, seguido com a contribuição de $7,60 \%$ de câncer de esôfago, $6,49 \%$ de câncer de próstata e $5,65 \%$ de câncer de fígado, dentre outros. No período de 1996 a 1999, tem-se um declínio significante na 
mortalidade por câncer de estômago no homem resultando numa contribuição de $16,14 \%$ de todos os cânceres, ou seja, menos $8,05 \%$ do período anterior, mesmo assim mantendo-se o primeiro em ocorrência no mesmo período e sexo. O segundo lugar é ocupado mais uma vez com mortalidade por câncer de traquéia, brônquios e pulmões, sendo que a proporção aumenta para $14,82 \%$. Neste período, ocorre uma inversão de lugares, sendo que mortalidade por câncer de próstata torna-se o terceiro em ocorrência com $10,63 \%$ de todos cânceres e mortalidade por câncer de esôfago mesmo tendo um aumento de $0,46 \%$, é levado para o quarto lugar $\mathrm{cm}$ contribuição com um percentual de $8,06 \%$. Mortalidade por cânecr de lígado diminui em $1,02 \%$, perdendo o quarto lugar para mortalidade por câncer de boca com um percentual de $5,39 \%$ na distribuição proporcional. (MINISTÉRIO DA SAÚDE 2004),

No mesmo estudo, porém, em mulheres, encontra-se uma distribuição proporcional por câncer segundo localização primária do tumor, no período de 19791983, numa sequiência de maiores ocorrências, a mortalidade por câncer de estômago contribuindo com $11,89 \%$, a de câncer de mama com $11,20 \%$, a de câncer de colo de útero com $7,57 \%$, a de traquéia, brônquios e pulmões com 7,04 \%, a de colon e reto com $5,44 \%$ bem perto do percentual de 5,33 devido à mortalidade por câncer de fígado. No período de 1995-1999, o mesmo estudo em mulheres, aponta o aumento da mortalidade por câncer de mama $(12.81 \%)$ e por colo de útero $(10,55 \%)$, com um declínio acentuado de $3,73 \%$ na mortalidade por câncer de estômago comparada ao período anterior, ficando com $8,16 \%$ de todos os cânceres e apresentando percentual próximo ao ano anterior por câncer de traquéia, brônquios e pulmões $(7,28 \%$ ), seguido por um percentual de 7,09 por mortalidade de câncer de colon e reto (MINISTÉRIO DA SAÚDE 2004).

\section{2-A Epidemiologia do câncer de pele no mundo e no Brasil}

O câncer de pele é o mais freqüente entre todos os cânceres em todo o mundo, principalmente nas populações de raça branca, com expressiva contribuição do aumento da incidência do carcinoma basocelular (CBC) nos últimos anos. 
"Dois estudos realizados no Reino Unido, utilizando a mesma metodologia, feitos na mesma região geográfica, com a mesma população e com intervalo de 10 anos entre cles, mostraram que a incidência do CBC aumentou de 173,5/100.000 habitantes/ano para 265,4/100.000 no ano 2000" (Holme et al. 2000 citado por KOPKE e SCHMIDT 2002, p.250).

Continuando, KOPKE e SCHMIDT (2002, p.250) citam Miller e Weinstock (1994) e Ko et. al (1994) quando transcrevem que essa tendência também foi detectada nos EUA, em outros locais da Europa e na Austrália, onde a incidência é a maior do mundo, da ordem de 726/100.000 habitantes/ano.

O CBC é relativamente benigno devido o seu poder limitado de metastatização. Raro em negros e orientais afeta mais homens que mulheres em qualquer faixa etária. Alguns artigos chamam a atenção que o CBC, além da associação da ocorrência familiar de outro câncer de pele, tem outros tumores malignos associados numa freqüência maior que demais tumores malignos. Um paciente de $\mathrm{CBC}$ tem o risco cumulativo de $44 \%$ de vir a ter outro, significando uma oportunidade 10 vezes maior do que o da população em geral. A exposição solar é o fator de risco no $\mathrm{CBC}$, sendo questionado esta importância devido a não ocorrência em algumas áreas expostas. Queimadura solar parece ser a maior responsável pela incidência do $\mathrm{CBC}$, sendo que um estudo demonstrou que a queimadura solar após os 60 anos de idade é importante para o aparecimento de carcinomas basocelulares múltiplos. Porém, a presença associada de pele clara, sardas antes de 15 anos de idade, olhos azuis e cabelos loiros ou ruivos, constitui características fenotípicas importantes a resposta a exposição solar (KOPKE e SCHMIDT 2002).

Foi estimado que um milhão de casos novos de câncer de pele seriam diagnosticados, em 2002, na população norte americana (CDC 2003).

No Brasil, a estimativa do aparecimento de casos novos de câncer de pele não melanoma, para o ano de 2003, contribuiu para uma provável taxa de incidência de 44,84 casos novos por 100.000 habitantes no sexo masculino, mantendo-se alta para 
o sexo feminino com uma estimativa de 47,80 casos novos por 100.000 habitantes o que classifica o câncer de pele o mais incidente de todos. $O$ câncer de pele melanoma (mais letal) tem uma pequena incidência no Brasil com estimativa de aparecimento de 2.185 casos novos, podendo levar ao 6́bito 645 casos para o mesmo período. A taxa bruta de incidência foi estimada em 2,46 novos casos de câncer de pele melanoma por 100.000 habitantes. Outra estimativa foi que a região sudeste do Brasil teria 26.040 casos de câncer não melanoma no sexo masculino em todos os estados que a compõem, mais 11.600 casos novos nas capitais e 1.430 casos novos de melanoma nos estados e 490 casos nas capitais neste mesmo sexo sendo que 340 iriam a óbito nos estados e 125 também morreriam nas capitais por melanoma em 2003. No sexo feminino, teve-se a seguinte estimativa: 1510 casos novos melanoma nos estados e 535 casos novos nas capitais com 260 casos e óbitos por melanoma localizados nos estados e 260 casos nas capitais (MINISTÉRIO DA SAÚDE 2003).

Para observação de quanto o câncer de pele aumenta em cada ano, confronta-se a estimativa da sua ocorrência em 2001 de 54.460 casos novos de câncer de pele não melanoma para ambos os sexos e 2.930 casos novos de câncer melanoma para homens e mulheres, totalizando 57.390 casos novos de câncer de pele em 2001 no Brasil, sendo que esta estimativa sobe para 86.525 para o ano 2003 nesse território nacional (MINISTÉRIO DA SAÚDE 2001).

Importante é o comportamento epidemiológico dos cânceres de pele. Enquanto o câncer de pele não melanoma tem uma alta incidência na população, o tipo melanoma incide numa baixa freqüência. Quando o enfoque é de quantos desses cânceres são letais, o câncer de pele não melanoma tem uma baixa letalidade e o tipo de câncer de pele melanoma tem uma letalidade alta.

As maiores taxas de incidência de melanoma cutâneo são encontradas na Austrália, sendo de 33,2 casos novos por 100.000 habitantes no sexo masculino e 25,4 casos novos por 100.000 no sexo feminino. Os EUA têm uma taxa de incidência, nos homens de $15,4 / 100.000$ hab. E nas mulheres de $11,6 / 100.000$ hab. A Dinamarca apresenta em homens (H) uma taxa de incidência (TI) de 10,5/100.000 
hab. E 13,4/ 100.000 hab. Nas mulheres (M), seguindo das (TI) do Canadá com 8,5/100.000 hab. (H) e 7,5/100.000 hab. (M), da Itália -Florença com 7,5/100.000 hab. $(\mathrm{H})$ e $9,0 / 100.000$ hab. (M), do Reino Unido com 5,8/100.000 hab. $(\mathrm{H})$ e 7,4/100.000 hab. (M) e Colômbia-Cali com uma (TI) menor de 2,5/100.000 hab. (H) e 2,7/100.00 hab. (M). Verificam-se, no Brasil, taxas de incidências de 5,3/100.000 hab. (H) em Porto Alegre de 5,1/100.000 hab.(H) em Goiânia e de 4,1/100.000 hab.( H) em Campinas, muito próximas um das outras. No período de 1997-1999, a cidade de São Paulo apresentou uma incidência de 6,7/100.00 hab. (H) e de $5,9 / 100.000$ hab. (M), contrariamente as taxas de incidência mundial onde em muitos países a mulheres detêm as maiores taxas (DEPARTAMENTO DE EPIDEMIOLOGIA DA FACULDADE DE SAÚdE PÚBLICA DA UNIVERSIDADE DE SÃO PAULO 2003).

"A incidência e a mortalidade por melanoma cutâneo estão aumentando em muitas regiões do mundo. A incidência parece estar dobrando em muitos países, a cada 10-15 anos, enquanto a sua mortalidade tem crescido em menor escala" (DEPARTAMENTO DE EPIDEMIOLOGIA DA FACULDADE DE SAÚdE PÚBLICA DA UNIVERSIDADE DE SĀO PAULO, p.39 2003).

São diagnosticados por ano na Europa em média 26.100 casos de melanoma em homens e 33.300 casos em mulheres (Ferlay et. al 2001 citado por VRIES et. al 2003, p.1). A taxa padronizada por idade de incidência por 100.000 hab., tanto em homens $(\mathrm{H})$ como em mulheres $(\mathrm{M})$ varia entre regiões, apresentando altas taxas no hemisfério norte da Europa (7,4 $(\mathrm{H})$ e $8,7(\mathrm{M}))$, na Europa Ocidental $(7,0(\mathrm{H})$ e 8,1 (M)) e a região da Europa Meridional $(3,8(\mathrm{H})$ e $4,6(\mathrm{M})$, com as menores taxas entre todas. Já as taxas padronizadas por idade de mortalidade por 100.000 hab. Apresentam-se semelhantes entre regiões, sendo $2,1(\mathrm{H})$ e $1,6(\mathrm{M})$ na Europa Setentrional, 1,8 (H) e 1,3 (M) na Europa Ocidental, 1,7 (H) e 1,1 (M) na Europa Oriental e 1,6 (H) e 1,1 (M) na Europa Meridional (VRIES et. al 2003)).

A taxa de incidência de melanoma nas populações brancas (EUA, Austrália) aumenta à medida que se aproxima do Equador (Tucker et. al 2003 citado por VRIES 
et. al 2003, p.2), diferentemente do que ocorre em alguns países da Europa Setentrional (Figuras 1 e 2) na população de pele muito branca e com alta exposição ao sol intermitente que passa suas férias nas áreas do Mediterrâneo (VRIES et. al 2003).

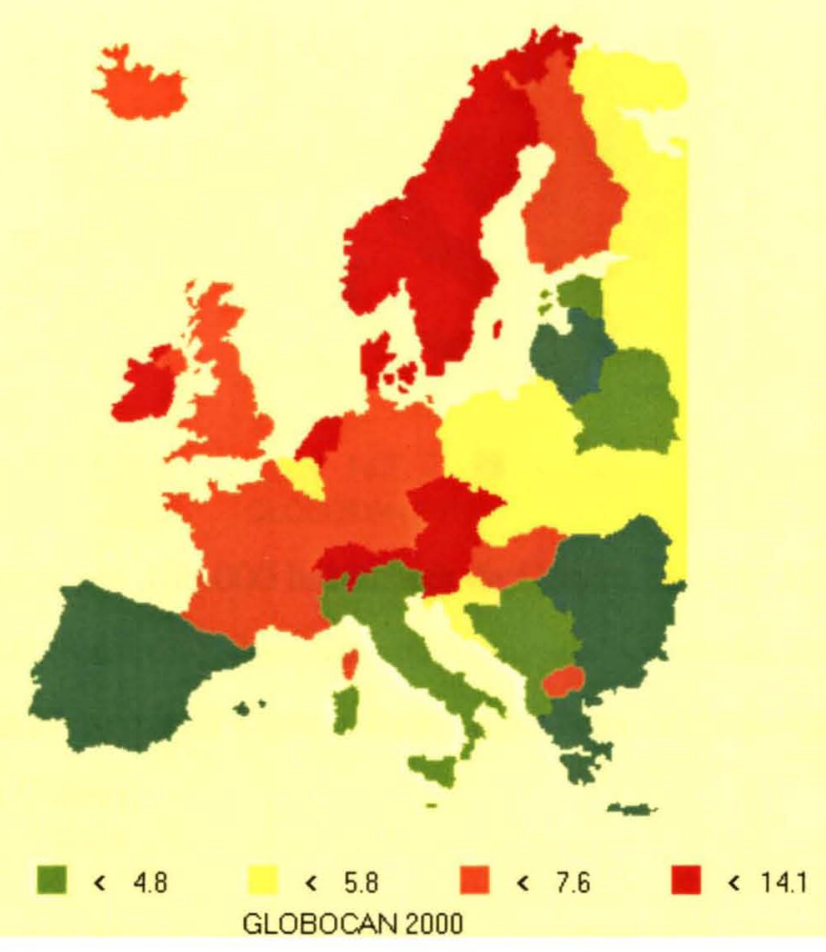

Figura 1. Incidência por 100.000 habitantes de Câncer de Pele Melanoma, na Europa no sexo masculino, com taxa padronizada por idade, 2000. Fontes: European Netword of Cancer Registries/ Internationa Agency for Research on Cancer. 


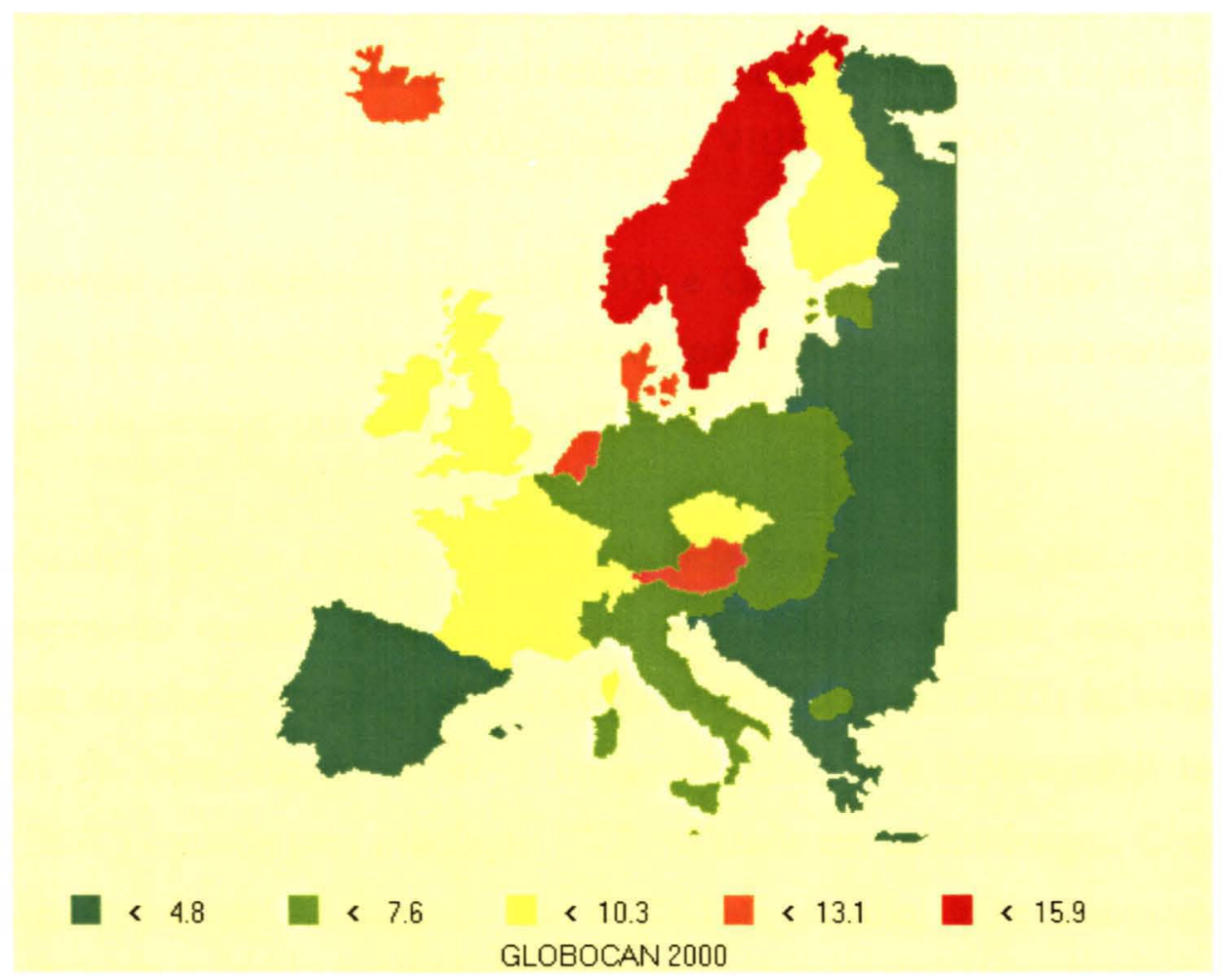

Figura 2. Incidência por 100.000 habitantes de Câncer de Pele Melanoma, na Europa, no sexo feminino, com taxa padronizada por idade, 2000.

Fontes: European Network of Cancer Registries/ International Agency for Research on Cancer.

Observa-se nos mapas anteriores que há um comportamento diferenciado entre os sexos em relação à incidência do melanoma na Europa, sendo que no sexo masculino a alta incidência se expande em diversos países em diferentes regiões.

O melanoma na Europa, durante o período de 1978-1989, teve a média de sobrevida de cinco anos aumentada de 59 para $70 \%$ nos homens e de 76 para $84 \%$ nas mulheres. Notou-se que os países com uma taxa de incidência relevante têm altas taxas de sobrevida, provavelmente resultante de uma detecção precoce de melanoma, que é o que ocorre com a Suíça e Suécia, com taxas média de sobrevida de cinco anos de $90 \%$ e $89 \%$ respectivamente, no período estudado (VRIES et. al 2003). 
Fatores endógenos como fototipo de pele, história clínica de nevus atípico, número de nevus, e história familiar de câncer de pele são preditores importantes de risco de melanoma (Tucker et. al 2003 citado por VRIES et.al 2003, p.2 ).

De acordo com Armstrong et. al (1993) e Gilchrest et. al (1999) citado por VRIES et. al (2003, p.2) o fator de risco exógeno mais importante para melanoma é a exposição da radiação por ultravioleta (UV).

O histórico, de que o risco de câncer de pele ocorre mais nas mulheres e que imunossupressão causada pela ultravioleta B (UV-B) pode estar relacionada à progressão do câncer de pele, estimulou HIRAMOTO et. al (2003) ao estudo do efeito do 17- beta-estradiol sobre a imunossupressão e a hipersensibilidade de contato (HSC) causada pela irradiação UVB realizada em camundongos. Concluem que os resultados obtidos sugerem que o 17- beta-estradiol inibe a supressão da resposta de HSC induzida por UVB.

A relação entre exposição solar e câncer de pele estimulou várias pesquisas. Em estudo da dependência do tempo e da dosagem na freqüência de mutação induzida pela radiação UV-B na derme e epiderme IKEHATA e ONO (2002 p.2) citam que a repetição de intensa exposição ao sol em longos intervalos, por exemplo, o banho de sol recreativo feito a cada verão, tem maior probabilidade de causar câncer de pele do que a exposição diária contínua, mesmo que as doses totais de raios UV sejam as mesmas.

JEMAL et al. (2000) estudaram a mudança do padrão da taxa de mortalidade de melanoma entre brancos nos Estados Unidos pelos fatores demográficos e geográficos e avaliaram a relação entre o padrão geográfico e o nível de radiação UV (UV-B) (Figura3). 


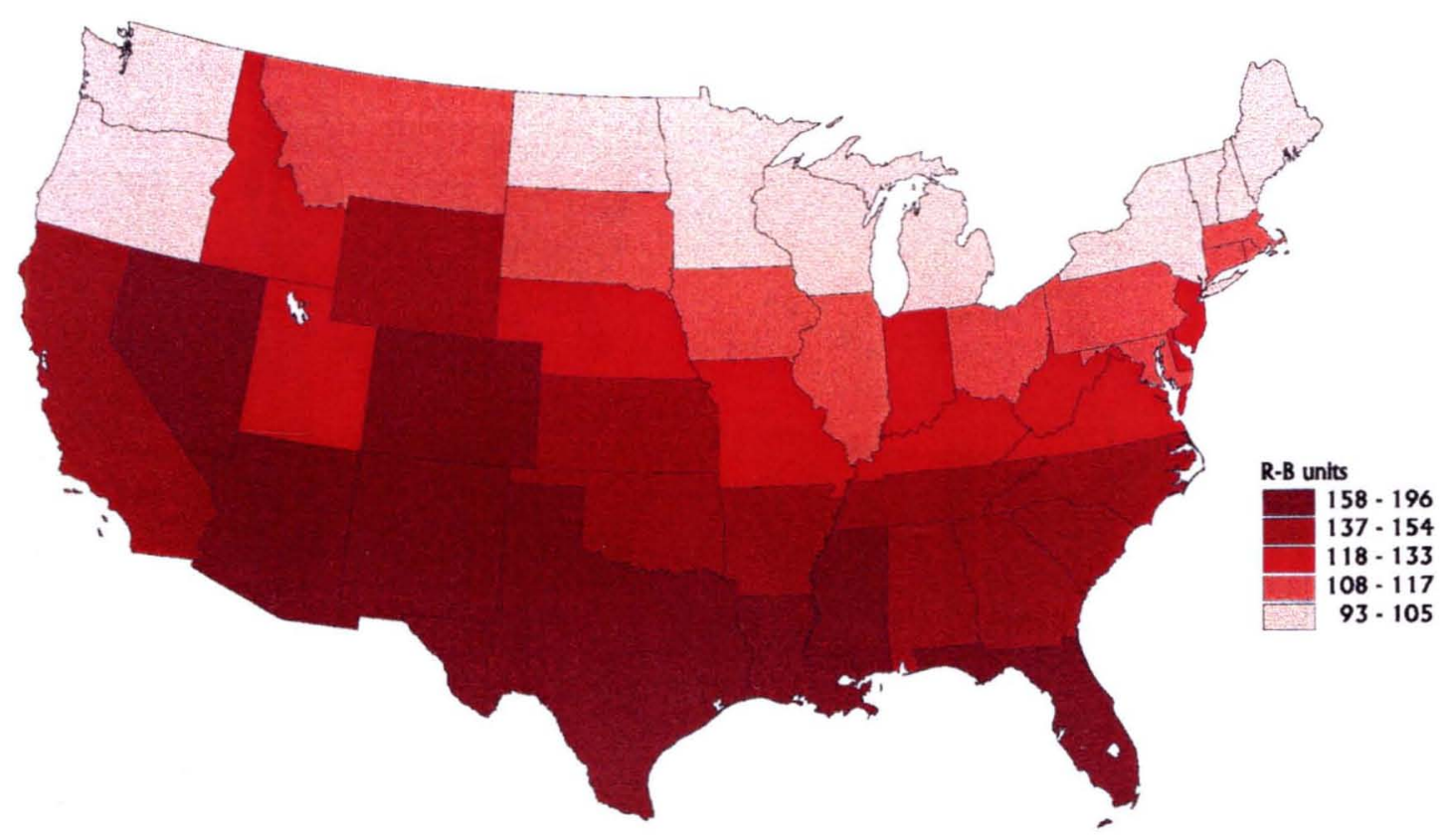

Figura 3 -Estimativa anual de Radiação Solar UV em unidades medidas RobertsonBerger (R-B) nos Estados Unidos.

Fonte: Division of Câncer Epidemiology and Genetics, Nacional Cancer Institute.

A distribuição da incidência de melanoma por estados foi realizada por meio de registros do Surveillance, Epidemiology, and End Results (SEER) levando em consideração o nível anual de UV-B. As áreas com baixo nível de UV-B incluem Connectitut, Detroit, Iowa, Seattle (WA) e as áreas com alto nível de UV-B, Utah e Atlanta, Hawaii, New 'éxico e San Francisco-Oakland. Para avaliar o efeito dos níveis de UV-B na taxa de mortalidade no tempo nos 48 estados contíguos utilizouse os períodos de 1950-1959, 1960-1969, 1970-1979, 1980-1989 e 1990-1995 (Figura 4). 


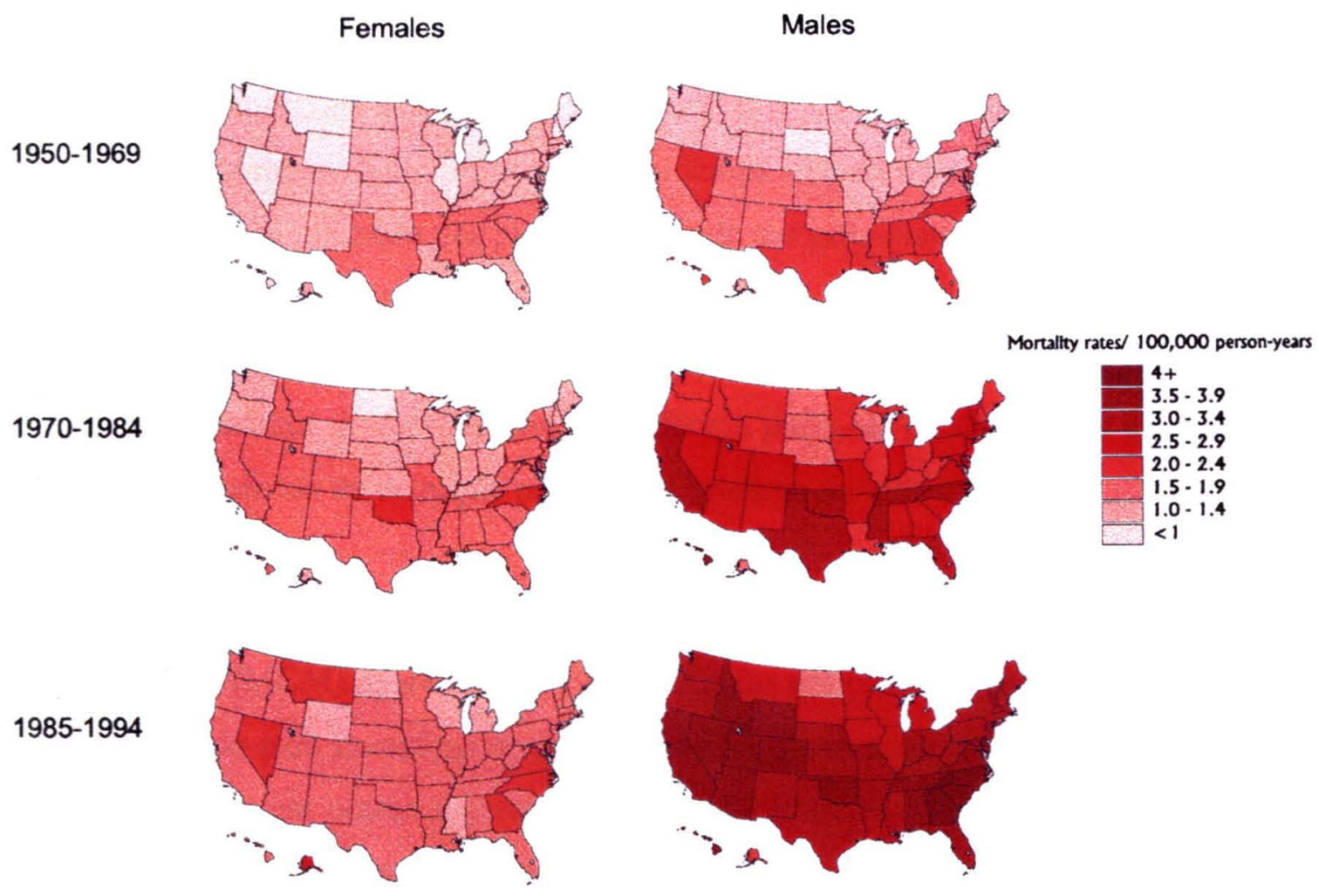

Figura 4. Taxa de mortalidade de melanoma específica por sexo e estado, em brancos nos Estados Unidos em vários períodos entre 1950 a 1994.

Fonte:Division of Cancer Epidemiology and Genetics, Nacional Cancer Institute.

A mortalidade por melanoma nos EUA teve um aumento de $191 \%$ nos homens e $84 \%$ nas mulheres, demonstrando que as taxas de incidência aumentam mais rapidamente que as taxas de mortalidade e em especial nos homens. Deve-se considerar o aumento de $543 \%$ na incidência de melanoma em quatro áreas geográficas (Atlanta, Connectitut, Detroit e San Francisco-Oakland) representado por taxa de 2.80 para 17.99/100.000 pessoas/ano nos homens brancos e $317 \%$, de 2.80 para 11.68, nas mulheres brancas no período de 1947-1950 até 1990-1994.

Lee (1997) citado por JEMAL et. al (2000 p.9) observou em estudo que o gradiente Norte-Sul de mortalidade de melanoma decresce desde o período 19501959. Concordando com os achados de Lee, JEMAL et.al $(2000$ p.9 ,10) analisam 
que os resultados em relação de UV-B e taxa de mortalidade de melanoma mostram que o gradiente de radiação persiste, mas parece ser menos marcante que no passado. Porém, há um importante impacto da radiação UV-B nas taxas de mortalidade por melanoma nos homens. Nas mulheres a incidência decresceu nas áreas com alta radiação UV-B demonstrando um padrão que pode dar uma pista porque as taxas de mortalidade aumentam mais no norte, onde se têm áreas de baixa radiação UV-B em relação ao sul onde se têm áreas com alta radiação UV-B. Aponta-se aqui que estas diferenças nos padrões de mortalidade e incidência pode ser resultante das diversas respostas às campanhas de deteç̧ão precoce e à conduta de proteção solar.

AUTIER et. al (2000), diante de tendências em mortalidade de melanoma cutâneo maligno (MCM) aparentemente contrastantes em países diversos, decidiram realizar um estudo para investigar se as diminuições observadas na Austrália e EUA estavam ocorrendo em outros lugares. A análise foi limitada às populações de pele clara com grande número de mortes por MCM com longa série histórica, selecionando populações representativas da maioria das regiōes do mundo. Como resultado apresentaram que na faixa etária de 30-59 anos, a taxa de mortalidade por $\mathrm{MCM}$, tanto em homens $(\mathrm{H})$ como em mulheres $(\mathrm{M})$, caiu em todos os países no ano de 1960. Na Austrália, no período de 1960-1990, a mortalidade por MCM teve um incremento, em média de $2 \%$ anualmente nos homens, ficando estável nas mulheres, com faixa etária de 30-59 anos. Nos EUA, foi observado que a média anual de incremento foi de $2 \%$ nos homens e $1 \%$ nas mulheres. França, Itália e Czechoslovakia tiveram as taxas de mortalidade por MCM aumentadas anualmente em 9 a $16 \%$ em ambos os sexos, sendo o maior incremento encontrado nas taxas nesta faixa etária. Já na faixa etária de 60-79 anos, encontraram taxas de mortalidade por MCM com grandes aumentos, principalmente nos homens. Na Austrália o percentual aumentado na taxa foi de $12 \%(\mathrm{H})$ e $4 \%(\mathrm{M}) ; 7 \%(\mathrm{H})$ e $2 \%(\mathrm{M})$ nos EUA e $9 \%(\mathrm{H})$ e $4 \%(\mathrm{M})$ nos países nórdicos. Com pequena diferença entre sexos a taxa de mortalidade por MCM teve um incremento de $6 \%(\mathrm{H})$ e $4 \%(\mathrm{M})$ no Canadá, repetindo o mesmo percentual de incremento no Japão; e $7 \%(\mathrm{H})$ e $5 \%(\mathrm{M})$ na UK.Na década de 60, a taxa de mortalidade por MCM foi baixa na Itália, França e Czechoslovakia, sendo que posteriormente a média anual do seu incremento foi de 
$24 \%(\mathrm{H})$ e $27 \%(\mathrm{M})$ na França; $15 \%(\mathrm{H})$ e $13 \%(\mathrm{M})$ na Itália e $17 \%(\mathrm{H})$ e $33 \%$ (M) na Czechoslovakia. Esses dados sugerem, assim que existem três grupos distintos em relação à curva epidêmica de mortalidade por MCM: o grupo em que a tendência de mortalidade ainda aumenta fortemente, outro grupo que esta tendência está começando a diminuir e o grupo que definitivamente está diminuído e os relacionam ao efeito da promoção a proteção ao sol e da vigilância de lesões pigmentadas na população.

\section{3- Melanoma: Classificação de Clark e Breslow}

Segundo o Grupo Brasileiro de Melanoma (2004) a sobrevida do paciente com melanoma é inversamente proporcional à cspessura da lesão tumoral que teve cm Clark et. al, em 1968, e em Breslow, em 1970, as primeiras definições.

ENOKINARA et. al (2004) analisaram a correlação clínica e patológica através da classificação de Breslow e Clark para a espessura de melanoma, detalhando os níveis de Clark que estão relacionados à profundidade da invasão do melanoma (figura 5):

Nível I: melanoma situa-se somente na epiderme e epitélio anexial sem invasão da derme papilar.

Nível II: Invasão da derme papilar com algumas células na interface da derme papilar e reticular.

Nível III: comprometimento de toda derme papilar atingindo a derme reticular na faixa de transição.

Nível IV: Invasão da derme reticular.

Nível V: Invasão da hipoderme. 


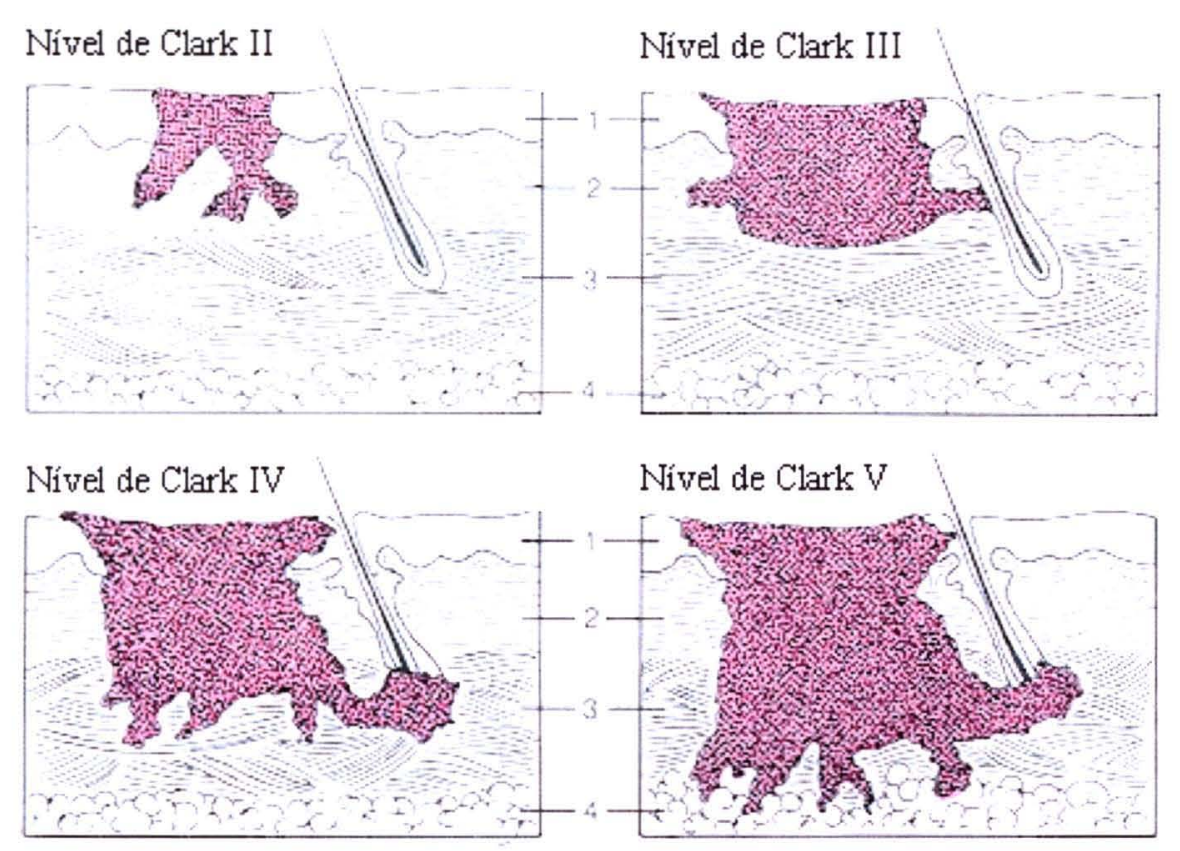

Figura 5. Classificação de Clark: Os cinco níveis histológicos dos melanomas cutâneos.

Fonte: Grupo Brasileiro de Melanoma.

Breslow demonstrou que a mensuração microscópica da espessura máxima da neoplasia superava algumas das dificuldades da avaliação em níveis, principalmente a diferenciação entre os níveis II e III, e o fato de que no nível IV podem ser classificados melanomas com espessuras expressivamente maiores (MACIEIRA 1999, p.1).

A espessura da lesão se tornou o melhor meio prognóstico na sobrevida do paciente com câncer de pele melanoma.

PEREIRA (2004, p.1) relata que paciente com lesão menor que $0,76 \mathrm{~mm}$ de espessura (Breslow) tem em 5 anos sobrevida próximo a $100 \%$, enquanto que pacientes com tumor maior que $4 \mathrm{~mm}$ de espessura apresentam apenas $40 \%$ de sobrevida em 5 anos. (Figura 6). 


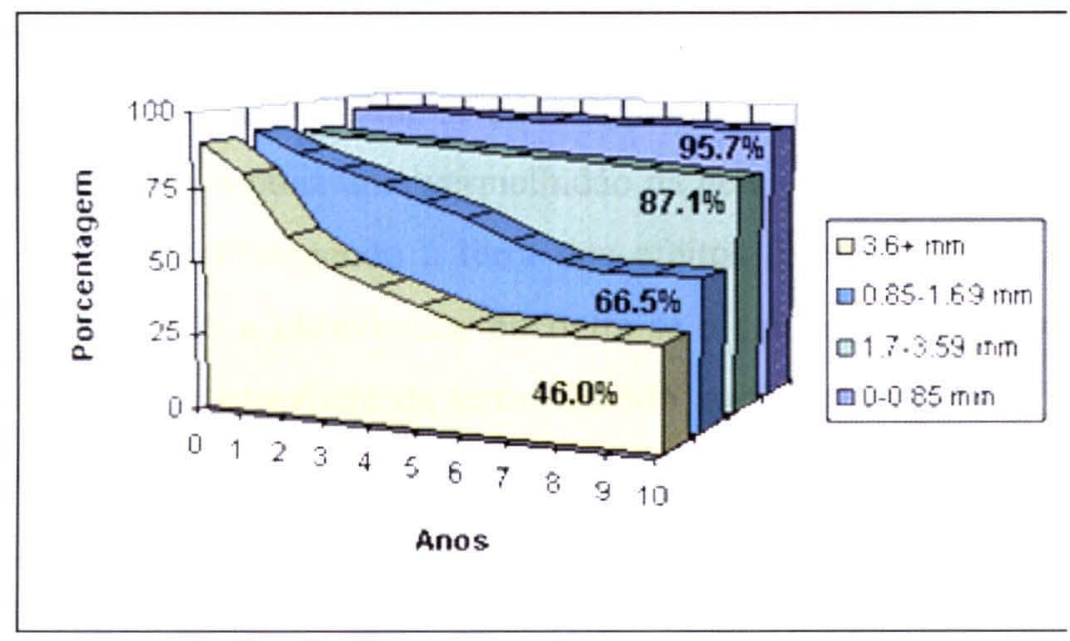

Figura 6: Taxa de sobrevivência em dez anos de pacientes com melanoma maligno (todos estágios) dividido em quatro grupos de espessura de lesão.

Fonte: New York University Melanoma Cooperative Group, 1991.

Como resultado de um questionário a patologistas para o consenso para o laudo anatomo-patológico do melanoma cutâneo, iniciativa do Grupo Multicêntrico e Multidisciplinar Brasileiro para Estudos do Melanoma-GBM, dentre outras variáveis histológicas contidas no questionário, o nível de Clark e profundidade segundo Breslow foram avaliados como indispensáveis à inclusão do laudo por todos entrevistados. Em que pese que o nível de Clark está sendo substituído pelo uso da profundidade segundo Breslow, sua utilização é importante principalmente quando a espessura da lesão for menor que $1 \mathrm{~mm}$, pois há correlação positiva de pior prognóstico, quanto maior for o índice. Em relação à profundidade segundo Breslow foi consenso que é o parâmetro de maior impacto na determinação da sobrevida global por melanoma cutâneo em cinco anos (GBM 2003).

\section{4- Radiação Ultravioleta}

A radiação solar emite ondas infravermelhas e ondas ultravioletas. A radiação ultravioleta é de natureza eletromagnética e de acordo com seu comprimento de onda se divide em A, B e C. A ultravioleta A (UVA), vizinha a luz visível vai de $400 \mathrm{~nm}$ 
(nanômetros) até 320nm, a ultravioleta B (UVB) esta entre 320nm e 290nm e a radiação ultravioleta C (UVC) situa-se entre $290 \mathrm{~nm}$ e $100 \mathrm{~nm}$. Em relação à altitude, a radiação ultravioleta produz uma vermelhidão na pele, $4 \%$ mais a cada 300 metros de altitude acrescida. Protegendo a terra dos efeitos de vários tipos de radiação, sendo a principal delas a ultravioleta, encontra-se a camada de ozônio que fica na estratosfera, acima da superfície da terra. Devido ao desenvolvimento industrial, o uso de produtos que emitem clorofluorcarbono, houve uma destruição parcial da camada de ozônio e como conseqüência a diminuição da proteção natural a vários tipos de radiação (PROJETO SABER 2004).

Segundo o Instituto Nacional de Pesquisa (INPE) / Centro de Previsão de Tempo e Estudos Climáticos (CPTC) / Ministério da Ciência e Tecnologia (2004) para medir a intensidade da radiação UV recebida pela superfície da terra e sua relevância aos efeitos sobre a pele humana, tem-se adotado o índice ultravioleta (IVU) que é uma medida do valor máximo diário da radiação ultravioleta, ou seja, é o meio dia solar, horário de máxima intensidade de radiação solar. A Organização Mundial de Saúde (OMS) recomendou que o Índice Ultravioleta fosse agrupado por categorias de intensidade de radiação solar, ilustrada a seguir ( Figura 7):

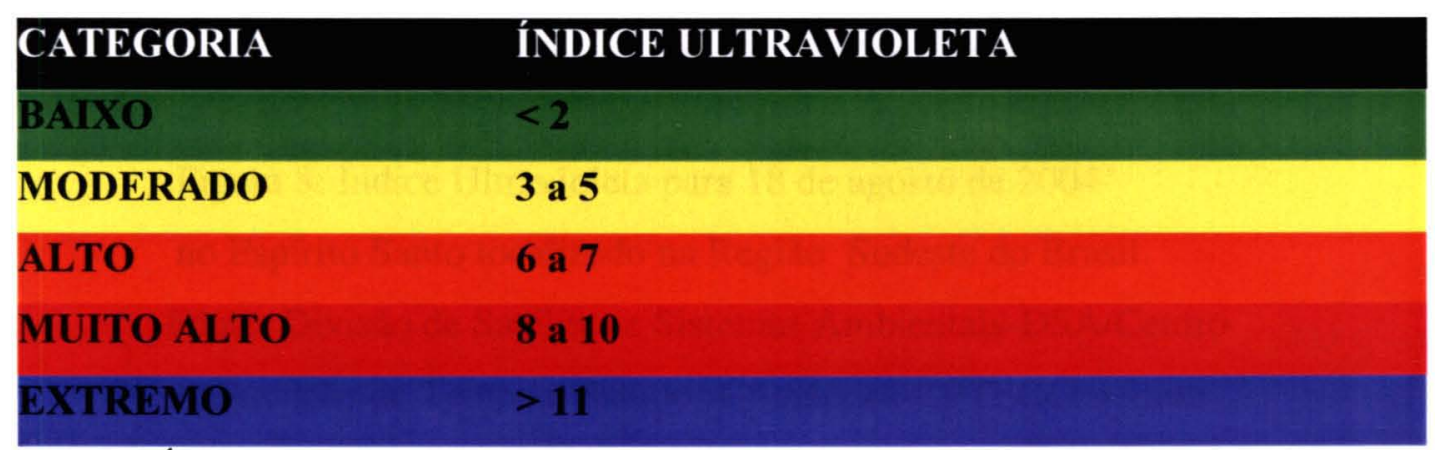

Figura 7:ÍndiceUltravioleta agrupado por categorias de intensidade de radiação solar. Fonte: CPTEC/INPE/Ministério da Ciência e Tecnologia.

Como exemplificação, o Espírito Santo apresentou no dia 18 de agosto de 2004, IUV com valores numéricos de 8 e 9 que representou uma categoria muito alto e alto de radiação solar, sendo um alerta a população local sobre a prevenção de 
queimaduras na pele e câncer de pele( Figura 8). Logo, o Índice Ultravioleta, é uma previsão calculada da quantidade de radiação UV prejudicial à pele que irá alcançar um local específico durante a hora do meio-dia solar. O intervalo de horário entre 11 h30 às 12 h30 é a hora máxima de iluminação solar.

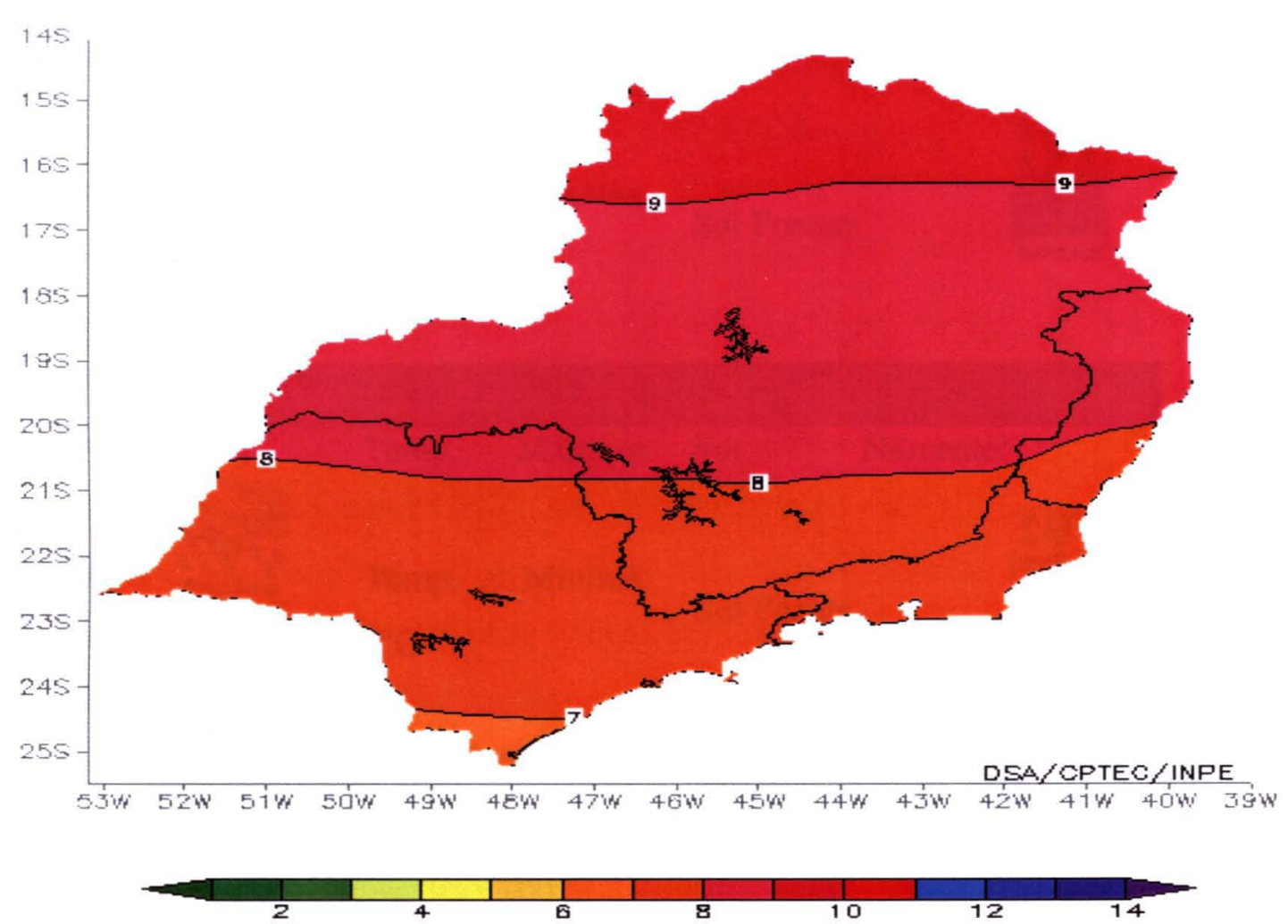

Figura 8: Índice Ultravioleta para 18 de agosto de 2004 no Espírito Santo localizado na Região Sudeste do Brasil. Fonte: Divisão de Satélites e Sistemas Ambientais-DSA/Centro de Previsão de Tempo e Estudos Climáticos-CPTEC/ Instituto Nacional de Pesquisa-INPE/Ministério da Ciência e Tecnologia. 
A previsão do Índice Ultravioleta que alcançará o município de Santa Maria de Jetibá, realizada pela Divisão de Satélites e Sistemas Ambientais, é de extrema intensidade, seguidamente, nos dias 14, 15 e 16 de fevereiro de 2005 (Figura 9).
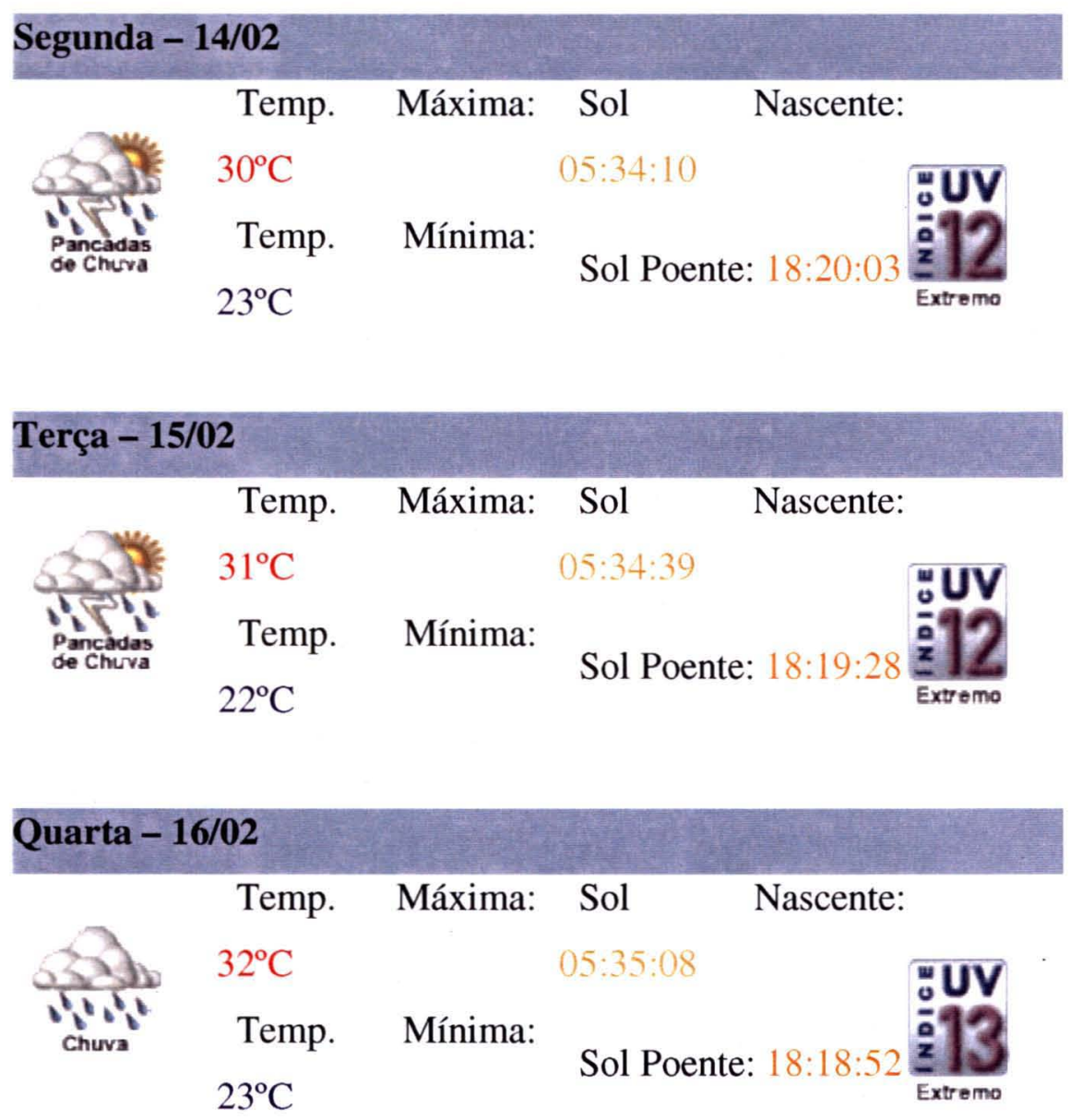

Figura 9: Previsão, consultada no dia 12 de fevereiro de 2005, do IUV para Santa Maria de Jetibá-Espírito Santo nos dias 14,15 e 16 de fevereiro de 2005.

Fonte: Divisão de Satélites e Sistemas Ambientais-DSA/Centro de Previsão de Tempo e Estudos Climáticos-CPTEC/ Instituto Nacional de PesquisaINPE/Ministério da Ciência e Tecnologia.

A Organização Mundial de Saúde, além de categorizar o Índice Ultravioleta como medida da intensidade dessa radiação, publicou as recomendações para a 
população exposta que vão desde "nenhuma precaução necessária até "extra proteção" (sic) que sinaliza, a permanência na sombra, o uso de boné, camisa e protetor solar e a não exposição ao sol do meio dia como medidas de extrema importância a serem adotadas ( Figuras 10 e 11)
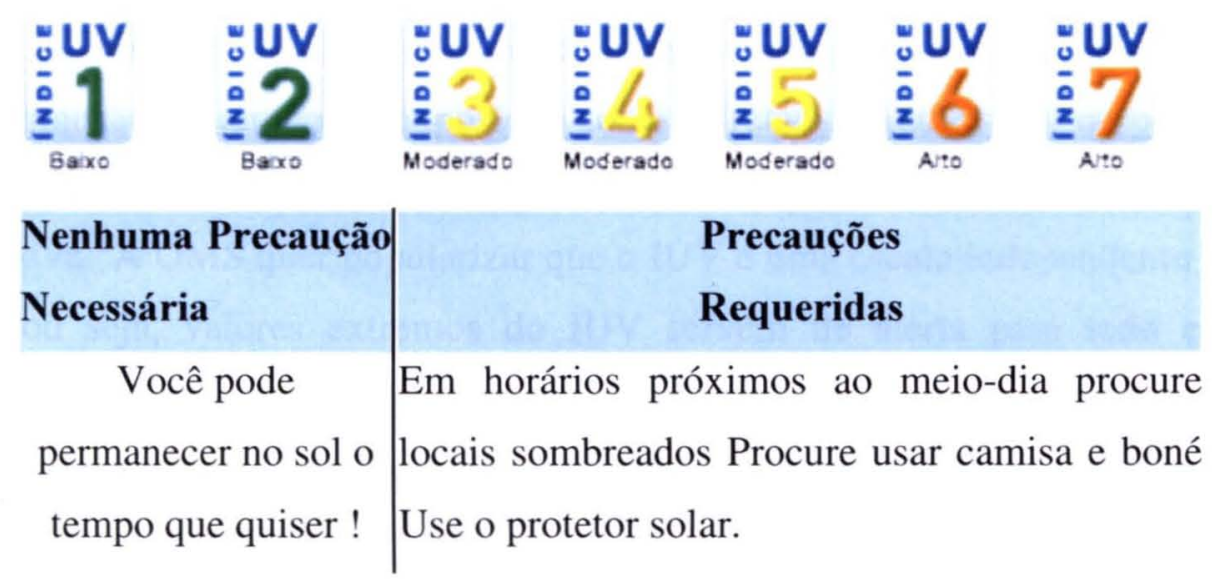

Figura 10: Recomendações da Organização Mundial de Saúde segundo a intensidade do Índice Ultravioleta: índices baixo, moderado e alto.

Fonte: Divisão de Satélites e Sistemas Ambientais-DSA/Centro de Previsão de Tempo e Estudos Climáticos-CPTEC/ Instituto Nacional de PesquisaINPE/Ministério da Ciência e Tecnologia.

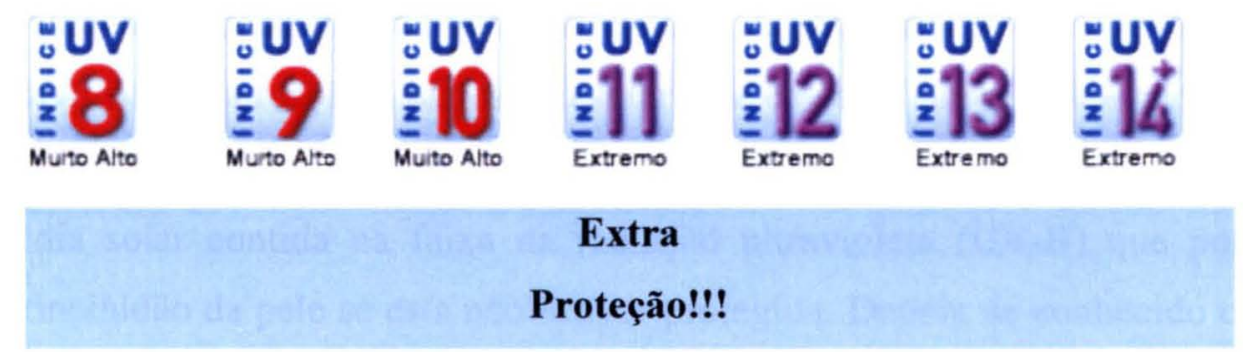

Evite o sol ao meio-dia

Permaneça na sombra

Use camisa, boné e protetor solar.

Figura 11: Recomendações da Organização Mundial de Saúde segundo a intensidade do Índice Ultravioleta : índices muito alto e extremo.

Fonte: Divisão de Satélites e Sistemas Ambientais-DSA/Centro de Previsão de Tempo e Estudos Climáticos-CPTEC/ Instituto Nacional de Pesquisa-INPE/Ministério da Ciência e Tecnologia. 
A Organização Mundial de Saúde quer conscientizar a população que são as escalas apresentadas nas figuras acima que referenciam os perigos oferecidos pela radiação ultravioleta, descartando a informação errônea de relacionar os valores de IUV ao tempo de exposição segura sem nenhuma medida de proteção. A determinação do tempo de exposição ao sol é relacionada ao lipo de pele, podendo ser subjetivo a caracterização da cor da pele, o que poderá levar a uma exposição excessiva. A OMS quer popularizar que o IUV é uma escala independente do tipo de pele, ou seja, valores extremos do IUV servem de alerta para todo e qualquer indivíduo, sendo que pessoas de pele mais claras têm que ter medidas de prevenção mais rigorosas do que as pessoas de pele mais escuras (MINISTÉRIO DA CIÊNCIA E TECNOLOGIA 2005).

Assim, a Organização Meteorológica Mundial, a Organização Mundial de Saúde e o Programa das Nações Unidas para o Meio Ambiente dentre outros órgãos governamentais propuseram a utilização do Índice Ultravioleta (IUV) para informar à população de risco a exposição excessiva a radiação UV e para alertar as pessoas sobre a necessidade de medidas preventivas e corretivas, definindo limites de tolerância de cada tipo de pele individual. A identificação do tipo de pele de cada indivíduo e sua reação à exposição solar é de extrema importância para utilização do Índice Ultravioleta. Utiliza-se a Dose Eritematosa Mínima (DEM) que é a energia média solar contida na faixa da radiação ultravioleta (UV-B) que poderá causar vermelhidão da pele se esta não estiver protegida. Depois de conhecido o DEM para cada fototipo de pele há necessidade da identificação do fototipo pessoal que é classificado (Tabela 1) conforme as reaçōes da pele à exposição solar em fototipo I, II, III, IV, V e VI (UNIVERSIDADE FEDERAL DO RIO DE JANEIRO, 2003). 
Tabela 1 -Fototipos da pele para a população brasileira.

\begin{tabular}{|c|l|l|}
\hline NÚMERICO & FOTOTIPO DE PELE & $\begin{array}{l}\text { CONSEQUENCIA } \\
\text { EXPOSIÇÃO SOLAR }\end{array}$ \\
\hline I & $\begin{array}{l}\text { Pele clara, olhos azuis, sardentos } \\
\text { e todas as crianças com menos } \\
\text { de 1 ano. }\end{array}$ & $\begin{array}{l}\text { Sempre queimam e nunca se } \\
\text { bronzeiam. }\end{array}$ \\
\hline II & $\begin{array}{l}\text { Pele clara, olhos azuis, verdes ou } \\
\text { castanhos claros e cabelos louros } \\
\text { ou ruivos. }\end{array}$ & $\begin{array}{l}\text { Sempre se queimam e às vezes se } \\
\text { bronzeiam. }\end{array}$ \\
\hline III & $\begin{array}{l}\text { A média das pessoas brancas } \\
\text { normais. }\end{array}$ & $\begin{array}{l}\text { Queimam-se moderadamente, } \\
\text { bronzeiam-se } \\
\text { uniformemente. }\end{array}$ \\
\hline IV & $\begin{array}{l}\text { Pele clara ou morena clara, } \\
\text { cabelos castanhos escuros e } \\
\text { olhos escuros. }\end{array}$ & $\begin{array}{l}\text { Queimam-se muito pouco, } \\
\text { bronzeiam-se bastante. }\end{array}$ \\
\hline VI & Pessoas morenas. & $\begin{array}{l}\text { Raramente se queimam, } \\
\text { bronzeiam-se muito. }\end{array}$ \\
\hline
\end{tabular}

Fonte: Sociedade Brasileira de Dermatologia

Ainda descrevendo orientações da UNIVERSIDADE FEDERAL DO RIO DE JANEIRO (2003 p.2) a intensidade de energia solar que chega à superfície da terra varia conforme a época do ano, a hora do dia, a latitude e a altitude de um local, sendo maior no verão, nas horas centrais do dia, nas latitudes mais baixas (mais próximas ao equador terrestre) e em áreas mais elevadas. Finaliza dizendo que o valor do IUV pode ser modificado conforme o conteúdo total de ozônio, a nebulosidade, a névoa e a calmaria dos ventos. 


\section{5-Dermatoscopia}

Segundo PASCHOAL (2004, p.1) o diagnóstico diferencial das lesões pigmentadas cutâneas, o diagnóstico e monitorização de lesões melanocíticas de alto risco, em pacientes de alto risco e a confirmação diagnóstica na suspeita clínica de melanoma são as principais indicações do uso do dermatoscópio como método diagnóstico.

LAMARÃO e MOURA (2001) descreveram que foi Johan Christophorus Kolhaus, em 1663 que fez as primeiras observações de capilares ungueais usando um microscópio. Em 1893, Unna, utilizou óleo de imersão para tornar a superfície cutânea mais translúcida, sendo que no início do século $\mathrm{XX}$ os microscópios mono e binoculares surgiram permitindo a observação da superfície da pele. Mas foi com o trabalho de Saphier, em 1920, na avaliação dos capilares na pele sã e em certas condições patológicas, que a designação dermatoscopia foi utilizada pela primeira vez. Em 1951 Leon Goldman utilizou pela primeira vez a dermatoscopia como método de investigação de lesões pigmentares e Rona Mackie em 1971 fez uso do mesmo equipamento para diferenciar as lesões pigmentares em benigna e maligna. Numa reunião de consenso entre investigadores em 1989, decidiu-se nova terminologia para a definição das características morfologicas das lesões. O conceito da regra do $A B C D$ da dermastocopia foi introduzido no meio acadêmico recentemente por Stolz et. al (sem data citada) e é baseado em um sistema algorítmico de "score", que permite a classificação das lesões melanocíticas em benignas e malignas.

Assim, o profissional que realiza exame complementar com dermatoscópio tem que ter os conhecimentos básicos da regra do $A B C D$ da dermatoscopia que são critérios de avaliação de uma lesão de pele. Os critérios são: A. Assimetria; B. Bordas; C. Cores e D. Diversas Estruturas. Utilizam-se pontuações que irão resultar em uma nota final. Escore menor que 4.75 representa provavelmente uma lesão melanocítica benigna; cscorc entre 4.75 c 5.45 aponta uma lesũo melanocítica 
suspeita e o profissional que decidirá pela exerése cirúrgica ou acompanhamento clínico e escore maior que 5.45 indica provavelmente que é uma lesão melanocítica maligna, sendo que a conduta será de exerése cirúrgica e realização de exame anatomo-patológico (HOSPITAL DO CÂNCER, 2004).

\section{6-O câncer de pele no Espírito Santo}

\section{1 -Câncer de pele não melanoma}

Não diferente do Brasil como um todo, o estado do Espírito Santo tem o câncer de pele não melanoma como o câncer que mais incide na sua população, enquanto estimativa do INCA. Foram estimados para o ano de 2003, 590 casos no sexo masculino e 560 casos no sexo feminino em todo o Estado, quase o dobro de casos em relação aos homens e cinco vezes mais nas mulheres se comparado com o ano 2000. Para a capital do Estado a estimativa cresceu de 40 para 70 casos novos de câncer de pele não melanoma do ano 2001 para o ano 2003 no sexo masculino e de 90 para 150 casos novos no mesmo período (MINISTÉRIO DA SAÚDE 2000, 2001, 2002 e 2003).

\section{2-Câncer de pele melanoma}

O câncer de pele melanoma no estado do Espírito Santo também se comporta com frequência muito pequena como em todos os estados brasileiros. Enquanto estimativa, no ano de 2003 esperou-se a ocorrência de 50 casos novos em homens e 40 casos novos em mulheres em todo o Estado, sendo que nos homens houve uma soma de dez casos por ano e nas mulheres a diferença de estimativa aconteceu entre os anos de 2001 e 2002, 30 e 40 casos respectivamente. A estimativa para a capital foi de 10 casos novos para ambos os sexos nos anos de 2001 e 2002, diferenciando em 2003, quando as mulheres tiveram estimados 5 casos novos e os homens mantiveram os 10 casos novos de câncer melanoma (MINISTÉRIO DA SAÚDE 2001, 2002 e 2003). 


\section{7- Os pomeranos}

\subsection{A Pomerânia:}

A Pomerânia situava-se na Europa e possuía uma superfície de $38409 \mathrm{~km}^{2}$ com uma extensão de 500 quilômetros de litoral. Sua capital Stettin, localizada estrategicamente na enseada do rio Oder que desemboca no Mar Báltico, tornou-se um porto importante na sua relação comercial com o mundo, ficando famosa pela construção naval. Possuía muitos lagos e rios, tanto no litoral como no seu interior, propiciando a pesca. Dividida pelos extremos do oeste e do leste ficou conhecida como Pomerânia Ocidental e Oriental. A Pomerânia Ocidental possuía grandes portos, terras férteis e clima adequado para a agricultura, principalmente no plantio de trigo e cevada. Já na Pomerânia Oriental os lavradores sofriam de geadas com poucos meses para o plantio de culturas. Tinha um litoral arenoso e baixo. Além do clima adverso, o solo não contribuía para a sobrevida dos pomeranos e só em 1752 , com a introdução da cultura da batata inglesa, bem adaptada a esse clima e ao solo, essa situação de difícil vida é modificada. Na Segunda Guerra Mundial, a Pomerânia teve uma parte do seu território transferida para antiga República Socialista da Polônia, uma outra parte para a República Democrática Alemã, sob o domínio da União Soviética e o restante para a República Federal da Alemanha, dominada pela França, Inglaterra e Estados Unidos da América (RÖLKE 1996).

“Como muitas vezes eram obrigados a saírem de uma hora para outra de suas propriedades, muitos s 6 conseguiram salvar a roupa do corpo. Em torno de $500 \mathrm{mil}$ morreram no caminho para Pomerânia Ocidental e restante da Alemanha. Famílias inteiras eram dizimadas " (RÖLKE 1996, p. 38).

Este foi o resultado da decisão dos poloneses e dos soviéticos em expulsar a população pomerana do seu território por vez dominado. 


\title{
7.2 A vinda dos pomeranos para o Brasil.
}

As principais comunidades pomeranas estão concentradas especialmente nos Estados Unidos e Canadá. Segundo RÖLKE (1996) a imigração para os Estados Unidos da América começa no ano de 1835 devido às condições sociais desfavoráveis dos pomeranos e a revolta dos luteranos à cristianização da Pomerânia.

\begin{abstract}
A partir de 1836, iniciou-se um processo de migração para a América, motivada pela pobreza geral que se instalara, sobretudo no campo, onde a maioria dos imigrantes pomeranos trabalhava como diaristas em grandes latifúndios. $O$ que provocou a pobreza entre a população foi o uso cada vez mais racional da terra, o início da industrialização com a invenção da máquina a vapor e a sintetização química do adubo mineral. Tudo isso fez com que cada vez mais pessoas sobrassem no campo (RÖLKE 2002, p.44).
\end{abstract}

Em consequiência desde processo mundial do capitalismo estima-se que no Brasil migraram 30.000 pomeranos no início e meados do século XIX com promessas do governo brasileiro de vida melhor. Migraram para Rio Grande do Sul em Pelotas, São Lourenço do Sul, Santa Cruz do Sul e Nova Petrópolis; Santa Catarina em Pomerode; Espírito Santo para os municípios de Santa Maria de Jetibá, Baixo Guandu, São Gabriel da Palha, Vila Pavão, Pancas, Domingos Martins, Santa Tereza e Afonso Cláudio e para Rondônia em Pimenta Bueno, Cacoal e Espigão do Oeste. (A TRIBUNA 1994).

Relata PACHECO (2000) que descendentes dos primeiros pomeranos vindos para o Espírito Santo foram residir na região central de Rondônia, no município de Cacoal, fundando uma colônia com o nome de Vila Alemã com a agricultura como principal fonte de renda. São aproximadamente 200 famílias capixabas que quando podem voltam ao Espírito Santo para ir ao encontro de parentes. 


\title{
7.3 A chegada dos pomeranos no Espírito Santo
}

Os pomeranos chegaram ao Espírito Santo em número pequeno, precisamente sete pessoas junto com os alemães no município de Santa Isabel, aproximadamente no ano de 1847, surgindo assim a primeiro colônia germânica (A TRIBUNA 1994).

\begin{abstract}
Essa primeira colonização começou nas mais difíceis condições e enfrentando as ameaças de assalto dos índios selvagens, além de carências e sacrifícios. O trabalho mais árduo, um clima diferente, alimentação defïciente, insuficiente habitação, praga de insetos e doenças, insegurança econômica e a falta de colocação dos produtos levaram o colono a lutar, duramente pela existência (GIEMSA e NAUCK 1939, p.455).
\end{abstract}

No período de 1872 a 1873 chegam ao Espírito Santo muitos pomeranos no Porto de Vitória nos navios Gutenberg, Adolph, Anne Helene, Maria Heyden, Doctor Barth e Hainan. Pisaram as terras capixabas trazendo nessa mudança muito sofrimento e promessa de dias melhores. Imigrantes pomeranos em número de 2.142 vão para Santa Maria de Jetibá e Jequitibá e formam a maior colônia de pomeranos do Espírito Santo (A TRIBUNA 1994).

Os pomeranos foram para as comunidades de São João do Petrópolis conhecida como Santa Cruz ou Santa Maria no vale do Santa Maria do Rio Doce, Santa Joana, Domingos Martins, Vila Pavão e Afonso Cláudio. Migraram para Itarana, Laranjas da Terra, Baixo Guandu no período de 1900 a 1920 (UNIVERSIDADE FEDERAL DO ESPÍRITO SANTO 2002). 


\subsection{A cultura: língua, costumes e hábitos.}

Devido ao difícil acesso às terras cedidas aos imigrantes, ainda encontram-se pomeranos que só falam um dialeto, o pomerod. Em algumas localidades do Espírito Santo é necessário ajuda de um tradutor para manter um diálogo. Conforme relato de historiadores, a Pomerânia começa a desistir da sua própria língua após a sua cristianização que trouxe a cultura alemã, assumindo o baixo alemão como língua. $O$ português, às vezes é falado numa mistura com o dialeto. Mas encontra-se cada vez mais o jovem inserido na comunidade, freqüentando escolas e falando o português.

Encontra-se ainda, no Espírito Santo, muitas casas de madeira, às vezes sem energia, esgoto e água tratada. A relação de trabalho existente consiste ainda na formada "meia" em que o patrão dá terreno com uma casinha para segurar o meeiro no lugar como também a lavoura branca, caso seja grande a colheita de café.

Os pomeranos têm na vestimenta a tradução de muito da sua cultura. Segundo RÖLKE 1996, desde a época dos latifundiários as festas têm destaque nas suas vidas: o casamento de batatas, o Kartoffelhochzeit, realizada na colheita da batata inglesa é uma destas festividades. Curioso era a maneira como demonstravam que a colheita tinha ocorrido no tempo esperado com uma produção de qualidade colocando assim as pilhas de batatas ensacadas no local onde ia acontecer a tão esperada festa. A música dava o tom da dança.

Outra festa, com uso de roupa especial, ocorria na confirmação dos garotos:

Roupa domingueira: para solenidade da confirmação os garotos recebem, pela primeira vez, calçado e meia; as meninas, sapatos de verniz, freqüentemente, e meias brancas, além de um vestido branco cheio de rendas,com laços vermelhos e azuis e de um colar de pérolas falsa coloridas. Aos garotos dão aos pais, ainda um fato preto, um cinto e um chapéu de feltro (WAGEMANN 1949, p.77). 
O casamento é também um momento de uma celebração com muita dança e canto.

A indumentária de festa dos adultos é o traje de casamento. As noivas, muitas vezes, usam vestido preto em vez de um branco. So entre os saxônios e os suíços é que as noivas se enfeitam com um véu. Elas gostam de trazer nos dedos anéis de prata. A roupa de casamento do homem é quase igual a da confirmação, diferindo desta apenas quanto ao cinto que deve ser bem ornamentado (WAGEMANN 1949, p.77).

Segundo TRESSMANN 2002, a festa de casamento, hochtijdsfest, dura em média três dias e é um acontecimento considerado de muita relevância para os pomeranos. Ocorre a cerimônia do quebra pratos, o puldaroowand, a cerimônia de casamento e o banquete de casamento chamado de hochtijdsdach.

Há muita alegria com o envolvimento de comunidade durante as festas, até na culinária para elaboração dos pratos que serão servidos para os convidados.

No último dia, o noivo derruba o mastro alto que indicava aos convidados o local dos festejos, para oficializar o término da festa.

Finalizando, deve-se citar, um pesquisador de fotografias que, além de passar alguns dias com os pomeranos registrando imagens belíssimas do seu dia a dia, relatou a cultura pomerana:

As imagens não tratam do primitivo, do pitoresco ou do exótico, pois as marcas de distinção dos traços pomeranos convertem-se na imagem do sujeito humano, que, como qualquer outra, expressa sua identidade através de sua cultura, local onde se encontra o caráter e a 
personalidade de um povo, que tem relações especificas com o universo, com o tempo e, inclusive, com os objetos que os circundam. (....) as marcas das rugas, o aspecto físico e a fisionomia da geração mais antiga, que aparecem nas fotografias, têm muito por nos dizer (....) que ainda é tempo de se investigar e de resgatar os detalhes da história, dos costumes, das crenças, cuidando e preservando essa memória mediante as canções, tradições antigas, orações e versos, não por nostalgia, mas para subsídio à possibilidade de desenhar e redesenhar o percurso histórico (BARROS 2002, p.22-23). 


\section{III-OBJETIVOS}

\section{1-Objetivo geral}

Analisar a contribuição de um programa de rastreamento de câncer de pele como estratégia de prevenção secundária, através do estudo da população atendida pelo "Programa de Assistência Dermatológica aos Lavradores Pomeranos no Interior do Estado do Espírito Santo" no período de 1997 a 2002 com enfoque no município de Santa Maria de Jetibá.

\section{2-Objetivo específico}

Descrever a distribuição do câncer de pele no município de Santa Maria de Jetibá pela população atendida no "Programa de Assistência Dermatológica aos Lavradores Pomeranos no Interior do Estado do Espírito Santo", segundo: tipo de câncer de pele, sexo, idade, atividade principal, origem étnica, tipo de pele, número de lesões, presença de câncer de pele e outro câncer na família, tempo de exposição ao sol e horários de exposição solar e proteção física, por ano de atendimento. 


\section{IV-MATERIAL E MÉTODO:}

\section{1-Área de estudo:}

Escolheu-se começar o estudo por um município, pois é neste espaço que a avaliação epidemiológica irá contribuir de forma mais rápida na organização de serviços de saúde, além de começar a organização da atenção oncológica ao câncer de pele pelo local mais importante, onde a população tem que ter seu o acesso garantido. Foram estudados a sede do município de Santa Maria de Jetibá e Garrafão, distrito do mesmo município.

O município é montanhoso e está localizado na microrregião Serra-Santa Tereza do Estado com uma distância de percurso de $78 \mathrm{Km}$ de Vitória. Localiza-se na macrorregião Centro -Vitória. (ANEXO 3 ). A área geográfica total é 736,3 $\mathrm{Km}^{2}$ e a densidade demográfica de todo município é de $39 \mathrm{hab} / \mathrm{km}^{2}$ com uma população de 28. 774 habitantes segundo censo de 2000 do Instituto Brasileiro de Geografia e Estatística (IBGE).

A área geográfica coberta pela Mata Atlântica no Brasil foi reduzida (ANEXO 4) sendo que Santa Maria de Jetibá é um dos municípios brasileiros com razoável área geográfica ainda coberta ( ANEXO 5).

A sede do município fica a $700 \mathrm{~m}$ de altitude e Garrafão (Pico) a $1200 \mathrm{~m}$ de altitude. $\mathrm{O}$ clima é temperado podendo chegar a temperaturas bem baixas no inverno, principalmente em Garrafão. O Distrito de Garrafão dista $50 \mathrm{Km}$ da sede de Santa Maria de Jetibá.

Foi colonizada pelos pomeranos que até hoje trabalham na lavoura que representam 90\% da população de todo município. Por volta de 1872 os primeiros imigrantes formam uma colônia pomerana em Santa Maria de Jetibá e Jequetibá. $O$ dialeto pomerano ainda é usado pela população. 
Predomina o setor de agricultura (hortigranjeiros). Santa Maria de Jetibá é o segundo maior produtor de ovos do Brasil e é responsável por $87 \%$ de produções capixabas, representadas por 3,6 milhōes de ovos diários. O município recebeu em julho de 2004 o prêmio Prefeito Empreendedor da Região Sudeste do Brasil, devido ao Programa Municipal de Agricultura Orgânica com incentivo financeiro de $30 \%$ do orçamento da Secretaria Municipal de Agricultura, estimulando a produção de produtos orgânicos. A adesão das famílias em não utilizar agrotóxicos na lavoura cresceu consideravelmente, alcançando 150 propriedades de Santa Maria que recebem benefícios e atualmente o município gera 200 toneladas de produtos sem agrotóxicos por mês, oferecendo mais de 40 produtos orgânicos.

Dados do IBGE de 1991 registram que $54,1 \%$ das crianças em domicilio com renda em até 1 salário mínimo encontra-se no meio rural; $62,9 \%$ do total de crianças do município vivem com abastecimento de água inadequado e $98,9 \%$ vivem com esgoto inadequado.

Dados do IBGE do censo de 2000 sobre a proporção da população residente alfabetizada por faixa etária, mostraram aumentos percentuais em todas as faixas etárias do ano de 1991 para 2000, sendo muito significante na faixa etária de 5 a 9 anos de idade, que passou de 39.9 para 54,7 respectivamente (MINISTÉRIO DA SAÚDE 2005).

Ainda segundo o censo de 2000 do IBGE, das 28.774 pessoas residentes em Santa Maria de Jetibá, 22.831 pessoas tinham 10 anos ou mais de idade e dessas 11.201 eram do sexo feminino e 11.630 do sexo masculino. $O$ censo demonstrou que 6.463 pessoas residentes de 10 anos ou mais de idade tinha um rendimento mensal até um salário mínimo e 2.082 dessa mesma amostra de pessoas com 10 anos ou mais de idade não tinham instrução ou menos de um ano de estudo.

Santa Maria de Jetibá foi um grande destaque na primeira divulgação do Censo de 2002 do IBGE no Rio de Janeiro devido ser o município que mais trabalha no Espírito Santo. Segundo CONDE (2002), 80\% dos moradores de Santa Maria de 
Jetibá são descendentes dos imigrantes pomeranos e são responsáveis pela cstatística apresentada pelo IBGE de que o percentual de 58,73 da população ocupada, com mais de 10 anos de idade, trabalha mais de 49 horas por semana no município.

\section{2-População estudada:}

Estudados 324 pacientes que demandaram atendimento de consulta dermatológica no "Programa de Assistência Dermatológica aos Lavradores Pomeranos do Interior do Estado do Espírito Santo" estabelecido pelo convênio de cooperação técnica entre a Secretaria Estadual de Saúde do Estado do Espírito Santo (SES-ES) através do Instituto Estadual de Saúde Pública (IESP), a Associação Albergue Martin Lutero através da Igreja Luterana e Universidade Federal do Espírito Santo (UFES) através do Hospital Universitário Dr. Cassiano de Moraes (HUCAM) no período de 1997 a 2002, lavradores pomeranos ou não do município de Santa Maria de Jetibá, em dois postos de atendimento, um em sua sede e o outro na localidade de Garrafão, resultando na análise de 432 lesões com diagnóstico clínico de câncer de pele. Dessas, 318 lesões foram confirmadas, pelo exame histopatológico, como câncer de pele no universo de 237 pacientes.

\section{3-Instrumentos e procedimentos}

Utilizado as fichas clínico-epidemiológicas (ANEXO 6) dos pacientes atendidos por demanda espontânea no "Programa de Assistência Dermatológica aos Lavradores Pomeranos do Interior do Estado do Espírito Santo" que tiveram diagnóstico clínico de câncer de pele e os resultados dos exames histopatológicos das lesões dos pacientes com diagnóstico clínico de câncer de pele realizado pelo serviço de patologia do HUCAM, no período de 1997 a 2002, da sede de Santa Maria de Jetibá e do Distrito de Garrafão.

Posteriormente foram informatizadas as fichas clínico-epidemiológicas formando um banco de dados a nível estadual da Secretaria de Estado da Saúde do 
espírito Santo, em programa específico, visto que o câncer de pele não é de notificação compulsória no Estado.

Fez-se o cruzamento dos dados dos casos com diagnóstico clínico com o histopatógico para obtenção do caso. A confirmação laboratorial foi critério na definição de caso de câncer de pele.

Todos os casos com resultado histopatológico de câncer de pele das lesões encaminhadas pelo "Programa de Assistência Dermatológica aos Lavradores Pomeranos no Interior do Estado do Espírito Santo" no período estudado do município de Santa Maria de Jetibá foram considerados.

Os pacotes computacionais utilizados, nesse trabalho, foram o Word, o Excel e o SPSS, versão 8.0.

\section{4-Análise dos dados}

\section{1- Seleção das variáveis}

Foram selecionadas as seguintes variávcis para o estudo:

1. sexo e idade; 2 . atividade principal; 3. número de lesões; 4.origem familiar: paterna e materna; 5.tipo de pele; 6.número de horas de exposição ao sol no dia; 7.horário de exposição ao sol no dia; 8.uso de protetor contra o sol; 9.história de câncer de pele na famńlia;10.história de outros cânceres na família;11.número de casos por local de atendimento;12.local das lesões;13.tipo de câncer de pele;14.tipo de tratamento.

\section{Análise dos resultados}

Foram descritas freqüências das variáveis, utilizando-se tabelas e gráficos para visualização dos casos de câncer de pele e seu comportamento epidemiológico em cada localidade e a totalidade do município de atendimento por ano de atendimento. 


\section{6-Limitação do estudo}

O câncer de pele não é doença de notificação compulsória e os dados são de uma determinada etapa do programa de rastreamento, não expressando o número real de casos novos existentes naquele município.

\section{7-Aspectos éticos}

As recomendações da Resolução no 196 de 10/10/96 do Conselho Nacional de Saúde para Pesquisa Científica em Seres Humanos foram cumpridas ncsta pesquisa.

Os dados secundários utilizados são provenientes das fíchas clínicoepidemiológicas preenchidos nos atendimentos realizados pelo "Programa de Assistência Dermatológica aos Lavradores Pomeranos no Interior do Estado do Espírito Santo" na unidade de saúde municipal da sede do município de Santa Maria de Jetibá e na unidade local de ensino de Garrafão e dados de resultados histopatológicos provenientes do arquivo do Serviço de Patologia do Hospital Dr. Cassiano Antônio de Moraes, do Programa de Informatização dos Exames Histopatológicos de Câncer de Pele da Associação Albergue Martin Lutero e do Programa Estadual de Prevenção e Controle do Câncer de Pele, sem divulgação de nomes pessoais. Houve conhecimento do projeto com permissão da Igreja Luterana, Secretaria Municipal de Saúde de Santa Maria de Jetibá, Secretaria do Estado da Saúde do Espírito Santo e Universidade Federal do Espírito Santo.

O projeto de pesquisa foi submetido ao comitê de ética da Universidade São Paulo (USP). 


\section{RESULTADO}

Analisados 324 pacientes com hipótese de câncer de pele pelo diagnóstico clínico na sede e no distrito de Santa Maria de Jetibá no período de 1997 a 2002, sendo que 227 pacientes procederam da sede do município em todos os anos e 97 pacientes do distrito de Garrafão atendidos nos anos de 1998, 2000 e 2002. Entre esses três anos de mais atendimento dermatológico, houve maior concentração em número de pacientes no ano 2000, em todo o município de Santa Maria de Jetibá com hipótese de câncer de pele. Visualiza-se um pequeno crescimento na suspeição de câncer na sede do município, com exceção do ano de 1999 que teve uma diminuição no diagnóstico clínico e conseqüentemente, na deteç̧ão de casos novos na sede do município. A maior concentração de diagnóstico clínico em Garrafão ocorreu no ano de 1998. Observando-se a descoberta de casos novos isoladamente na sede do município verifica-se um aumento na freqüência de casos nos anos de 2000, 2001 e 2002 (Tabela 2).

Tabela 2. Pacientes atendidos no "Programa de Assistência Dermatológica aos Lavradores Pomeranos no Interior do Estado do Espírito Santo", com diagnóstico clínico de câncer de pele em Santa Maria de Jetibá no período de 1997 a 2002.

\begin{tabular}{c|c|c|c|c|c|c|}
\hline Localidade & \multicolumn{2}{|c|}{ Sede } & \multicolumn{2}{|c|}{ Garrafăo } & \multicolumn{2}{|c|}{ Total } \\
\hline No ano & $\mathrm{N}^{\circ}$ & $\%$ & $\mathrm{~N}^{\circ}$ & $\%$ & $\mathrm{~N}^{\circ}$ & $\%$ \\
\hline 1997 & 38 & 16,7 & - & - & 38 & 11,7 \\
\hline 1998 & 30 & 13,2 & 43 & 44,3 & 73 & 22,5 \\
\hline 1999 & 28 & 12,3 & - & - & 28 & 8,6 \\
\hline 2000 & 45 & 19,8 & 30 & 30,9 & 75 & 23,1 \\
\hline 2001 & 43 & 18,9 & - & - & 43 & 13,3 \\
\hline 2002 & 43 & 18,9 & 24 & 24,7 & 67 & 20,7 \\
\hline Total & 227 & 100,0 & 97 & 100,0 & 324 & 100,0 \\
\hline
\end{tabular}

Fonte: Secretaria de Estado da Saúde do Espírito Santo. 
Evidencia-se que dos 324 pacientes encaminhados para confirmação histopatológica de câncer de pele, $78,4 \%$ dos pacientes tiveram apenas uma lesão, mas destaca-se que deste universo pode-se encontrar $1,5 \%$ dos pacientes com cinco lesões em todo o município de Santa Maria de Jetibá (Tabela 3).

Tabela 3. Número de lesões por pacientes com diagnóstico clínico de câncer de pele, Santa Maria de Jetibá, 1997 a 2002.

\begin{tabular}{c|c|c|}
\hline Número lesões & $\begin{array}{c}\text { Número de } \\
\text { paciente }\end{array}$ & Percentual \\
\hline 1 & 254 & 78,4 \\
\hline 2 & 48 & 14,8 \\
\hline 3 & 12 & 3,7 \\
\hline 4 & 5 & 1,5 \\
\hline 5 & 5 & 1,5 \\
\hline Total & 324 & 100,0 \\
\hline
\end{tabular}

Fonte: Secretaria de Estado da Saúde do Espírito Santo.

$\mathrm{Na}$ descrição da tabela 4 , verifica-se que $83,1 \%$ das lesões dos pacientes examinados, em todo o município, tiveram um diagnóstico clínico de Carcinoma Basocelular (CBC). Observa-se que $14,5 \%$ das lesões dos pacientes de Garrafão estavam sem preenchimento das ficha clínico-epidemiológica e conseqüentemente sem o seu diagnóstico clínico. O Carcinoma Espinocelular (CEC) foi o segundo câncer de pele com diagnóstico clínico $(4,2 \%)$ e a hipótese diagnóstica com suspeição de melanoma cutâneo atingiu o percentual de 3,2 em todo o município. 
Tabela 4. Características das lesões dos pacientes atendidos pelo Programa de Assistência Dermatológica aos Lavradores Pomerano no Interior do Estado do Espírito Santo", Santa Maria de Jetibá, 1997 a 2002.

\begin{tabular}{|c|c|c|c|c|c|c|}
\hline \multirow{2}{*}{$\begin{array}{l}\text { Localidade } \\
\text { Diagnóstico Clínico das } \\
\text { lesões }\end{array}$} & \multicolumn{2}{|c|}{ Sede } & \multicolumn{2}{|c|}{ Garrafão } & \multicolumn{2}{|c|}{ Geral } \\
\hline & $\mathbf{N}^{\circ}$ & $\%$ & $\mathbf{N}^{\circ}$ & $\%$ & $\mathbf{N}^{\circ}$ & $\%$ \\
\hline Melanoma & 10 & 3,6 & 4 & 2,9 & 14 & 3,2 \\
\hline CEC & 12 & 4.3 & 6 & 4,3 & 18 & 4.2 \\
\hline CBC & 255 & 91,4 & 104 & 75,4 & 359 & 83,1 \\
\hline CBC ou CEC & - & - & 3 & 2,2 & 3 & 0,7 \\
\hline CBC ou Mclanoma & - & - & 1 & 0.7 & 1 & 0.2 \\
\hline Outros tumores & 2 & 0,7 & - & - & 2 & 0.5 \\
\hline Sem ficha & - & - & 20 & 14,5 & 20 & 4,6 \\
\hline Sem informação & - & - & - & - & 15 & 3,7 \\
\hline Total & 279 & 100,0 & 138 & 100,0 & 4.32 & 100.0 \\
\hline
\end{tabular}

Fonte: Secretaria de Estado da Saúde do Espírito Santo.

O principal procedimento terapêutico utilizado nas lesões com suspeita clínica de câncer de pele foi biopsia excisional $(92,8 \%)$, ou seja, a retirada completa da tumoração (tabela 5). 
Tabela 5. Procedimentos terapêuticos nas lesões dos pacientes atendidos pelo Programa de Assistência Dermatológica aos Lavradores Pomerano no Interior do Estado do Espírito Santo", com diagnóstico clínico de câncer de pele, Santa Maria de Jetibá, 1997 a 2002.

\begin{tabular}{|c|c|c|c|c|c|c|}
\hline \multirow{3}{*}{$\begin{array}{l}\text { Conduta } \\
\text { Terapêutica }\end{array}$} & \multicolumn{4}{|c|}{ Localidade } & \multirow{2}{*}{\multicolumn{2}{|c|}{ Total }} \\
\hline & \multicolumn{2}{|c|}{ Sede } & \multicolumn{2}{|c|}{ Garrafão } & & \\
\hline & $\mathrm{N}^{\circ}$ & $\%$ & $\mathrm{~N}^{\circ}$ & $\%$ & $\mathrm{~N}^{\circ}$ & $\%$ \\
\hline Exerése cirúrgica & 275 & 93,5 & 126 & 91,3 & 401 & 92,8 \\
\hline Biopsia incisional & 7 & 2,4 & 11 & 8,0 & 18 & 4,2 \\
\hline * Encaminhado & 7 & 2,4 & - & - & 7 & 1,6 \\
\hline Ignorado & 5 & 1,7 & 1 & 0,7 & 6 & 1,4 \\
\hline Total & 294 & 100,0 & 138 & 100,0 & 432 & 100,0 \\
\hline
\end{tabular}

Fonte: Secretaria de Estado da Saúde do Espírito Santo.

* Encaminhado para outro serviço de maior complexidade.

Na análise da frequiência do câncer de pele, em Santa Maria de Jetibá, dos casos com confirmação histopatológica, em todo período estudado, verifica-se que dentre as lesões examinadas 59,5\% tiveram resultados de Carcinoma Basocelular (CBC), coincidentemente o equivalente ao mesmo percentual nas duas localidades, 59,5 na sede e 59,4 no distrito. O Carcinoma Espinocelular (CEC) permaneceu em segundo lugar de ocorrência em todo município com 7,9 \%, destacando-se que na sede o CEC apareceu com uma freqüência maior em 7,3 percentuais que em Garrafão. Esta classificação não teve a contribuição dos casos de Carcinoma Espinocelular in situ que foram computados a parte $(2,3 \%)$. Confirmou-se histopatologicamente $1,9 \%$ de Melanoma e 0,7 \% de Melanoma in situ no período de 1997 a 2002 em Santa Maria de Jetibá. Dos casos com diagnóstico clínico de câncer de pele, 17,6 \% não tiveram confirmação histopatológica e 7,0 ficaram sem resultado histopatológico (Tabela 6). 
Tabela 6.Resultado histopatológico das 432 lesões com diagnóstico clínico de câncer de pele, Santa Maria de Jetibá, período de 1997 a 2002.

\begin{tabular}{|c|c|c|c|c|c|c|}
\hline \multirow{2}{*}{ Resultado histopatológico } & \multicolumn{2}{|c|}{ Sede } & \multicolumn{2}{|c|}{ Garrafāo } & \multicolumn{2}{|c|}{ Geral } \\
\hline & $\mathbf{N}^{\circ}$ & $\%$ & $\mathrm{~N}^{\circ}$ & $\%$ & $\mathbf{N}^{\circ}$ & $\%$ \\
\hline Melanoma & 5 & 1,7 & 3 & 2,2 & 8 & 1,9 \\
\hline CEC & 30 & 10,2 & 4 & 2,9 & 34 & 7,9 \\
\hline CBC & 175 & 59,5 & 82 & 59,4 & 257 & 59,5 \\
\hline Carcinoma misto & 5 & 1,7 & 1 & 0,7 & 6 & 1,4 \\
\hline CEC in Situ & 6 & 2,0 & 4 & 2,9 & 10 & 2,3 \\
\hline Melanoma in Situ & 1 & 0,3 & 2 & 1,4 & 3 & 0,7 \\
\hline Sem resultado histopatológico & 16 & 5,4 & 14 & 10,1 & 30 & 7,0 \\
\hline Encaminhados para outro serviço & 7 & 2,4 & - & - & 7 & 1,7 \\
\hline Não confirmou câncer de pele & 48. & 16,3 & 28 & 20,3 & 76 & 17,6 \\
\hline Total & 294 & 100,0 & 138 & 100,0 & 432 & 100,0 \\
\hline
\end{tabular}

Fonte: Secretaria de Estado da Saúde do Espírito Santo.

A proporção dos tipos de câncer de pele com confirmação histopatológica, encontrada nas lesões dos pacientes atendidos no período de 1997 a 2002 no município é: 80,8 \% são CBC, $10,7 \%$ são CEC e 2,5 são Melanoma com um aparecimento pequeno de CEC in situ $(3,1 \%)$, de Carcinoma Misto $(1,9 \%)$ e Melanoma in situ $(0,9)$. As maiores freqüências encontradas foram $\mathrm{CBC}$ com 85,4\% em Garrafão, o CEC com um percentual de 13,5 na sede do município e 3,1\% de Melanoma no distrito de Garrafão (Tabela 7). 
Tabela 7. Proporção dos tipos de câncer de pele nas lesões confirmadas histopatologicamente, Santa Maria de Jetibá, período de 1997 a 2002.

\begin{tabular}{|c|c|c|c|c|c|c|}
\hline \multirow{2}{*}{$\begin{array}{l}\text { Confirmação Histopatológica } \\
\text { por tipo de câncer de pele por } \\
\text { lesões. }\end{array}$} & \multicolumn{2}{|c|}{ Sede } & \multicolumn{2}{|c|}{ Garrafão } & \multicolumn{2}{|c|}{ Geral } \\
\hline & $\mathbf{N}^{\circ}$ & $\%$ & $\mathbf{N}^{\circ}$ & $\%$ & $\mathrm{~N}^{\circ}$ & $\%$ \\
\hline Melanoma & 5 & 2,3 & 3 & 3,1 & 8 & 2,5 \\
\hline CEC & 30 & 13,5 & 4 & 4,2 & 34 & 10,7 \\
\hline СBC & 175 & 78,8 & 82 & 85,4 & 257 & 80,8 \\
\hline Carcinoma misto & 5 & 2,3 & 1 & 1.0 & 6 & 1,9 \\
\hline CEC in situ & 6 & 2,7 & 4 & 4,2 & 10 & 3,1 \\
\hline Melanoma in situ & 1 & 0,5 & 2 & 2,1 & 3 & 0,9 \\
\hline Total & 222 & 100,0 & 96 & 100,0 & 318 & 100,0 \\
\hline
\end{tabular}

Fonte: Secretaria de Estado da Saúde do Espírito Santo.

Tabela 8. Local das lesões confirmadas, pelo exame histopatológico, como casos de câncer de pele. Santa Maria de Jetibá, 1997 a 2002.

\begin{tabular}{l|c|c|c|c|c|c|}
\hline & \multicolumn{2}{|c|}{ Sede } & \multicolumn{2}{c|}{ Garrafáo } & \multicolumn{2}{c|}{ Geral } \\
\hline Local da lesão & $\mathrm{N}^{\circ}$ & $\%$ & $\mathrm{~N}^{\circ}$ & $\%$ & $\mathrm{~N}^{\circ}$ & $\%$ \\
\hline Cabeça & 172 & 77,9 & 74 & 78,8 & 246 & 78,2 \\
\hline Membro superior & 23 & 10,4 & 2 & 2,1 & 25 & 7,9 \\
\hline Membro inferior & 6 & 2,7 & 2 & 2,1 & 8 & 2,5 \\
\hline Tronco & 20 & 9,0 & 16 & 17,0 & 36 & 11,4 \\
\hline Total & 221 & 100,0 & 94 & 100,0 & 315 & 100,0 \\
\hline
\end{tabular}

Fonte: Secretaria de Estado da Saúde do Espírito Santo.

Conforme tabela anterior (Tabela 8), o local do tegumento mais atingido por câncer de pele foi a cabeça, tanto na sede $(77,9 \%)$ como no Distrito de Garrafão $(78,8 \%)$. O segundo local mais atingido sofreu diferenciação conforme a localidade sendo que na sede, foi o membro superior com $10,4 \%$ e no Distrito de Garrafão foi o tronco com 17,0 \%. Em relação ao local da pele menos atingindo, os pacientes da sede de Santa Maria de Jetibá apresentaram menos lesões de câncer de pele no membro inferior e o Distrito de Garrafão, no membro superior e inferior (Figura 11). 
Observa-se que três lesões do total de 318 , não tiveram seus locais de acometimento cutâneo identificados.

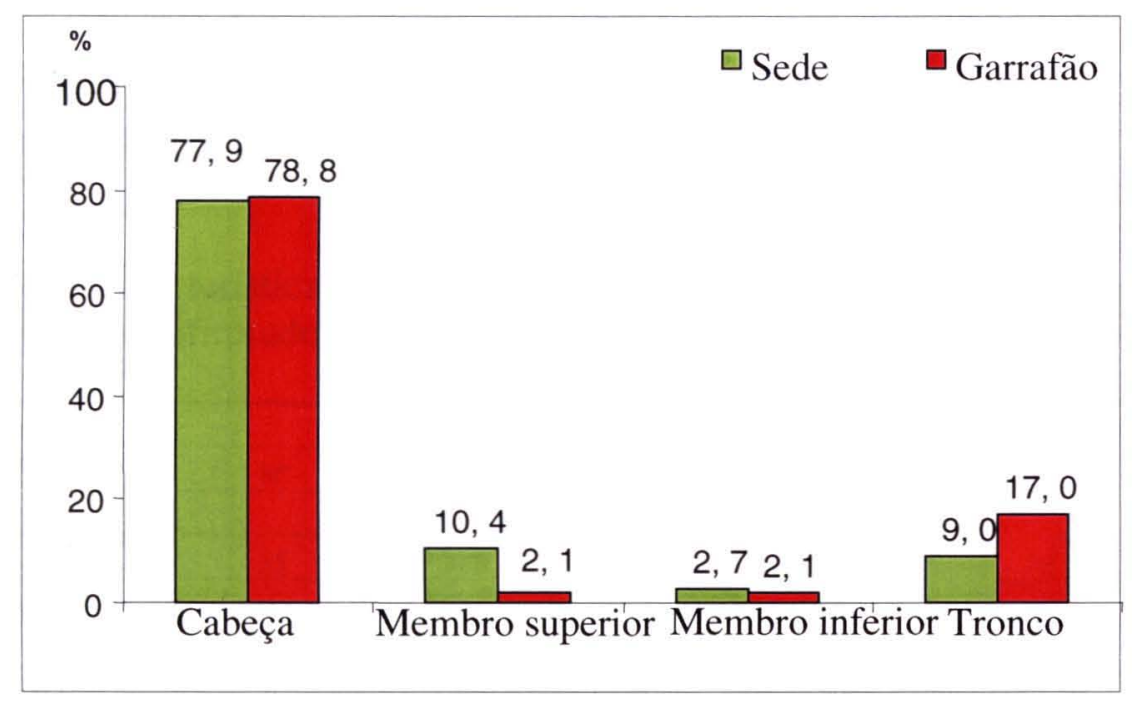

Figura 11. Local das lesões confirmadas, pelo exame histopatológico, como casos de câncer de pele. Santa Maria de Jetibá, 1997 a 2002. Fonte: Secretaria de Estado da Saúde do Espírito Santo.

Tabela 9. Proporção dos tipos de câncer de pele em pacientes com diagnóstico clínico confirmado pelo exame histopatológico por localidade de atendimento e sexo, Santa Maria de Jetibá, 1997 a 2002.

\begin{tabular}{|c|c|c|c|c|c|c|}
\hline \multirow[b]{2}{*}{ Tipo de câncer } & \multicolumn{2}{|c|}{ Sede } & \multicolumn{2}{|c|}{ Garrafão } & \multicolumn{2}{|c|}{ Geral } \\
\hline & Masculino & Feminino & Masculino & Feminino & Masculino & Feminino \\
\hline Melanoma & 1 & 4 & & 2 & 1 & 6 \\
\hline CEC & 6 & 13 & 1 & 2 & 7 & 15 \\
\hline $\mathrm{CBC}$ & 43 & 96 & 20 & 34 & 63 & 130 \\
\hline $\begin{array}{l}\text { Carcinoma } \\
\text { misto }\end{array}$ & 1 & 2 & 1 & - & 2 & 2 \\
\hline CEC in Situ & 3 & 2 & 1 & 2 & 4 & 4 \\
\hline $\begin{array}{l}\text { Melanoma in } \\
\text { Situ }\end{array}$ & 1 & - & 1 & 1 & 2 & 1 \\
\hline Total & 55 & 117 & 24 & 41 & 79 & 158 \\
\hline
\end{tabular}

Fonte: Secretaria de Estado da Saúde do Espírito Santo. 
Quando analisado a proporção dos tipos de câncer de pele com cónfirmação histopatológica nos pacientes atendidos no período de 1997 a 2002 no município encontra-se 63 pacientes do sexo masculino e 130 pacientes do sexo feminino tiveram o diagnóstico de CBC selado com histopatologia com CBC, chegando a 193 casos de CBC. Apresenta-se um total de 237 pacientes com câncer de pele confirmado pelo exame histopatológico (Tabela 9).

Tabela 10. Características sócio-demográficas de pacientes com diagnóstico de câncer de pele confirmado pelo exame histopatológico. Santa Maria de Jetibá, 1997 a 2002.

\begin{tabular}{|c|c|c|c|c|c|c|}
\hline \multirow{2}{*}{$\begin{array}{c}\text { Características } \\
\text { socio-demografficas }\end{array}$} & \multicolumn{2}{|c|}{ Sede } & \multicolumn{2}{|c|}{ Garralăo } & \multicolumn{2}{|c|}{ Geral } \\
\hline & $\mathrm{N}^{\circ}$ & $\%$ & $\mathrm{~N}^{0}$ & $\%$ & $N^{\circ}$ & $\%$ \\
\hline \multicolumn{7}{|l|}{ Sexo } \\
\hline Masculino & 55 & 32,0 & 24 & 36,9 & 79 & 33,3 \\
\hline Feminino & 117 & 68.0 & 41 & 63,1 & 158 & 66,7 \\
\hline Total & 172 & 72,6 & 65 & 27,4 & 237 & 100,0 \\
\hline \multicolumn{7}{|l|}{ Faixa etária (anos) } \\
\hline 14 a 29 & 4 & 2,7 & 2 & 3,2 & 6 & 2,9 \\
\hline 30 a 39 & 12 & 8,2 & 3 & 4,8 & 15 & 7,2 \\
\hline 40 a 49 & 28 & 19,0 & 12 & 19,4 & 40 & 19,1 \\
\hline 50 a 59 & 34 & 23,1 & 17 & 27,5 & 51 & 24,4 \\
\hline 60 a 69 & 32 & 21,8 & 10 & 16,1 & 42 & 20,1 \\
\hline 70 a 79 & 28 & 19,1 & 16 & 25,8 & 44 & 21,1 \\
\hline $80 \mathrm{c}$ mais & 9 & 6,1 & 2 & 3,2 & 11 & 5,2 \\
\hline Total & 147 & 100,0 & 62 & 100.0 & 209 & 100,0 \\
\hline \multicolumn{7}{|l|}{ Atividade } \\
\hline Lavrador & 131 & 86,2 & 56 & 98,2 & 187 & 89,5 \\
\hline Outras & 21 & 13,8 & 1 & 1.8 & 22 & 10.5 \\
\hline Total & 152 & 100,0 & 57 & 100,0 & 209 & 100,0 \\
\hline
\end{tabular}

Fonte: Secretaria de Estado da Saúde do Espírito Santo.

Das características sócio-demográficas dos pacientes com diagnóstico de câncer de pele, confirmado pelo exame histopatológico, a variável sexo teve a maior freqüência na mulher tanto na sede do município como no Distrito de Garrafão, com 68,0 e 63,1 percentuais, respectivamente (Figura 12). As faixas etárias entre 50 a 59 anos $(23,1)$ e 60 a 69 anos $(21,8)$ foram as mais atingidas na sede de Santa Maria de Jetibá. No Distrito de Garrafão, os maiores percentuais encontram-se na faixa de 50 a 59 anos $(27,5)$ e a faixa etária de 70 a 79 anos $(25,8)$. Verifica-se em todo o município, no período estudado, os extremos acometidos compreendem 2,9 de frequiência na faixa etária de 14 a 29 anos a 5,2 em 80 anos e mais. Analisando-se a 
atividade principal exercida pelo paciente, a de lavrador representa 89,5\% do todo analisado, porém já se aponta uma pequena diminuição deste percentual na sede $(86,2)$ em relação ao distrito $(98,2)$ (Tabela 10$)$ do município de Santa Maria de Jetibá.

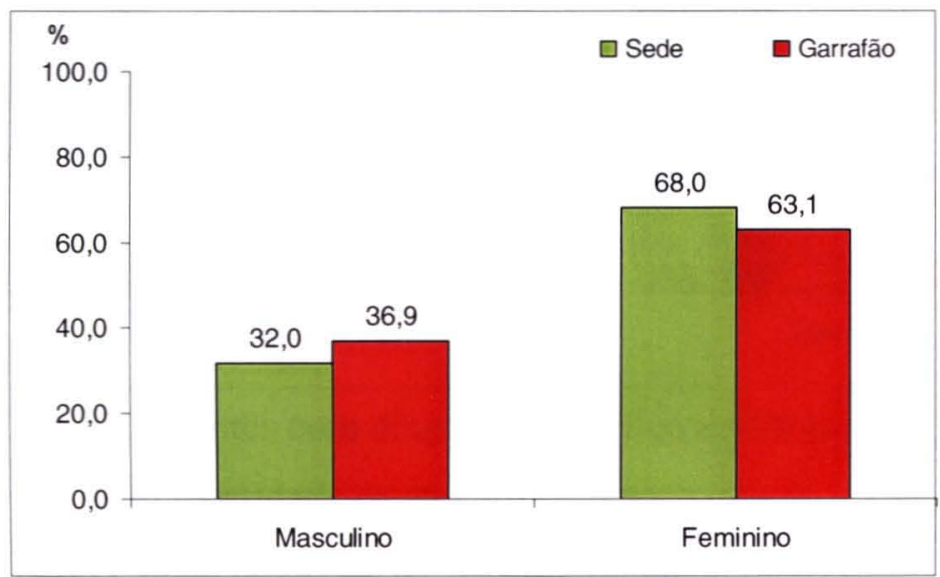

Figura 12. A distribuição por sexo dos pacientes com câncer de pele confirmados pelo exame histopatológico, Santa Maria de Jetibá, 1997 a 2002. Fonte: Secretaria de Estado da Saúde do Espírito Santo.

Observa-se um percentual elevado de etnia pomerana/alemã, tanto na sede $(93,8)$ quanto em Garrafão $(88,0)$. A etnia italiana se coloca como segunda em ocorrência entre os pacientes da sede $(4,4 \%)$ e em Garrafão (6,6\%) (Figura 13), sendo equivalentes tanto no lado materno quanto paterno (Tabela 11). 


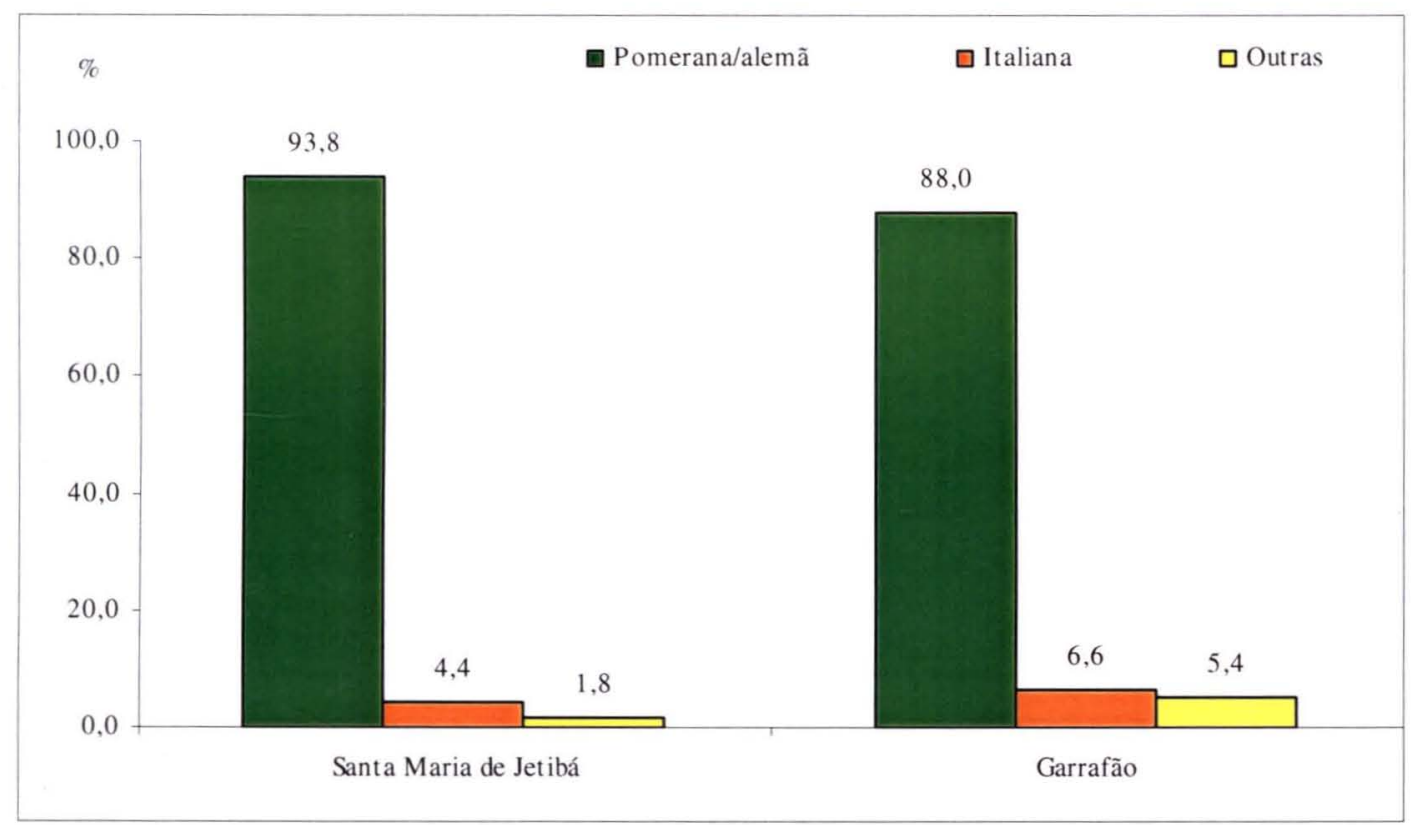

Figura 13. Etnia dos pacientes com diagnóstico clínico e histopatológico de câncer de pele segundo localidade de atendimento.

Fonte: Secretaria de Estado de Saúde do Espírito Santo

Quanto à história familiar, 33,8 \% dos pacientes com diagnóstico clínico e histopatológico de câncer de pele, na sede de Santa Maria de Jetibá, tiveram câncer de pele na família relatado e com o percentual de 28,9 em relação ao acometimento por outro tipo de câncer na família. Tanto história familiar de câncer de pele como história familiar de câncer tem seu percentual diminuído no Distrito de Garrafão (Tabela 11 e Figura 14). 
Tabela 11. Histórico familiar dos pacientes com diagnóstico clínico e histopatológico de câncer de pele. Santa Maria de Jetibá, 1997 a 2002.

\begin{tabular}{|c|c|c|c|c|c|c|}
\hline Etnia materna & $\mathrm{N}^{\circ}$ & $\%$ & $\mathrm{~N}^{\circ}$ & $\%$ & $\mathrm{~N}^{\mathrm{o}}$ & $\%$ \\
\hline Pomerana/alemã & 136 & 92.5 & 48 & 87,3 & 184 & 91,1 \\
\hline Italiana & 8 & 5,5 & 3 & 5,4 & 11 & 5,4 \\
\hline Outras & 3 & 2,0 & 4 & 7,3 & 7 & 3,5 \\
\hline Total & 147 & 100,0 & 55 & 100,0 & 202 & 100,0 \\
\hline \multicolumn{7}{|l|}{ Etnia paterna } \\
\hline Pomerana/alemã & 139 & 94,6 & 47 & 87,0 & 186 & 92.5 \\
\hline Italiana & 6 & 4,1 & 4 & 7,4 & 10 & 5,0 \\
\hline Outras & 2 & 1,3 & 3 & 5,6 & 5 & 2,5 \\
\hline Total & 147 & 100,0 & 54 & 100,0 & 201 & 100,0 \\
\hline \multicolumn{7}{|c|}{$\begin{array}{l}\text { Histórico familiar de câncer } \\
\text { de pele }\end{array}$} \\
\hline Sim & 49 & 33,8 & 16 & 34,0 & 65 & 33,9 \\
\hline Não & 96 & 66,2 & 31 & 66,0 & 127 & 66,1 \\
\hline Total & 145 & 100,0 & 47 & 100,0 & 192 & 100,0 \\
\hline \multicolumn{7}{|c|}{ Histórico familiar de câncer } \\
\hline Sim & 33 & 28,9 & 16 & 32,7 & 49 & 30,1 \\
\hline Não & 81 & 71,1 & 33 & 67,3 & 114 & 69,9 \\
\hline Total & 114 & 100,0 & 49 & 100,0 & 163 & 100,0 \\
\hline
\end{tabular}

Fonte: Secretaria de Estado da Saúde do Espírito Santo

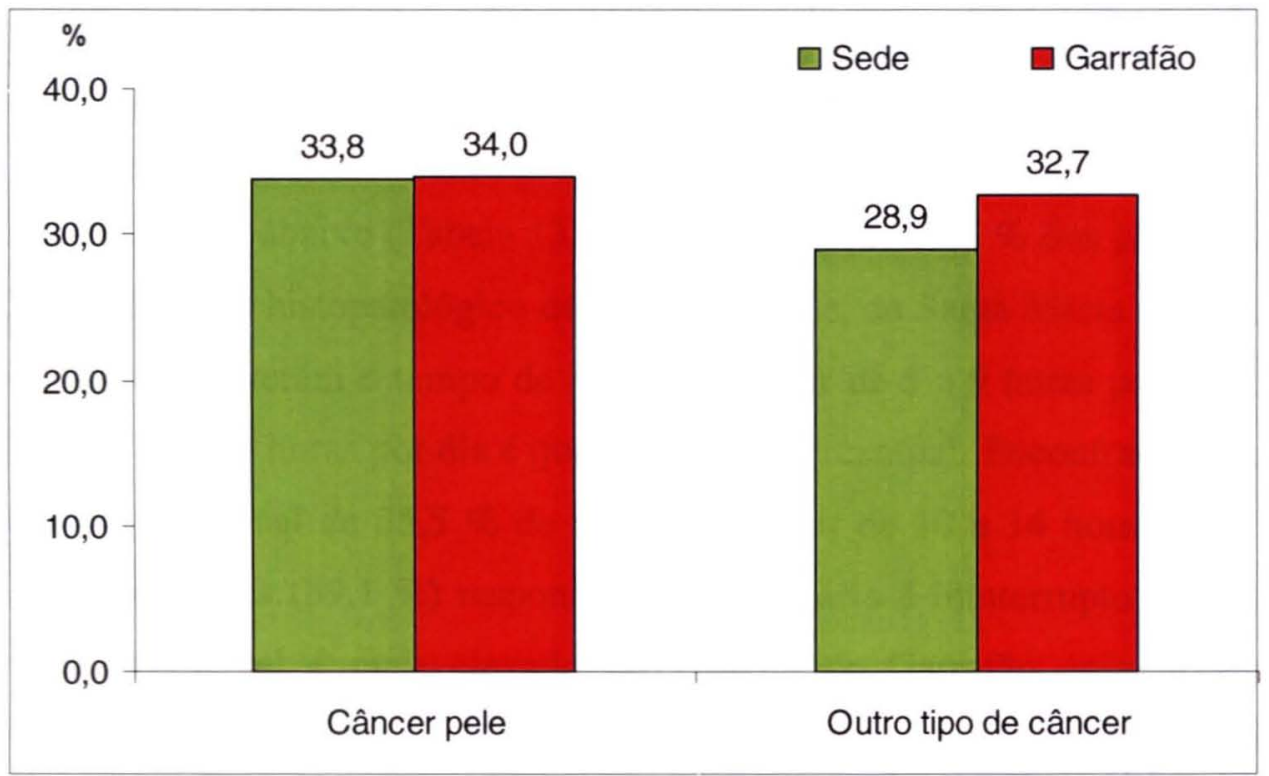

Figura 14. Histórico familiar de câncer de pacientes com diagnóstico clínico e histopatológico de câncer de pele. Santa Maria de Jetibá, 1997 a 2002. Fonte: Secretaria de Estado da Saúde do Espírito Santo. 
Quando analisado o tipo de pele dos pacientes com câncer de pele com confirmação histopatológica, o tipo 1 aparece mais na sede (13\%), um pouco mais que três vezes o encontrado no distrito $(3,6 \%)$. O tipo de pele 2 é o mais encontrado $(75,1 \%)$ nos pacientes com câncer de pele em todo o município. Grande parte dos pacientes com casos de câncer de pele em Santa Maria de Jetibá tinha uma pele do tipo 1 e $2(85,6 \%)$. Não foram evidenciados tipos de pele 5 e 6 no período estudado (Tabela 12).

Tabela 12. Classificação segundo fototipos de pele dos pacientes atendidos pelo "Programa de Assistência Dermatológica aos Lavradores Pomeranos do Interior do Estado do Espírito Santo" com diagnóstico clínico e histopatológico de câncer de pele. Santa Maria de Jetibá no período de 1997 a 2002.

\begin{tabular}{c|c|c|c|c|c|c|}
\hline & \multicolumn{2}{|c|}{ Sede } & \multicolumn{2}{c|}{ Garrafão } & \multicolumn{2}{c|}{ Geral } \\
\cline { 2 - 7 } Fototipos de Pele & $\mathrm{N}^{\circ}$ & $\%$ & $\mathrm{~N}^{\circ}$ & $\%$ & $\mathrm{~N}^{\circ}$ & $\%$ \\
\hline 1 & 19 & 13,0 & 2 & 3,6 & 21 & 10,5 \\
\hline 2 & 106 & 72,6 & 45 & 81,8 & 151 & 75,1 \\
\hline 3 & 20 & 13,7 & 8 & 14,6 & 28 & 13,9 \\
\hline 4 & 1 & 0,7 & 0 & 0,0 & 1 & 0,5 \\
\hline Total & 146 & 100,0 & 55 & 100,0 & 201 & 100,0 \\
\hline
\end{tabular}

Fonte: Secretaria de Estado da Saúde do Espírito Santo.

Conforme tabela abaixo (Tabela 13) demonstra-se que $56,6 \%$ dos pacientes com diagnóstico clínico e histopatológico de câncer de pele, de Santa Maria de Jetibá, no período estudado, tiveram o tempo de exposição solar de 5 a 9 horas por dia, sendo que a jornada de oito horas por dia é que eleva este percentual. Encontra-se ainda um considerável percentual de $35,5 \%$ de exposição solar de 10 a 14 horas por dia. A maioria dos pacientes $(89,1 \%)$ respondeu que o horário é ininterrupto à exposição solar. Este percentual é mais elevado no Distrito de Garrafão com $96,2 \%$ de pacientes expostos ao sol o dia todo sem interrupção. $O$ uso de chapéu como protetor solar chegou a um percentual de 75,9 no paciente com câncer de pele em todo o município, sem diferença no percentual significativa nos dois locais de atendimento. A resposta positiva sobre o uso de manga comprida como proteção solar se apresentou com $37,2 \%$ na sede do município e $25,5 \%$ no Distrito de Garrafão. Um 
pouco mais elevado foi o percentual sobre o uso de calça comprida também como medida de proteção ao sol, sendo que no meio urbano apareceu com 51,4 \% e no meio rural com 30,9\%. Bem diminuído foi o percentual respondido sobre o uso de filtro solar que atingiu a 8,9 em todo município, sendo bem menos utilizado no Distrito de Garrafão $(3,6)$.

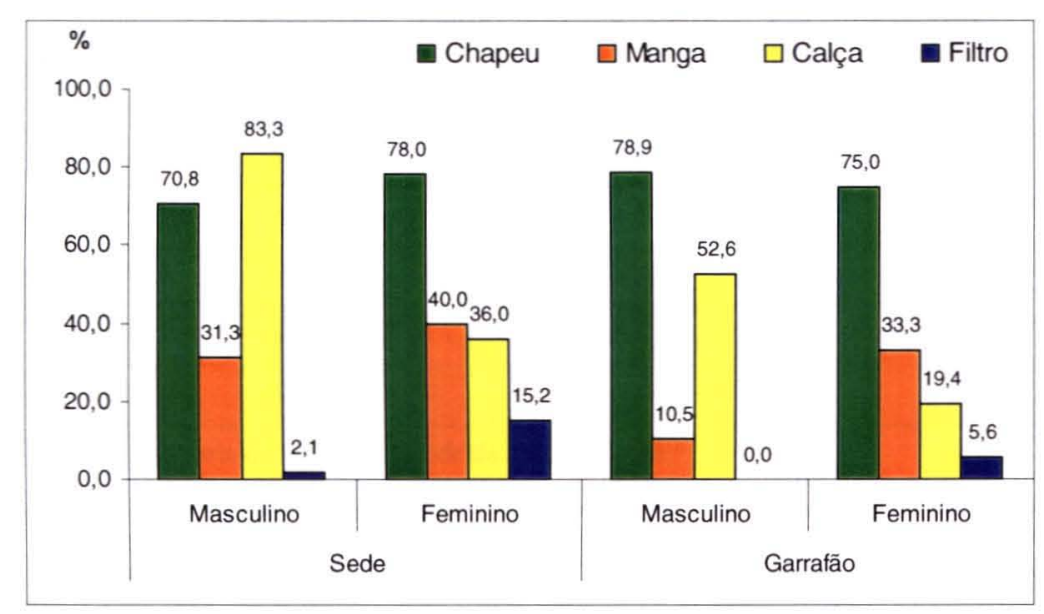

Figura 15. Métodos de proteção solar adotados por pacientes com diagnóstico clínico e histopatológico de câncer de pele, conforme sexo. Santa Maria de Jetibá, 1997 a 2002.

Fonte: Secretaria de Estado da Saúde do Espírito Santo.

Ao analisar os métodos de proteção solar entre os sexos, nos pacientes com câncer de pele confirmado pelo exame histopatológico (Figura15), na sede do município o uso de calças compridas é o método mais utilizado pelos homens $(83,3 \%)$, enquanto no sexo feminino é o chapéu, com 78,0 \%. Chama a atenção na sede que $70,8 \%$ dos homens utilizam chapéu e como outras medidas de proteção, o uso de manga comprida aparece com somente $31,3 \%$ e um percentual muito baixo de uso de protetor solar de $2,1 \%$. O sexo feminino distribui, mais uniformemente na sede, estes percentuais, ou seja, 40,0\% fazem uso de mangas compridas, 36,0\% de calça comprida e $15,2 \%$ de filtro solar como métodos de proteção solar. No Distrito de Garrafão o uso de chapéu é o método de proteção solar mais utilizado em ambos os sexos, sendo que os homens fazem maior uso $(78,9 \%)$ que as mulheres $(75,0 \%)$. Há uma diferença bem acentuada no uso de mangas compridas entre os sexos, de $22,8 \%$, representado por maior proteção entre as mulheres. O uso de calças compridas tem um percentual muito mais elevado nos homens $(52,6)$ em relação às 
mulheres $(19,4)$. O sexo masculino não faz proteção com filtro solar e um pequeno percentual de mulheres $(5,6)$ o faz.

Tabela 13. Medidas de proteção adotados pelos pacientes com diagnóstico clínico e histopatológico de câncer de pele do " Programa de Assistência Dermatológica aos Lavradores Pomeranos no Interior do Estado do Espírito Santo", Santa Maria de Jetibá, 1997 a 2002.

\begin{tabular}{|c|c|c|c|c|c|c|}
\hline \multirow{2}{*}{$\begin{array}{l}\text { Tempo de exposição ao sol } \\
\text { (horas) por dia }\end{array}$} & \multicolumn{2}{|c|}{ Sede } & \multicolumn{2}{|c|}{ Garrafäo } & \multicolumn{2}{|c|}{ Geral } \\
\hline & $\mathbf{N}^{\circ}$ & $\%$ & $\mathbf{N}^{\circ}$ & $\%$ & $\mathbf{N}^{\circ}$ & $\%$ \\
\hline 0,4 & 15 & 10,1 & 1 & 1,9 & 16 & 7,9 \\
\hline $5 \times 9$ & 80 & 53,7 & 35 & 64,8 & 115 & 56,6 \\
\hline $10 \mathrm{a} 14$ & 54 & 36,2 & 18 & 33,3 & 72 & 35.5 \\
\hline Total & 149 & 100,0 & 54 & 100,0 & 203 & 100,0 \\
\hline Horário de exposiçăo ao sol & $\mathbf{N}^{\circ}$ & $\%$ & $\mathrm{~N}^{\circ}$ & $\%$ & $\mathbf{N}^{\circ}$ & $\%$ \\
\hline Antes $9: 00$ e após 14:00 & 15 & 10,0 & 1 & 1,9 & 16 & 7,9 \\
\hline Entre $9: 00$ e 14:00 & 5 & 3.3 & 1 & -1.9 & 6 & 3.0 \\
\hline O dia todo & 130 & 86.7 & 51 & 96,2 & 151 & 89.1 \\
\hline Total & 150 & 100,0 & 54 & 100,0 & 173 & 100,0 \\
\hline Uso de chapéu & $\mathbf{N}^{\circ}$ & $\%$ & $\mathrm{~N}^{\circ}$ & $\%$ & $\mathrm{~N}^{\circ}$ & $\%$ \\
\hline Sim & 112 & 75,7 & 42. & 76,4 & 154 & 75,9 \\
\hline Naso & 36 & 24,3 & 13 & 23,6 & 49 & 24,1 \\
\hline Total & 148 & 100,0 & 55 & 100,0 & 203 & 100,0 \\
\hline Uso de manga comprida & $\mathbf{N}^{\circ}$ & $\%$ & $\mathrm{~N}^{*}$ & $\%$ & $\mathbf{N}^{\circ}$ & $\%$ \\
\hline $\operatorname{Sim}$ & 55 & 37.2 & 14 & 25.5 & 69 & 34.0 \\
\hline Năo & 93 & 62,8 & 41 & 74,5 & 134 & 66,0 \\
\hline Total & 148 & 100,0 & 55 & 100.0 & 203 & 100,0 \\
\hline Uso de calça. & $N^{\infty}$ & क & $\mathrm{N}^{\circ}$ & $\boldsymbol{x}$ & $N^{\circ}$ & $\boldsymbol{x}$ \\
\hline Sim & 76 & 51.4 & 17 & 30,9 & 93 & 45.8 \\
\hline Nå & 72 & 48,6 & 38 & 69,1 & 110 & 54,2 \\
\hline Total & 148 & 100,0 & 55 & 100,0 & 203 & 100,0 \\
\hline Uso de filtro solar & $\mathbf{N}^{\circ}$ & $\%$ & $\mathrm{~N}^{\circ}$ & $\%$ & $\mathbf{N}^{\bullet}$ & $\%$ \\
\hline Sim & 16 & 10,9 & 2 & 3,6 & 18 & 8.9 \\
\hline Não & 131 & 89.1 & 53 & 96.4 & 184 & 91,1 \\
\hline Total & 147 & 100,0 & 55 & 100,0 & 202 & 100,0 \\
\hline
\end{tabular}

Fonte: Secretaria de Estado de Saúde do Espírito Santo.

A proporção por ano entre medidas de proteção solar mostra o uso de chapéu foi a medida mais utilizada em todos os anos. Como há mais de uma medida de proteção solar adotada pelos pacientes, pode-se perceber que as medidas que mais cresceram proporcionalmente foram o uso de camisa de manga comprida e o uso de calça comprida com o decorrer dos anos. Mesmo tendo um decréscimo proporcional no 
ano de 2002, o chapéu continuou sendo a medida de proteção solar mais usada pelos pacientes (Tabela 14). Visualiza-se um aumento no comportamento dos pacientes em relação à proteção solar em relação ao ano de 1997 (Figura 16).

Tabela 14. Proporção das medidas de proteção ao sol por ano de atendimento em pacientes com diagnóstico clínico de câncer de pele, Santa Maria de Jetibá, período de 1997 a 2002.

\begin{tabular}{|c|c|c|c|}
\hline Ano & Uso de Chapéu \% & Uso de Camisa de Manga \% & Uso de calça Comprida \% \\
\hline 1997 & 60,5 & 15,8 & 15,8 \\
\hline 1998 & 64,4 & 28,8 & 27,4 \\
\hline 1999 & 75,0 & 39,3 & 57,1 \\
\hline 2000 & 66,7 & 30,7 & 46,7 \\
\hline 2001 & 62,8 & 32,6 & 44,2 \\
\hline 2002 & 53,7 & 28,4 & 46,3 \\
\hline
\end{tabular}

Fonte: Secretaria de Estado da Saúde do Espírito Santo.

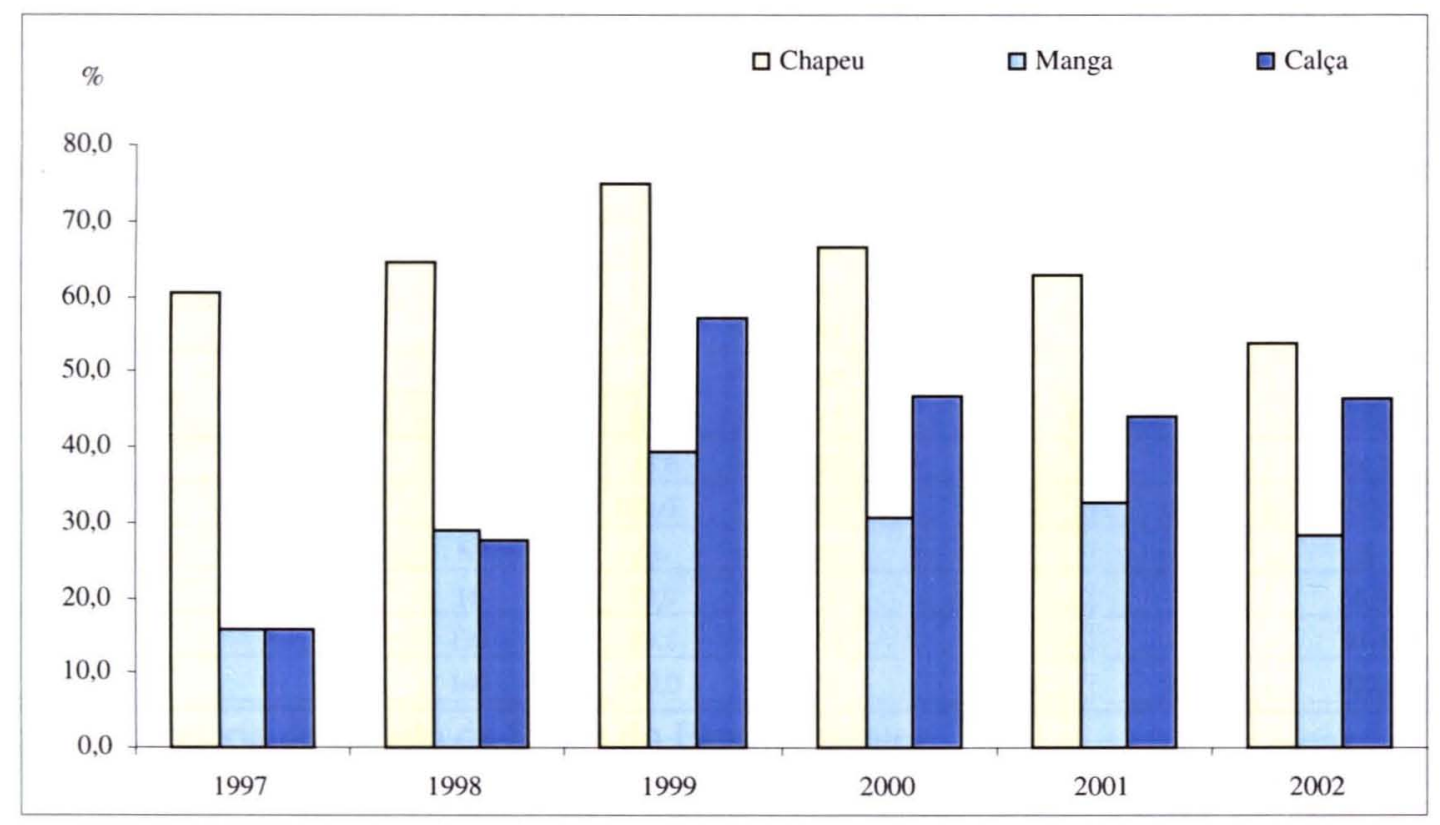

Figura 16. Proporção entre as medidas de Proteção, com exceção do uso de filtro solar, adotada por pacientes com diagnóstico clínico de câncer de pele segundo ano de atendimento, Santa Maria de Jetibá, 1997 a 2002.

Fonte: Secretaria de Estado da Saúde do Espírito Santo.

Chama bastante atenção o início da ida das crianças para a lavoura. No ano de 1998, observa-se que 50 \% dos pacientes com diagnóstico clínico de câncer de pele 
tiveram o início da atividade de lavrador com nove anos ou menos de idade no município de Santa Maria de Jetibá, sendo que o Distrito de Garrafão expressou o maior percentual que foi de $52,17 \%$. Há um percentual expressivo do início da atividade de lavrador nas crianças e adolescentes, somando o dado *desde a infância, o que totaliza 97,2 em todo o município, quase a totalidade dos pacientes (Tabela 15).

Tabela 15. Início da atividade de lavrador por faixa etária no município de Santa Maria de Jetibá no ano de 1998.

\begin{tabular}{|c|c|c|c|c|c|c|}
\hline \multirow[t]{2}{*}{ Faixa Etária em anos } & \multicolumn{2}{|l|}{ Sede } & \multicolumn{2}{|c|}{ Garrafāo } & \multicolumn{2}{|l|}{ Geral } \\
\hline & $\mathrm{N}^{\circ}$ & $\%$ & $N^{\circ}$ & $\%$ & $\mathbf{N}^{*}$ & $\%$ \\
\hline$\leq 9$ & 11 & 45,8 & 24 & 52,2 & 35 & 50,0 \\
\hline $10 a 15$ & 12 & 50,0 & 14 & 30,4 & 26 & 37.2 \\
\hline 16 a 20 & - & $\cdot$ & - & - & $\cdot$ & - \\
\hline$\geq 21$ & 1 & 4,2 & - & - & 1 & 1,4 \\
\hline Não preenchido & - & - & 1 & 2,2 & 1 & 1,4 \\
\hline * Desde infaincia & - & - & 7 & 15,2 & 7 & 10,0 \\
\hline Total & 24 & 100,0 & 46 & 100,0 & 70 & 100,0 \\
\hline
\end{tabular}

Fonte: Secretaria de Estado da Saúde do Espírito Santo

* No ano de 1998 houve este preenchimento indevido na variável.

Quatro anos depois, em 2002, este percentual tem uma discreta diminuição, passando para $44,12 \%$ de pacientes com início de atividade de lavrador com nove anos ou menos, coincidindo com o mesmo percentual na faixa etária de 10 a 15 anos de idade no município estudado. A diminuição é equivalente na área urbana e rural, em torno de 4\% do ano de 1998 para o ano de 2002 (Tabela 16). 
Tabela 16. Início da atividade de lavrador por faixa etária no município de Santa Maria de Jetibá no ano de 2002.

\begin{tabular}{|c|c|c|c|c|c|c|}
\hline \multirow[t]{2}{*}{ Faixa Etária em anos } & \multicolumn{2}{|c|}{ Sede } & \multicolumn{2}{|c|}{ Garrafăo } & \multicolumn{2}{|c|}{ Geral } \\
\hline & $\mathrm{N}^{\circ}$ & $\%$ & $\mathrm{~N}^{\circ}$ & $\%$ & $\mathrm{~N}^{\circ}$ & $\%$ \\
\hline$\leq 9$ & 17 & 41,5 & 13 & 48,2 & 30 & 44,1 \\
\hline $10 \mathrm{a} 15$ & 18 & 43,9 & 12 & 44,4 & 30 & 44,1 \\
\hline $16 \times 20$ & 2 & 4.9 & 2 & 7,4 & 4 & 5,9 \\
\hline$\geq 21$ & 1 & 2,4 & - & $\cdot$ & 1 & 1.5 \\
\hline Näo preenchido & 3 & 7,3 & - & $\cdot$ & 3 & 4,4 \\
\hline Desde infancia & $=$ & - & - & - & $:$ & - \\
\hline Total & 41 & 100,0 & 27 & 100,0 & 68 & 100,0 \\
\hline
\end{tabular}

Fonte: Fonte: Secretaria de Estado da Saúde do Espírito Santo

Demonstrado na tabela 17 a freqüência do acometimento do câncer de pele no sexo no periodo de estudo. O Carcinoma basocelular ( $\mathrm{CBC}$ ), o mais freqüente de todos os tipos de cânceres de pele no município (80\%), aparece com igual ocorrência em homens e mulheres, tanto na sede, com 78,3 para ambos os sexos, como em Garrafão, $84 \%$ nos homens e $84,8 \%$ nas mulheres, este percentual aumentado em décimos. O melanoma cutâneo maligno (MCM) teve sua maior freqüente nas mulheres, tanto na sede $(3,1 \%)$ como no distrito $(4,3 \%)$. O mesmo ocorreu com o diagnóstico histopatológico do carcinoma espinocelular que confirmou caso de câncer de pele mais no sexo feminino nas duas localidades: $13,9 \%$ na sede e $4,3 \%$ no distrito, sendo porém considerada pequena em relação ao sexo masculino que foi: $11,6 \%$ na sede e $4,0 \%$ no distrito. Neste caso o que chama a tenção é a diferença do achado entre localidades sem considerar a variável sexo. 
Tabela 17. Proporção dos tipos de câncer de pele pacientes com diagnóstico clínico confirmado pelo exame histopatológico por localidade de atendimento e sexo, Santa Maria de Jetibá, 1997 a 2002.

\begin{tabular}{|c|c|c|c|c|c|c|}
\hline \multirow{2}{*}{$\begin{array}{l}\text { Tipos de câncer } \\
\text { de pele }\end{array}$} & \multicolumn{2}{|c|}{$\begin{array}{l}\text { Santa Maria } \\
\text { de Jetibá }\end{array}$} & \multicolumn{2}{|c|}{ Garrafảo } & \multicolumn{2}{|c|}{ Total } \\
\hline & Masculino & Feminino & Masculino & Feminino & Masculino & Feminino \\
\hline Melanoma & 1 & 4 & 0 & 2 & 1 & 6 \\
\hline CEC & 6 & 13 & 1 & 2 & 7 & 15 \\
\hline $\mathrm{CBC}$ & 43 & 96 & 20 & 34 & 63 & 130 \\
\hline Carcinoma misto & 1 & 2 & 1 & - & 2 & 2 \\
\hline CEC in Sin & 3 & 2 & 1 & 2 & 4 & 4 \\
\hline Melanoma in Situ & 1 & 0 & 1 & 1 & 2 & 1 \\
\hline Total & s5 & 117 & 24 & 41 & 79 & 158 \\
\hline
\end{tabular}

Fonte: Secretaria de Estado da Saúde do Espírito Santo.

Tabela 18. Tipos de câncer de pele em lesões de pacientes com diagnóstico clínico e histopatológico pelo ano de ocorrência, Santa Maria de Jetibá, 1997 a 2002.

\begin{tabular}{|c|c|c|c|c|c|c|c|c|c|c|c|c|}
\hline \multirow{2}{*}{$\begin{array}{l}\text { Tipos de } \\
\text { cáncer }\end{array}$} & \multicolumn{2}{|c|}{ Mclanoma } & \multicolumn{2}{|c|}{ CEC } & \multicolumn{2}{|c|}{$\mathrm{CBC}$} & \multicolumn{2}{|c|}{$\begin{array}{l}\text { Carcinoma } \\
\text { Misto }\end{array}$} & \multicolumn{2}{|c|}{ CEC in situ } & \multicolumn{2}{|c|}{$\begin{array}{l}\text { Melanoma } \\
\text { in situ }\end{array}$} \\
\hline & $\mathbf{N}^{*}$ & $\%$ & $\mathrm{~N}^{*}$ & $\%$ & $N^{\circ}$ & \% & $\mathrm{N}^{\bullet}$ & $\boldsymbol{x}$ & $\mathrm{N}^{\circ}$ & $\boldsymbol{x}$ & $N^{\circ}$ & $\%$ \\
\hline 1997 & 3 & 37.5 & 3 & 8,8 & 26 & 10.1 & $\cdot$ & - & 1 & 10,0 & - & $\cdot$ \\
\hline 1998 & 3 & 37.5 & 4 & 11.8 & 53 & 20.6 & - & - & 3 & 30.0 & 2 & 66.7 \\
\hline 1999 & 1 & 12,5 & 6 & 17,6 & 17 & 6.6 & - & - & - & $\cdot$ & - & - \\
\hline 2000 & - & $*$ & 10 & 29,4 & 59 & 23,0 & 3 & 50,0 & 2 & 20,0 & - & - \\
\hline 2001 & - & - & 7 & 20.6 & 34 & 13,2 & 2 & 33,3 & 2 & 20,0 & 1 & 33.3 \\
\hline 2002 & 1 & 12,5 & 4 & 11,8 & 68 & 26,5 & 1 & 16,7 & 2 & 20,0 & - & - \\
\hline Total & 8 & 100,0 & 34 & 100,0 & 257 & 100.0 & 6 & 100.0 & 10 & 100.0 & 3 & 100,0 \\
\hline
\end{tabular}

Fonte: Secretaria de Estado da Saúde do Espírito Santo.

Desprezando-se as 114 lesões resultantes do encaminhamento para outro serviço, da não confirmação histopatológica de câncer de pele e das lesões sem resultado histopatologico, analisa-se que 318 lesões confirmaram o diagnóstico de câncer de pele, que teve um comportamento epidemiológico diferenciado através do período de 
1997 a 2002. As lesões de melanoma cutâneo foram mais detectadas nos anos de 1997 e 1998, as de CEC no ano 2000 com um percentual de 29,4 de ocorrência dentre o período. $\mathrm{O} C B C$ teve sua maior deteç̧ão pelo atendimento do programa no ano de 2002 com 68 lesões diagnosticadas histopatológicamente. Sempre apresentando números pequenos, o Carcinoma Misto, o CEC in situ e o Melanoma in situ se distribuem aleatoriamente no período.Os anos de 1998, 2000 e 2002 são os que apresentam um número maior de lesões cutâneas de câncer, resultante do atendimento na sede e no distrito do município de Santa Maria de Jetibá (Tabela 18). 


\section{VI - DISCUSSÃO}

Muitos estudos publicados têm enfatizado a importância do câncer de pele nas populações brasileiras e internacionais. Se por um lado o Carcinoma Basocelular (CBC) aparece nos estudos devido sua alta incidência por outro o Melanoma, de menor ocorrência, leva a muitas investigações por sua alta letalidade.

Mencionam-se, aqui, os estudos de interesse para esse trabalho:

Rastreamento (screening) de câncer de pele como medida de descoberta de casos:

ROCHA et. al (2002) mediram a prevalência das lesões cutâneas pré-malignas e malignas, determinando a sensibilidade e a especificidade de rastreamento para estas lesões. O estudo transversal teve a escolha aleatória de 48 setores censitários da zona urbana de Pelotas-Rio Grande do Sul e um elenco de perguntas específicas sobre surgimento de lesões de pele nos últimos seis meses e /ou presença de lesões em áreas expostas. Os autores citando Brandt 1996 (p.102) problematizam o rastreamento de qualquer doença e descrevem algumas premissas que devem ser observadas: a. o rastreamento (screening) deve contemplar doenças de alta prevalência, elevada morbidade e mortalidade; $b$. o tratamento precoce da doença rastreada deve ser capaz de reduzir seus desfechos desfavoráveis; c. o rastreamento deve ser de baixo custo e com menor risco possível à população rastreada. Por ter sido um estudo de base populacional, o que o faz representativo da população, podese determinar a prevalência das lesões cutâneas pré-malignas e malignas que teve um achado de $20,7 \%$ de deteç̧ão, menor do que encontrado em algumas campanhas nacionais, 26\% no Paraná em 1998 e 40,17\% em Minas Gerais no ano de 1992, conforme citam os próprios autores, como também a prevalência das lesõcs cutâncas malignas que teve um percentual de 2,3, percentual menor do encontrado num estudo de base populacional no Canadá no período de 1994-1995(3,8 \%). Por fím, concluem que o rastreamento $\varepsilon$ importante quando seletivo, voltado para grupos de 
pessoas sob risco e propõem novos estudos para o país que tem na sua população diversas origens étnicas, vivendo em diferentes latitudes.

Apresentou-se a ocorrência de casos de câncer de pele em Santa Maria de Jetibá em todos os anos, contribuindo para a prevenção secundária do câncer de pele que é a descoberta precoce dos casos. Não se apresenta neste trabalho o número de nevos displásicos e ceratoses actnícas, respectivamente, precursoras de melanoma cutâneo e de câncer de pele não melanoma que foram diagnosticados e tratados no "Programa de Assistência Dermatológica aos Lavradores Pomeranos do Interior do Estado do Espírito Santo" pela não priorização destas informações contidas na planilha, porém a resolução diante das lesões pré-neoplásicas é alta tanto no diagnóstico clínico como no tratamento de todas as lesōes rastreadas, diminuindo, provavelmente, os investimentos e os custos dos serviços de saúde.

SANTOS NEVES (2003) relata que o resultado do "Programa de Assistência Dermatológica aos Lavradores Pomeranos no Interior do Estado do Espírito Santo" na análise de vários observadores e médicos, é o controle do câncer de pele no interior do estado devido à constatação da diminuição da gravidade dos casos.

Segundo PAGUNG (2002) os descendentes de imigrantes pomeranos apresentavam tumores de pele com tamanho demasiadamente grande que inclusive dificultava o tratamento devido seu diagnóstico tardio. Com a implantação desse referido programa no interior do Espírito Santo, hoje os tumores diagnosticados são pequenos e com pouco tempo de evolução. Assim, o autor frisa que, o "Programa de Assistência Dermatológica aos Lavradores Pomeranos no Interior do Estado do Espírito Santo" alcança o seu objetivo principal que é a prevenção e a detecção precoce do câncer de pele nesta população sob risco. 
Número de mulheres e homens que procuraram atendimento e a deteç̧ão precoce de câncer de pele, sua faixa etária, o diagnóstico clínico de câncer de pele e sua acurácia:

GOLEMAN et. al (1978), revisando 1187 carcinomas em 955 pacientes no Serviço de Dermatologia do Hospital das Clínicas da Faculdade de Medicina da Universidade de São Paulo (USP), diagnosticaram 704 Carcinomas Basocelulares $(59,30 \%)$, 470 Carcinomas Espinocelulares $(39,60 \%)$ e 13 Carcinomas de Colisão (sic) $(1,10 \%)$. Ocorreu predomínio, em todos os carcinomas, do sexo masculino (55 \%) e a maior frequiência encontrada em relação à idade média dos pacientes diagnosticados pela primeira vez tanto com Carcinoma Basocelular (CBC) como Carcinoma Espinocelular (CEC) foi 57 anos.

No Estado do Piauí, PRADO (1978) estudando tumores de pele nesta população no período de 1964-1984, encontrou $91 \%$ das lesões diagnosticadas como CBC, $7 \%$ CEC e $2 \%$ de Melanoma Maligno. $O$ estudo que realizou sobre $C B C$ identificou o sexo feminino como o mais freqüente $(57 \%)$ e no estudo sobre o CEC o sexo masculino prevaleceu com 55,6 \% e em relação à faixa etária mais acometida foi acima de 60 anos de idade $(51,4 \%)$ nos dois estudos.

BANDEIRA et.al (2003) estudaram 704 carcinomas basocelulares em 623 pacientes, num período de 1991 a 1996, em Recife-Pernambuco, justificado pela sua alta incidência local e para melhor conhecer a sua epidemiologia. Foi evidenciado que os carcinomas basocelulares são tumores de freqüência elevada, com predominância no sexo feminino e acometimento mais freqüente na faixa etária de 55 a 72 anos de idade.

Há uma coincidência nas informações sobre o estudo em Santa Maria de Jetibá em relação ao sexo feminino como o mais diagnosticado clinicamente de câncer de pele com o estudo realizado em Recife. Porém este dado pode ser confundido visto que as mulheres são as que mais procuram serviço de saúde, o que pode elevar o este percentual. 
Presser e Taylor (1973) citados por KOPKE e SCHMIDT (2002) relatam que a acurácia diagnóstica para $\mathrm{CBC}$ é em torno de $70 \%$ entre dermatologistas acadêmicos, de $65 \%$ para os dermatologistas de clínica privada e $64 \%$ para residentes, considerado um percentual muito baixo dentro do esperado visto que este tipo de câncer de pele tem alta incidência. O percentual encontrado de $82,4 \%$ de acerto no diagnóstico de todos os cânceres de pele no estudo de Santa Maria de Jetibá é alto, podendo-se extrapolar em dizer que a acurácia diagnóstica para CBC também foi alta por tratar-se do diagnóstico clínico mais realizado e mais sujeito a erros e principalmente a acertos devido os anos de experiência dos dermatologistas do programa. O "Programa de Assistência Dermatológica aos Lavradores Pomeranos no Interior do Estado do Espírito Santo" adotou como norma que todo o paciente com a descrição das lesões cutâneas realizadas pelos acadêmicos de medicina, são diagnosticados pelos dermatologistas como momento de aprendizado do aluno e conseqüentemente uma uniformidade nos critérios clínicos para selar o diagnóstico clínico de câncer de pele.

Para mclhorar a acurácia cm rclação ao diagnóstico do mclanoma cutânco, utiliza-se o dermatoscópio que aumenta em aproximadamente 10 vezes a visualização da lesão e permite a avaliação das camadas mais profundas da pele. A dermatoscopia, exame complementar, auxilia o médico classificar a lesão em benigna, suspeita e maligna, decidindo o acompanhamento clínico ou é a exerése cirúrgica das lesões suspeitas e malignas (HOSPITAL DO CÂNCER, 2003). Neste trabalho, para descoberta de melanoma maligno cutâneo, utiliza-se o dermatoscópio, porém por tratar-se de programa de rastreamento, retira-se a lesão melanocítica com dúvida no diagnóstico clínico, selando-o com o diagnóstico histopatológico.

\section{Lesão única:}

Numa amostra de 955 pacientes, GOLEMAN et. al (1978) encontraram 47,12\% de lesão única de carcinoma basocelular, 36, 02\% de carcinoma espinocelular único e os demais percentuais de múltiplas lesões. PRADO (1987) encontrou no estudo sobre carcinoma basocelular $64 \%$ de lesão única. BANDEIRA et.al (2003) 
apresentaram no seu estudo que a maioria dos pacientes tinham apenas uma lesão entre os carcinomas basocelulares. No estudo presente também é alto o percentual de lesão única $(78,4)$.

Acometimento de áreas do tegumento cutâneo na suspeita de lesões de câncer de pele:

Observa-se uma relativa raridade no acometimento do $\mathrm{CBC}$ em áreas expostas como dorso dos antebraços e mãos que comumente estão expostos ao sol e a ocorrência em áreas mais protegidas do sol ou cobertas, como o canto interno dos olhos, o espaço retroauricular e as regiões inguinocrurais, levando Kople e Schmidt a questionar sobre a real importância da exposição solar como fator de risco preponderante (KOPLE e SCHMIDT 2002).

Segundo KORTING e DENK (1997) o CBC tem uma ocorrência de 80 a $90 \%$ na face e apenas $2 \%$ no couro cabeludo.

MDNELLI et al. (1982) no estudo, em Londrina-Paraná, encontrarám que a face é o local de maior acometimento da lesão cutânea com $98,68 \%$.

O estudo ora apresentado, não diferindo dos demais estudos, tem a cabeça como local mais atingindo, com o percentual $(78,2)$ em todo o município, devido principalmente $o$ acometimento da face.

\section{Origem étnica:}

ARMOSTRONG e HOLMAN (1984) estudando a origem étnica como fator de risco para melanoma maligno cutâneo, dentre outros, na Austrália Ocidental, através de estudo analítico de caso controle com 511 pacientes pareados com 511 controles, observaram que imigrantes Australianos têm menos risco para melanoma do que os nascidos na Austrália e também que a idade de chegada destes imigrantes na Austrália é o principal fator como risco para melanoma. Dentre as conclusões a que 
se chegaram foi que não há associação significante entre ocorrência de mclanoma c origem céltica. Outro achado foi a redução de risco para melanoma nos indivíduos sulistas da Europa o que é compatível com as baixas taxas de incidência na Espanha e outras populações latinas. Uma explicação é a pigmentação mais escura dos Europeus sulistas se comparada à pigmentação de outros caucasianos. Outra explicação poderia ser dada pelos costumes de exposição solar ou estado cultural e sócio-econômico das pessoas do sul da Europa em relação aos outros australianos.

MENDONÇA (1992) analisando o risco crescente de melanoma de pele no Brasil encontrou taxas de incidência mais altas em São Paulo e Porto Alegre, regiões com grande concentração de indivíduos com pele clara, do que as encontradas em Recife e Fortaleza. Concluiu que há necessidade de estudos nas regiões Sudeste e Sul, onde imigrantes europeus e seus descendentes se dedicam ao trabalho agrícola, sob um clima tropical com exposição ao sol continuadamente, desde a infância, devido às condições favoráveis ao desenvolvimento de câncer de pele. Segundo a autora, as campanhas de rastreamento realizadas na Austrália e Escócia tiveram êxito na descoberta de casos de melanoma de pele em estágio inicial e finaliza que a condução de estudos no Brasil para identificar grupos de alto risco se torna necessário para uma política de controle com medidas adequadas e específicas.

Santa Maria de Jetibá possui um número expressivo de lavradores com origem étnica pomerana/alemã, apresentando todas as condições de risco apresentadas acima como início de atividade agrícola na infância, exposição excessiva ao sol em localidades de clima tropical, sendo um exemplo dos demais municípios priorizados no "Programa de Assistência Dermatológica aos Lavradores Pomeranos no Interior do Estado do Espírito Santo" sendo necessários estudos de prevalência para uma definição de medidas de controle com intervenções específicas a este grupo especial da população. 
Tipo de Pele, história familiar de câncer de pele:

Destaca-se um estudo controlado para investigação de fatores de risco no desenvolvimento de carcinoma basocelular, numa população de 259 casos de carcinoma basocelular e 518 controles, pareados segundo sexo e idade, que as peles claras de tipo I e II de Fitzpatrick, a atividade profissional desenvolvida sob exposição constante à luz solar e as alterações cutâneas resultantes da exposição crônica à radiação solar representam fatores de risco por si só. Nesse estudo citado, os casos de CBC foram em maior número pacientes com pele do tipo III, resultado da amostra, sendo que pode ser valorizada devido a informação agregada que estas a pessoas tinham história de exposição intensa a queimaduras solares. Assim se agrupou, com base nesta informação, as pessoas com tipo de pele 3 e história de queimadura com as pessoas com tipo de pele 1 e 2 . Estatisticamente foi comprovado que pessoas com tipo de pele 3 com história prévia de queimadura solar estão incluídos como fator de risco significante para câncer de pele, juntamente com pessoas com tipo de pele 1 e 2 (MAIA et.al 1995).

No mesmo estudo de análise de regressão logística estudada pelos autores, não há confirmação que olhos e cabelos claros, história familiar de câncer de pele, exposição solar intensa, aparecimento de efélides na infância, dentre outros, ora não citados, representem fatores de risco. Porém, Hogan et al (1989) citados pelos autores encontrou no seu estudo que história de câncer de pele era significante para CBC e MacDonald (1976) também citado pelos mesmos autores relata que os indivíduos com uma história familiar de câncer de pele evoluem mais cedo para o câncer de pele. Outra controvérsia apontada foi na definição do que é exposição intensa a luz solar. Hogan et al (1989) citados mais uma vez pelo autor, quantificou esta exposição solar variável e intensa como atividade ao ar livre no mínimo por seis horas dia, o que inclui vendedor e trabalhador ambulantes e no estudo por eles realizados os casos de $\mathrm{CBC}$ ocorreram, mais comumente, em trabalhadores rurais (MAIA et.al 1995). 
HOLMAN e ARMSTRONG (1984) no já referido estudo sobre fatores de risco para melanoma maligno cutâneo, demonstram que a história familiar de melanoma é um fator de risco significante, predizendo a existência de um fator genético específico de predisposição no desenvolvimento de melanoma.

A ocorrência familiar do melanoma é descrita freqüentemente com ênfase à história familiar da síndrome névica displásica e seu potencial em malignização (AZULAY 1985).

Tem-se um número alto de pacientes em Santa Maria de Jetibá com diagnóstico clínico e histopatológico de câncer de pele associado ao tipo de pele I e II $(85,6 \%)$ e com história familiar de câncer de pele de $33,9 \%$ e história familiar de câncer de $30,1 \%$. Supõe-se que este percentual importante de números de pacientes com tipo de pele I e II foram fatores, que somado aos demais, favoreceram o aparecimento do câncer de pele.

\section{Ocupação c Câncer de Pelc:}

MINELLI et al. (1982) demonstraram no estudo em Londrina-Paraná que a ocupação tem nos lavradores seu maior percentual $(43,85 \%)$, seguido pela ocupação do lar, porém com acompanhamento as atividades da lavoura $(29,10 \%)$.

GARCIA et. al (2001) estudando câncer de pele descrevem que a ocupação, associado a outras variáveis como idade, sexo, fenótipo de pele, a exposição solar, a educação e o estilo de vida se tornam fatores de risco na patogênese do câncer de pele. O risco que constitui a exposição solar devido à ocupação está mais claro para câncer de pele não melanoma, pois está relacionada às ocupações que se desenvolvem ao ar livre.

Santa Maria de Jetibá apresentou a definição que esta população vive sob risco de ter câncer de pele visto trabalhar por muitas horas em áreas de lavouras descobertas, sem proteção solar, como abrigos ou tendas para favorecer sombras no período de 
maior radiação solar. Lavrador é a principal atividade exercida por essa população atendida no "Programa de Assistência Dermatológica aos Lavradores Pomeranos no Interior do Estado do Espírito Santo" num percentual de $(86,2 \%)$ na sede do município e um percentual maior no distrito de Garrafăo $(98,2 \%)$ sugerindo que esta condição social contribuiu para o achado de casos de câncer de pele nessas localidades.

BEDREGAL et. al (2002 p.1289) afirmam que a oferta de serviços de saúde nos países deveria ser produto da análise onde confluem o conhecimento e a opinião do nível técnico, as características demográficas e epidemiológicas da população e suas necessidades por ela percebidas. Continuando sua descrição, apontam "que um sistema de serviços de saúde cuja planificação se baseia nas necessidades percebidas pelas pessoas deve contemplar o centro da promoção, da prevenção primária, a atenção primária e o auto cuidado".

Os lavradores em Santa Maria de Jetibá têm o estímulo do município para o não uso de agrotóxicos nos seus plantios, sendo necessário uma maior conscientização do aparecimento de câncer de pele por condições inadequadas de proteção solar na sua ocupação. O Instituto Nacional do Câncer deverá ser o grande incentivador nas definições de políticas públicas para desenvolvimento de ações de prevenção e controle do câncer de pele nestes grupos especiais como intervençōcs visando meio ambiente e ocupação.

\section{Prevenção do câncer de pele e as medidas de proteção solar:}

Diferentemente do presente estudo, HORA et. al (2003) diante de 500 questionários de frequientadores das maiores academias de ginástica da cidade de Recife-Pernambuco, para avaliar o conhecimento quanto à prevenção de câncer e sua relação com a exposição solar, encontraram que a medida de fotoproteção mais utilizada dentre eles foi o protetor solar com 92,7\%, seguida pelo uso de óculos escuros $(63 \%)$ e uso de chapéu $(50,5 \%)$. Totalizaram nesta avaliação que $76 \%$ destes freqüentadores de academia de ginástica fazem alguma proteção solar e que 
40,4\% destes indivíduos que estão numa faixa etária abaixo dos 20 anos de idade, não faziam nenhuma proteção solar.

No estudo de COSTA e WEBER (2004), que avaliaram os hábitos de exposição ao sol e de fotoproteção dos universitários da Região Metropolitana de Porto AlegreRS, tem-se que $85,2 \%$ desta amostra usam filtro solar e como outros meios físicos de fotoproteção, encontrou-se $42 \%$ usando camiseta, $34,8 \%$ usando chapéu e $38,4 \%$, guarda-sol. Participaram da pesquisa 343 universitários do sexo masculino $(33,3 \%)$ e 687 do sexo feminino $(66,7 \%)$ e com uma idade média de $22,7( \pm 5,4)$.

No presente estudo de Santa Maria de Jetibá, o comportamento dos lavradores (89,5\% dos pacientes com câncer de pele em todo o município), apresenta-se diferente dos dois estudos mencionados, tendo o filtro solar como medida de proteção menos utilizada no período de 1997 a 2002 com o percentual de 8,9. Este comportamento pode sugerir uma menor condição sócio-econômica do lavrador para aquisição do filtro solar e a sua indisponibilidade pela rede do SUS-ES diferentemente do estudo em Recife-PE acima citado que 75,4 \% dos entrevistados tinham renda familiar acima de 10 salários mínimos. Encontra-se na sede um percentual três vezes maior $(10,9)$ que no distrito de Garrafão $(3,6)$, percentuais estes às custas do comportamento feminino em relação ao uso de filtro solar que aparece com 15,2 na sede do munić́pio e no distrito de Garrafăo com 5,6. A medida de proteção solar mais usada pelos pacientes com câncer de pele descobertos "Programa de Assistência Dermatológica aos Lavradores Pomeranos no Interior do Estado do Espírito Santo", em Santa Maria de Jetibá no período de 1997 a 2002 foi o chapéu de abas largas $(75,9 \%)$, sendo, sendo porém uma medida inconstante que teve picos de maior uso nos anos de 1998, 2000 e 2002, proporcionalmente ao uso de outras medidas. Verifica-se que não houve uma mudança de hábitos em relação às medidas de proteção solar nessa população no período estudado. Pode-se sugerir que, neste período de estudo, houve algum tipo de informação educativa sobre proteção solar pelas autoridades sanitárias, porém sem uma continuidade que resultasse em mudança de comportamento pelos anos seguintes. 
No preenchimento da ficha clínico-epidemiológica, todos os anos, há um momento educativo a cada paciente com a hipótese diagnóstica de câncer de pele perante seus hábitos e características fenotípicas, como prevenção do câncer de pele estendido aos seus familiares, com a intenção de mudança de comportamento na comunidade. É o momento de aconselhamento realizado por duas médicas sanitaristas e uma enfermeira com especialização em saúde da família.

NORA et. al (2004) estudaram a freqüência de aconselhamento para prevenção de câncer de pele entre as diversas especialidades médicas em Caxias do Sul e a encontraram baixa, com exceção desta frequiência na especialidade de dermatologia aonde foi alta. Este estudo teve como amostra 499 pessoas atendidas na área de dermatologia em ações comunitárias, com critérios para pacientes de alto risco no desenvolvimento de câncer de pele que foi apresentar pelo menos um fator dentre ter lesão dermatológica de ceratose actínica, ter a classificação por fototipo I ou II de Fitzpatrick e história familiar e/ou pessoal de câncer de pele e adotadas definições das atividades inseridas na prevenção primária que se destacam, dentre outras, a orientação quanto à exposição ao sol e câncer de pele, a utilização de roupas apropriadas, uso de chapéu e bculos, limitar o tempo de exposição ao sol e o hábito da pessoa permanecer na sombra e das atividades na prevenção secundária, as de rastreamento e diagnóstico precoce com aconselhamento para mudança de comportamento em relação à exposição solar (Cummings, Tripp e Herrmann 1997 citados por NORA et.al 2004, p.50). Os autores encontraram que mesmo diante ao paciente de alto risco a maioria destes pacientes não recebeu aconselhamento para prevenção do câncer com outro especialista a ser o dermatologista $(65,4 \%)$ e que as consultas com o clínico geral resultou em $11,3 \%$ de orientações devidas. Dos pacientes de alto risco com menos de 20 anos que não tinham recebido orientação, $80,5 \%$ tinham consultado com o pediatra.

O "Programa de Assistência Dermatológica aos Lavradores Pomeranos no Interior do Estado do Espírito Santo" tem em um dos seus pilares a orientação ao paciente com diagnóstico clínico de câncer de pele, já comentada anteriormente, e é realizada em $100 \%$ desses atendimentos, como também todo o paciente atendido 
com outra dermatose, porém com fototipo de pele I ou II, com ceratose actínica, eritema solar ou qualquer outro sinal de fotodano, supõem-se ser aconselhado na sua totalidade pelos estudantes de medicina componentes do programa. Não há dados disponíveis sobre 0 aconselhamento sobre medidas de prevenção para câncer de pele na atenção primária da rede municipal.

O comportamento do sexo feminino, perante as medidas de proteção solar, é bastante diferente do que as do sexo masculino nas duas localidades estudadas no Espírito Santo. Pode-se perceber, na sede de Santa Maria de Jetibá, uma tentativa entre o sexo feminino em assegurar de forma mais uniforme a distribuição por cada medida de foto proteção, quando se tem um percentual maior no uso de chapéu de abas largas $(78,0)$ do que o encontrado no sexo oposto $(70,8)$ e 8,7 percentuais a mais no uso de camisa com mangas compridas como também 13,1 percentuais a mais no uso de filtro solar pelas mulheres. A única medida de proteção usada a mais pelos homens é o uso de calças compridas que pode indicar um viés na interpretação visto tratar-se de indumentária masculina, podendo sugerir que não é representativo como conscientização do homem desta medida como fotoprotetora. Mesmo assim, as mulheres utilizam calças compridas como meio de proteção solar $(36,0 \%)$ na sede. Quando se desloca esta análise para o distrito de Garrafão, pode-se levantar a hipótese que homens, no meio rural, começam a mudar seu comportamento diante à exposição ao sol, pois se encontra como meio de proteção mais utilizado por eles o uso de chapéu de abas largas $(78,9 \%)$ em detrimento ao percentual de 52,6 de uso de calças compridas (sugere-se uma contribuição dada pelo costume homem no meio rural na não utilização da calça comprida como vestimenta do dia a dia). Ao contrário do esperado, o sexo masculino usa menos freqüentemente (- 22,8\%) camisas com mangas compridas que o sexo feminino nesta área rural. As mulheres em Garrafão também apresentam um comportamento diferenciado e de certa forma uniforme também com uma distribuição semelhante ao comportamento das mulheres da sede do município, pois utilizam o chapéu $(75,0 \%)$ como principal meio de proteção solar até o uso de filtro solar $(5,6 \%)$. 
HORA et.al (2003) apontaram no seu estudo que $65,8 \%$ dos indivíduos que conheciam os fotodanos eram do sexo feminino. Descrevem também que o nível de escolaridade influencia o conhecimento dos danos ou das conseqüências da exposição solar, ou seja, quanto mais alto o nível de escolaridade maior o conhecimento sobre as medidas de proteção solar.

\section{Número de horas de exposição solar:}

Em relação ao número de horas de exposição ao sol, COSTA e WEBER (2004) na amostra estudada, expõem que os universitários daquela região apresentam o maior percentual na exposição, até duas horas diárias, de segunda a sexta-feira. Há uma mudança nos horários de exposição solar no verão, sendo que $70,6 \%$ dos estudantes se expõem após as 15 horas, sendo que desses estudantes, 43,7\% também se expõem entre 10 às 15 horas.

Observa-se que, tanto a sede como o distrito de Santa Maria de Jetibá, os pacientes com câncer de pele se expõem ao sol 5 a 9 horas diárias, sendo que a freqüência maior dentre este período é a exposição solar por oito horas diárias. $O$ aumento da exposição solar ocorre no período de colheita na lavoura. Quanto ao horário de exposição solar, 89,1\% dos pacientes atendidos no programa com diagnóstico de câncer de pele, responderam que utilizavam o horário de exposição solar prejudicial à pele, contribuição na sua quase totalidade do hábito dos lavradores iniciarem suas atividades bem antes das nove horas com um descanso pequeno em torno de meia hora para o almoço, geralmente às 9 horas da manhã, permanecendo na lavoura nos horários indevidos até as 18 horas do dia.

KINNEY et.al (2000) descreveram várias experiências de utilização do índice ultravioleta como ferramenta útil na prevenção do câncer de pele. Relatam como primeiras e bem sucedidas experiências aconteceram na Austrália, em 1982, onde se monitorizou o índice e se divulgou a dose de ultravioleta diária como Dose Eritematosa Mínima (DEM), em noticiários noturnos nas suas principais cidades, e na Nova Zelândia, no ano de 1987 e no Canadá, no ano de 1992, destacando-se com 
divulgações diárias da radiação ultravioleta como campanhas de conscientização pública de proteção solar. Em 1994, os Estados Unidos através da Agência de Proteção Ambiental e do Serviço Metereológico Nacional realizam a previsão diária da quantidade de radiação ultravioleta, ou seja, o Índice Ultravioleta (IUV), para proteção a saúde das populações dos grandes centros. Os autores reforçam que havendo uma compreensão melhor do que é o f́ndice Ultravioleta ter-se-á uma ferramenta preventiva e protetora a saúde. Enfatizam que a divulgação diária deste índice poderá conscientizar e influenciar no comportamento da cada indivíduo. Como exemplo citam a experiência positiva em relação ao uso do IUV no sul da Flórida, em 1996, com a comunidade dermatológica local e 9000 professores das 133 escolas municipais, envolvendo também pais de alunos. Um vídco explicando o que era o IUV e sua medida protetora foi mostrado e a divulgação diária do IUV foi iniciada e mantida em todas as escolas, mudando o comportamento dos professores e alunos, incluindo a fotoproteção nas atividades ao ar livre.

No Brasil, há disponibilidade on-line do Índice Ultravioleta (IUV) e o DEM por Estado e municípios com orientação da Sociedade Brasileira de Dermatologia para promoção e a proteção individual e coletiva. Parece ser de extrema importância a utilização desse índice nas áreas com população sob risco de câncer de pele, no caso - município de Santa Maria de Jetibá onde o estudo provoca a afirmativa que a maioria da população tem fototipo de pele 1 e 2 e é lavradora, expondo-se ao sol por horas seguidas devido a sua atividade na agricultura. Sugere-se ao município a divulgação do IUV para monitoramento do horário de trabalho na lavoura.

\section{Exposição cumulativa ao sol no decorrer da vida:}

Goldberg (p.31) citado por BANDEIRA et.al (2003) "evidenciou que, quando os indivíduos se submetem a exposições solares por volta dos 20 anos, inicia-se um processo de carcinogênese que se manifesta tardiamente, por volta da faixa da faixa etária de 40 a 60 anos, justificando, dessa forma, os efeitos cumulativos mais tardios". 
Metade dos pacientes atẹndidos pelo "Programa de Assistência Dermatológica aos Lavradores Pomeranos no Interior do Estado do Espírito Santo" com diagnóstico clínico de câncer de pele iniciaram a atividade na lavoura em Santa Maria de Jetibá com nove anos ou menos e um percentual expressivo de 87,14 cm 1998 (sendo que nesse ano o percentual eleva-se para 97,14 devido a informação *desde a infância em 10\%) e 88,24 em 2002 de crianças e adolescentes na faixa etária de menor de nove anos a 15 anos de idade se expuseram ao sol devido ocupação neste mesmo município e como consequiência provável sofreram efeitos cumulativos do sol com aparecimento de câncer de pele na vida adulta. A prevenção à exposição solar deve iniciar-se na infância e adolescência. A Academia Americana de Dermatologia $(A A D)$ conduziu uma pesquisa com pais de crianças com 12 anos de idade ou menos durante os meses de junho e julho de 1997. A importância desta pesquisa teve a justificativa que exposição solar durante os primeiros anos de vida podem aumentar o risco de ocorrer câncer melanoma. Atribuíram, além do aumento de melanoma, também a alta incidência de carcinoma de células basais e carcinoma de células escamosas, nos Estados Unidos primariamente à exposição ao sol. O resultado da pesquisa foi que 74\% (363) dos 491 adultos usavam uma ou mais medidas de proteção solar. Destas medidas, o protetor solar foi a mais utilizada (53\%), seguido de proteção em lugares com sombra (30\%), chapéus (27\%) e camisas (8\%). Após a pesquisa, várias organizações, incluindo a $\mathrm{AAD}$, iniciaram uma campanha de promoção educacional sobre a proteção ao sol. O aumento da conscientização do adulto sobre medidas de saúde à educação das crianças e adolescentes é fundamental para mudança de comportamento perante a exposição solar, evitando queimaduras na pele. Sugerem assim a inclusão de componentes educacionais em currículos escolares como também medidas ambientais na própria escola, provendo locais com sombras e programação de atividades ao ar livre antes das 10 horas e depois das 16 horas (AMERICAN ACADEMY OF DERMATOLOGY 1997).

Neste estudo dos lavradores pomeranos no Espírito Santo parece ser necessário, diante $o$ alto percentual de crianças com atividade na lavoura, estimular a mudança da cultura preservada por anos em que as crianças acompanham os pais no trabalho e logo em seguida iniciam de fato sua profissão agrícola que na maioria das vezes 
persiste por toda a vida laborativa. Realizar as atividades de trabalho, em locais sombreados, devem ser estimulados pelo menos para as crianças até 15 anos de idade.

\section{Diagnóstico histopatológico confirmando caso de câncer de pele}

STENBECK et al (1990), estudando a incidência do câncer de pele não melanoma em Queesland, resultado de uma pesquisa de 6 meses durante 0 ano de 1984, encontraram dentre os 3048 diagnósticos de tumores, 2805 casos de câncer de pele não melanoma comprovado histopatológicamente, sendo que 2106 casos de carcinoma de células basais (75,08 \%) e 699 (24,92\%) de CEC. A importância desses estudos é a demonstração que o carcinoma basocelular é o que mais acomete qualquer população estudada. Santa Maria de Jetibá também teve um comportamento epidemiológico com predomínio de ocorrência de CBC $(80,8 \%)$ e CEC $(10,7 \%)$ no diagnóstico clínico e histopatológico das lesões.

Segundo AZULAY (1985), o câncer de pele não melanoma representa $90 \%$ dos cânceres de pele, sendo que a maior contribuição é do CBC com $70 \%$ de ocorrência.

Encontrou-se dados do câncer de pele não melanoma em Santa Maria de Jetibá um pouco mais freqüente, ou seja, $96,5 \%$, incluído $1,9 \%$ de carcinoma misto.

O estudo sobre rastreamento de câncer de pele, no período de 1997 a 2002, em Santa Maria de Jetibá, mostrou um percentual de descobertas de melanoma, incluído o melanoma in situ de $3,4 \%$, percentual próximo ao percentual de 3 de freqüência dos tumores malignos epiteliais, descrito por AZULAY (1985).

\section{Sexo entre os casos confirmados histopatológicamente de câncer de pele}

Quando se analisa o sexo naqueles pacientes com o diagnóstico clínico comprovado pelo exame histopatológico, verifica-se no período estudado que o $\mathrm{CBC}$ ocorre com maior freqüência na mulher tanto na sede como no distrito bem 
como o CEC. O melanoma também aparece 6 vezes mais no sexo feminino. As lesões in situ do CEC têm uma frequiência igual entre os sexos, sendo que o melanoma in situ aparece mais no sexo masculino numa freqüência muito pequena, $2 \%$ nos homens e $1 \%$ nas mulheres.

Como o estudo em Santa Maria de Jetibá, em relação ao acometimento por sexo no CBC, MINELLI et al. (1982) observaram num estudo retrospectivo de 1.163 casos de neoplasia cutânea, em Londrina-Paraná, que 66,46 \% da amostra estudada no período de 1970 a 1979 era de casos de carcinoma basocelular. Analisou-se também que a faixa etária com maior freqüência foi a de $60-69$, no valor de 29,75 percentuais, seguida imediatamente pela faixa etária de $50-59$ com $24,19 \%$ e que em relação ao sexo, homens $(50,58 \%)$ e mulheres $(49,41 \%)$ se aproximam na ocorrência do caso. Em Santa Maria de Jetibá o câncer de pele ocorre entre 40 a 79 anos de idade, sendo que há maior acometimento, com um pequeno aumento percentual, a faixa etária de 50 a 59 anos $(24,4)$.

\section{Tratamento:}

Segundo KOPKE e SCHMIDT (2002 p.265,267) o tratamento do CBC tem sido negligenciado por ter um bom prognóstico. Ocorrem 50\% de recidiva, ou seja, uma chance em duas de retratamento do $\mathrm{CBC}$ primário. $\mathrm{O}$ tumor recidivado carrega maior potencial de agressividade logo o objetivo deve ser o correto tratamento do tumor primário. Ainda segundo os autores, o tratamento de escolha para $\mathrm{CBC}$ é a cirurgia. A aplicação tópica do 5- fluoruracil sobre o $\mathrm{CBC}$ tem suas restrições, pois pode ocorrer a persistência de ninhos tumorais localizados, um pouco mais profundamente na derme, o que pode levar a recidiva tardia.

No programa de rastreamento ora estudado, não se tem uma consolidação dos casos de recidiva. Tem-se como conduta importante a exerése cirúrgica de quase $100 \%$ das lesões detectadas no dois dias de rastreamento com uma equipe de dois cirurgiões plásticos e acadêmicos de medicina que tenham já passado pela parte da clínica dermatológica. A utilização do 5-fluoruracil é usada topicamente nas 
ceratoses actnícas, e não nas lesões suspeitas de câncer de pele, que em 100\% os casos são encaminhados para o histopatológico na confirmação do caso.

AZULAY (1985) descreve que o tratamento para o CEC é igual ao do CBC, curetagem simples, eletrocauterização, exerése cirúrgica simples ou crioterapia.

O programa de rastreamento em estudo, como o procedimento do $\mathrm{CBC}$, tem na sua conduta a exerése cirúrgica da lesão para posterior encaminhamento da peça para o serviço de patologia do Hospital Universitário Dr. Cassiano Antônio de Moraes (HUCAM).

A extirpação da lesão deve ser completa no caso de melanoma maligno in situ com uma margem de $1 \mathrm{~cm}$ e se possível toda a espessura da derme. No caso do tratamento do melanoma maligno do nível III e IV, os gânglios linfáticos regionais são retirados, além da excisão ampliada e profunda da lesão DOMONKOS et.al (1985).

O mesmo procedimento de exerése cirúrgica ocorre com as lesões suspeitas de melanoma, a menos que a avaliação dermatológica e cirúrgica indiquem $o$ encaminhamento para o Hospital Santa Rita, referência para procedimentos de alta complexidade ou mesmo o ambulatório de cirurgia do HUCAM, mais especializado com melhores condições operacionais.

O importante é a resolutividade do "Programa de Assistência Dermatológica aos Lavradores Pomeranos no interior do Estado do Espírito Santo" no que se refere ao encerramento do caso, ou seja, diagnóstico clínico com o imediato tratamento cinúrgico das lesōes e das peças para o exame histopatológico ou encaminhamento do paciente para serviços mais especializados para procedimentos mais complexos. 
$O$ rastreamento durante o período estudado e a contribuição para o problema detectado:

A descoberta de casos ocorre ano a ano e tem relevância enquanto prevenção secundária. Para uma análise da situação epidemiológica, há necessidade de organizar o fluxo de informações, colhidas nos locais de atendimento, permitindo assim um banco de dados fidedignos, próximo da realidade.

Para melhorar os registros do câncer com dados completos e de qualidade no apoio aos programas de prevenção e controle do câncer o CDC implantou desde 1994 o Programa Nacional de Registros de Câncer (NPCR, sigla em inglês) nos estados e territórios dos EUA. O NPCR é um instrumento de processamento e comunicação de dados que complementa o Programa de Vigilância, Epidemiologia e Resultados Finais (SEER, sigla em inglês). Todos os dados sobre câncer da população dos EUA entram no sistema de informação do NPCR e SEER além de realizar trabalhos de investigações especiais como estudos para examinar os padrões de atenção do câncer em populações específicas (CDC 2003). O Espírito Santo publicou somente o registro de câncer de base populacional da Grande Vitória, do ano de 1997, o que torna a SES-ES sem um registro em potencial para estudos de câncer.

A SES-ES necessita ter um centro de informações, onde todos as fontes de dados sejam contempladas, como no caso dos registros citados. As informações colhidas por protocolo a SES-ES, deverão fazer parte deste centro das informações.

No presente trabalho aponta-se para um estudo de prevalência nos locais com população sob risco de adoecer por câncer de pele, como contribuição ao Programa Estadual de Vigilância e Avaliação do Câncer. 


\section{VII- CONCLUSÕES}

1. O rastreamento do câncer de pele como experiência no Espírito Santo, avaliado num município, mostrou-se efetivo como estratégia de prevenção secundária, ou seja, no diagnóstico precoce dos casos a cada ano, principalmente pelo seu alto grau de acerto clínico $(82,4 \%)$ e sua resolutividade no tratamento das lesões de câncer de pele : $92,8 \%$ das lesões foram retiradas cirurgicamente e $1,6 \%$ encaminhadas para serviço de maior complexidade, tendo como etapa anterior o diagnóstico e tratamento das lesões pré-câncer.

2. Nesse estudo epidemiológico descritivo em que se quantificou as variáveis, sexo, idade, atividade principal, origem étnica, história de câncer de pele na família, dentre outras, os lavradores $(89,5 \%)$ têm relevante história de descendência européia, apresentando origem étnica pomerana ou alemã de 93,8 na sede de Santa Maria de Jetibá e de 88,0 no Distrito de Garrafão. Constatou-se número importante de lesões de câncer de pele no rastreamento realizado no período de 1997 a 2002 (das 432 lesões rastreadas, 318 tiveram confirmação histopatológica de câncer de pele ocorridas em 237 pacientes). Esses lavradores pomeranos de todo o município de Santa Maria de Jetibá têm fototipos de pele 1 e 2 em percentual alto de 85,6\%. A atividade agrícola inicia-se na infância e na adolescência onde foi encontrado um percentual de 97,2 envolvendo crianças e adolescentes na faixa etária maior ou igual a nove anos até 15 anos de idade no ano de 1998. A exposição ao sol é excessiva, chegando a 10 a 14 horas seguidas ao dia (35,5\%), com trabalho na lavoura de forma ininterrupta $(89,1 \%)$ e inconstância nos hábitos de uso de chapéu de abas largas, camisa de mangas compridas, calças compridas e protetor solar, configurando assim medidas precárias em relação à radiação ultravioleta. Conclui-se que lavradores pomeranos formam grupos especiais para prevenção e controle do câncer de pele no município de Santa Maria de Jetibá. 


\section{VIII -RECOMENDAÇÕES}

1. Propõe-se uma organização da atenção oncológica, iniciando pelo município, primeiro nível de atenção, lugar que deverá acontecer a prevenção da ocorrência dos casos incluindo como recomendação a divulgação do índice de ultravioleta diária e a dose eritematosa mínima para conscientização pública, como também o aconselhamento as crianças e adolescentes na rede local de saúde e educação para a proteção solar. A implementação de uma rede de atenção oncológica deverá ser assegurada pela união, estado e município e o que se refere à prevenção, diagnóstico e tratamento do câncer de pele deverá ser mantida a eqüidade a grupos especiais.

2. A reestruturação do "Programa de Assistência Dermatológica aos Lavradores Pomeranos no Interior do Estado do Espírito Santo" deverá ocorrer na interação com o município tanto na continuidade do cuidado ao paciente no seu território de moradia como na garantia o acesso do paciente na alta complexidade, como uma ação conjunta de estado-município na referência do caso. Para ser um programa de referência a grupos especiais parece ser de importância vital sua diferenciação, onde as intervenções na saúde dos lavradores pomeranos gere medidas eficazes que venham a mudar o perfil do comportamento da prevalência de uma comunidade.

3. A mudança de hábitos de uma comunidade se dará principalmente com a inserção dos indivíduos em ações coletivas da atenção primária, e sua conscientização de que formam grupos especiais, iniciando com posturas individuais, bem como exigindo como cidadãos, sua inclusão na priorização nas políticas pública de saúde, pois constituem população sob risco eminente de adoecer.

4. Assim, este estudo propõe a União, ao Estado do Espírito Santo e a todos os municípios que tenham na sua população, grupos especiais sob risco de adoecer por câncer de pele, incluindo Santa Maria de Jetibá, Estudo de Prevalência de Câncer de Pele nos municípios mapeados e medidas de intervenções para a prevenção e controle da doença. 


\section{VIII-REFERÊNCIAS}

American Cancer Society. Sun-protection behaviors used by adults for their children. MMWR 1998; $47(23) ; 480-482$.

A Pomerânia Capixaba. A Tribuna, Espírito Santo, 1994 mai 31; suplemento especial.

Armstrong B.K e Holman CDJ. Pigmentary traits, ethnic origin, benign nevi, and family history as risk factors for cutaneous malignant melanoma. Journal of the National Cancer Institute [on-line] $1984 ; 72(2)$ :257-66. Disponível em <URL: http: //www.ciesen.org/docs/001-510/001-510 html >[2004 ago 23].

Autier P, Boyle P, Giles GG, Robertson C, Severi G. Mortality from cutaneous melanoma: evidence for contrating trends between populacions. Bristish Journal of Cancer 2000; 82(11): 1887-1891.

Azulay RD. Dermatologia. Rio de Janeiro: Guanabara Koogan; 1985.

Bandeira AM, Bandeira V, Silva JF e Mazza E. Carcinomas basocelulares:estudo clínico e anatomopatológico de 704 tumores. An bras Dermatol 2003; 78(1): 23-34.

Barros P. Ke ik dir af nemem? Du kaft rina kooma: Programa de Assistência aos Lavradores Pomeranos do Espírito Santo, 15 anos. Vitória (ES); Universidade Federal do Espírito Santo.Pro-Reitoria de Extensão; 2002.

Bedregal P, Quezada M, Torres M, Scharager J, Garcia J. Necesidades de salud desde la perspectiva de los usuários. Rev Méd Chile 2002; 130:1287-1294.

Centers for Disease Control and Prevention. Registros del cáncer: base para la prevencion y el control del cáncer.[on line] 2003.Estados Unidos. Disponível em <URL: http://www.cdc.gov/spanish/cancer/fs/registe-s.htm>[2004 set 8]. 
Centers for Disease Control and Prevention Nacional for Chronic Disease Prevention and Health Promotion. Prevención y control del cáncer: para abordar la segunda causa, en importanci, demuerte del pais. Una mirada al ano 2002. Estados Unidos; 2002.

Centers for Disease Control and Prevention. Preventing skin cancer: findings of the Task Force on Community Preventive Services on reducing exposure to ultraviolet light and Counseling to prevent skin cancer: recommendations and rationale of the U.S. Preventive Services Task Force. MMWR 2003;52(No. RR-15):[1-16].

Coelho CC. Uma idéia e o novo rosto de um povo. Du kaft rina kooma: Programa de Assistência aos Lavradores Pomeranos do Espírito Santo, 15 anos. Vitória (ES); Universidade Federal do Espírito Santo. Pro-Reitoria de Extensão; 2002.

Conde W. IBGE revela perfil de trabalho no ES. A Gazeta, Vitória, 2002 dez 21; cad 9:10

Costa FB e Weber MB. Avaliação dos hábitos de exposição ao sol e de fotoproteção dos universitários da Região Metropolitana de Porto Alegre, RS. An brás Dermatol 2004; 79(2):149-155.

Departamento de Epidemiologia. Faculdade de Saúde Pública da Universidade de São Paulo. Aspectos Epidemiológicos do Câncer no município de São Paulo. Fatores de Risco. São Paulo: Editores Antonio Pedro Mirra, Maria do Rosário Dias de Oliveira Latorre, Donaldo Botelho Veneziano; 2003.

Domonkos NA, Arnold HL, Odom RB. Andrews, Tratado de dermatologia. Barcelona (Espanha): Salvat; 1985. 
Fitzpatrick TB, Arndt KA, Clark WH, Eisen AZ, Van Scott EJ, Vaughan JH. Dermatology in general medicine. United States of America; McGraw-Hill Book Company; 1971.

Garcia RR, Miyares JHH, Pávon MAA. Cáncer de piel y ocupación. Rev cubana Méd, 2001; 40(4): 266-272.ISSN 0034-7523.

Giemsa G, Nauck EG. Uma viagem de estudos ao Espírito Santo. Hamburgo: Universidade de Hanseática: 1939.An Gcográficos: p.451-701.

Goleman B, Friedhofer H, Rivitti EA, Anger M, Sousa LC e Goleman R. Carcinomas e Espinocelulares de Pele. An bras Dermatol , Rio de Janeiro, 1978;53 (4):373-383.

Grupo Multicêntrico e Multidisciplinar Brasileiro para Estudo do Melanoma.GBM. Consenso para o laudo anatomo-patológico do melanoma cutâneo. Bol Informativo do GBM 2003; 23:1-4.

Hiramoto K, Tanaka H, Yanagihara N, Sato EF, Inoue M.Effect of 17-beta-estradiol on immunosuprresssion induced by ultraviolet $B$ irradiation. Med News Dermatologia 2003; 66:5.

Hora C, Batista CVC, Guimarães PB, Siqueira R e Martins S. Avaliação do conhecimento quanto à prevenção do câncer da pele e sua relação com exposição solar em freqüentadores de academia de ginástica, em Recife. An bras Dermatol, Rio de Janeiro, 2003; 78(6):693-701.

Hospital do Câncer. Departamento de Oncologia Cutânea.Centro de Tratamento e Pesquisa. Dermatoscopia.[on line] 2003.Brasil. Disponível em <URL: http://www.hcanc.org.br/dmeds/pele/pele5.html>[2004 set 8]. 
Ikehata $H$, Ono T.Mutation inducion with UVB in mouse skin epidermis is suprpreessed in acute high-dose expose. Med News Dermatologia 2002; 54:2.

Jemal A, Devesa SS, Fears TR, Hartge P. Cancer Surveillance series: Changing patterns of cutaneous malignant melanoma mortality rates among whites in the United States. Journal of the National Cancer Institute [on line] 2000;92(10)[ 14 telas] Disponível em <

URL:http://jncicancerspectrum.oupjournals.org/cgi/content/full/jinci;92/10/811> [2004 ago 9].

Enokihara M, Birkenhauer MC e Michalany N. GBM-Apoio ao diagnóstico. [serial online]2004.Disponível em URL:http://www.gbm.org.br/ac_livre/apoio/art008.asp> [ 2004 set 5].

Instituto Brasileiro de Geografia e Estatística. Santa Maria de Jetibá-ES. População e Domicílios -Censo 2000 com Divisão Territorial 2001. IBGE-Cidades@. [on-line] 2005; Brasil; Disponível em <URL:http://www.ibge.gov.br/cidadesat/xtras/temas...

Kinney JP, Long CS e Geller AC.Índice Ultravioleta: Uma Ferramenta Útil. Dermatology Online Journal. [on-line] 2000; 6(1):2.Disponível em <URL:http://www.dermatology.cdlib.org/DOJ vol 6 num 1/original/screens/kinneyesp.html.

Kopke LFF, Schmidt SM.Carcinoma basocelular. An bras Dermatol, Rio de Janeiro, 2002;77:249-282.

Korting GM, Denk R. Diagnóstico diferencial em dermatologia. São Paulo; Manole Ltda; 1977.

Lamarão P, Moura C. Dermatoscopia. Rev Sociedade Portuguesa de Dermatologia $\begin{array}{lllll}\text { e Venerologia } \quad \text { (on-line] 2001;59 } & \text { (3). Disponível em }\end{array}$ <URL:http//www.dermo.pt/detalhes/? det=111>[2004 set 8]. 
Latorre MRDO. A mortalidade por câncer de estômago no Brasil: análise do período de 1977 a 1989. Cad Saúde Pública [on-line] 1997; 13:67-78. Disponível na <Word Wide Web:http: //www.scielo.br/scielo.php?script=sci_arttex\&pid=SO102$311 X 1997000500007 \&$ Ing $=$ pt\&nrm=iso $>$ ISSN 0102-311X.

Lima A, Santos I. Fatores de risco dos tumores cutâneos. Med News Dermatologia $2004 ; 71: 2-3$.

Maceira JP. Microestagiamento do Melanoma (Espessura de Breslow x Níveis de Clark. Bol Informativo do Grupo Brasileiro Melanoma.1999; 4:1

Maia M, Proença NG e Moraes JC.Risk factors for basal cell carcinoma: a case control study. Rev Saúde Pública 1995; 29:27-37.

Mendonça, Gulnar Azevedo e Silva. Increasing risk of cutaneous melanoma no Brasil. Rev Saúde Pública 1992, 26(4): 290-294. ISSN 0034-8910.

Minelli L, Pereira VL e Dayer L. Estatística do Carcinoma Basocelular, em Londrina, Paraná. Bol de La Oficina Sanitária Pan-americana 1982; 93:10-17.

Ministério da Ciência e Tecnologia. Centro de Previsão de Tempo e Estudos Climáticos.Instituto Nacional de Pesquisa.Divisão de Satélites e Sistemas Ambientais. O que é Índice Ultravioleta? [on-line] Brasília; Disponível em <URL:http://www. satélite.cptec.inpe.br/uv/o_que_e_iuv.html [ 2004 ago 30]

Ministério da Ciência e Tecnologia.Centro de Previsão de Tempo e Estudos Climáticos. Instituto Nacional de Pesquisa. Divisão de Satélites e Sistemas Ambientais. Previsão do tempo [on-line] Brasília; Disponível em <URL:http://www. satélite.cptec.inpe.br/tempo/indice_uv.shtml [ 2005 fev 12]

Ministério da Ciência e Tecnologia. Centro de Previsão de Tempo e Estudos Climáticos. Instituto Nacional de Pesquisa. Divisão de Satélites e Sistemas 
Ambientais. Por que apresentar o Índice Ultravioleta ao invés do tempo de exposição? [on-line] Brasília; Disponível em <URL:http://www. satélite.cptec.inpe.br/uv/IUV_e Tempo de_Exposição.html [ 2005 fev 12]

Ministério da Saúde. Destaques do Governo. Indicadores Municipais de Saúde.

Demografia- Município: Santa Maria de Jetibá/ES [on-line] Brasília, 2005;

Disponível em <URL:http://

portalweb02.saude.gov.br/portal/aplicacoes/tabfusion/tabfusion.cfm

[ 2005 fev 10]

Ministério da Saúde. Secretaria Nacional de Assistência à Saúde. Instituto Nacional de Câncer.Coordenação de Programas de Controle do Câncer. Atlas de Mortalidade por Câncer No Brasil 1979-1999. [online] Rio de Janeiro; 2004.Disponível em < URL: http: //www.inca.gov./Atlas [ 2004 set 8 ].

Ministério da Saúde.Secretaria Nacional de Assistência à Saúde.Instituto Nacional de Câncer.Coordenação de Programas de Controle do Câncer.Câncer no Brasil-Dados dos Registros de Câncer de Base Populacional.-Volume I. Rio de Janeiro; 1991.

Ministério da Saúde. Secretaria Nacional de Assistência à Saúde. Instituto Nacional de Câncer. Coordenação de Programas de Controle do Câncer. Câncer no BrasilDados dos Registros de Câncer de Base Populacional.-Volume II. Rio de Janeiro; 1995.

Ministério da Saúde. Instituto Nacional do Câncer. Estimativas de incidência e mortalidade por câncer no Brasil. Rio de Janeiro; 2000.

Ministério da Saúde. Instituto Nacional do Câncer. Estimativas de incidência e mortalidade por câncer no Brasil. Rio de Janeiro; 2001. 
Ministério da Saúde. Instituto Nacional do Câncer. Estimativas de incidência e mortalidade por câncer [on-line] Rio de Janeiro; 2002. Disponível em <URL: http: //www.inca.br/cancer/epidemiologia/estimativa2002/brasil.html[2002 set 24]

Ministério da Saúde. Instituto Nacional do Câncer. Estimativas de incidência e mortalidade por câncer. [on-line] Rio de Janeiro; 2002.Disponível em <URL:http: //www.inca.br/cancer/epidemiologia/estimativa2002/são paulo.html[2002 set 24]

Ministério da Saúde. Instituto Nacional do Câncer. Estimativas de incidência e mortalidade por câncer. [on-line] Rio de Janeiro; 2002. Disponível em <URL:http://www.inca.br/cancer/epidemiologia/estimativa2002/espiritosanto.html.... .[2002 set 24]

Ministério da Saúde. Instituto Nacional do Câncer. Estimativas de incidência e mortalidade por câncer. [on-line] Rio de Janeiro; 2002. Disponível em <URL:http://www.inca.br/cancer/epidemiologia/estimativa2002/metodologia.html.... .[2002 set 24]

Ministério da Saúde. Instituto Nacional do Câncer. Estimativas de incidência e mortalidade por câncer [on-line] Rio de Janeiro; 2003. Disponível em <URL:http://www.inca.br/cancer/epidemiologia/estimativa2003/tabelasestados.asp?. Uf=BR[2003 jun 18]

Ministério da Saúde.Instituto Nacional do Câncer. Estimativas de incidência e mortalidade por câncer [on-line] Rio de Janeiro; 2003. Disponível em <URL:http://www.inca.br/cancer/epidemiologia/estimativa2003/tabelaestados.asp?U F=ES.[2003 jun 18]

Ministério da Saúde. Instituto Nacional do Câncer. Estimativas da incidência e Mortalidade por câncer; 2003. [on-line] Rio de Janeiro; 2003. Disponível em< URL:http://www.inca.gov.br/cancer/epidemiologia/morbidade.html.>[2003 mar 13] 
Ministério da Saúde. Instituto Nacional do Câncer. Falando sobre câncer e seus fatores de risco. Rio de Janeiro; 1998.

Ministério da Saúde. Instituto Nacional do Câncer. O câncer no Brasil. [on-line] Rio de Janeiro;2003.Disponível em<URL:http://

www.inca.gov.br/câncer/epidemiologia/câncer no Brasil.html.>[2003 mar 13]

Nora $\mathrm{AB}$, Panarotto $\mathrm{D}$, Lovatto $\mathrm{L}$ e Boniatti $\mathrm{MM}$. Frequiência de aconselhamento para . An bras Dermatol , Rio de Janeiro, 2002;77:249-282.

Organização Mundial da Saúde. La incidência mundial del câncer podria aumentar en un 50\% y llegar a 15 millones de nuevos casos en el año 2020.El Informe mundial sobre el câncer demuestra que las actuaciones sobre el consumo de tabaco, la dieta y lãs infeccionais puden prevenir un tercio de los cânceres y de que es posible curar otro tercio [on- line] 2004. Disponível em < URL: http://www.who.int/mediacentre/reases/2003/pr27/es/print.html> [2004 jun 21].

Pacheco R. Abrindo caminho a facão, um pedaço da Pomerânia capixaba em Rondônia. Século-O Esp Sant em revista [serial on-line]2000. Disponível em <URL: http://www.seculodiario.com/seculo/rodrigop>[2003 mar 13].

Pagung R. Pomeranos, sentindo na pele. Du kaft rina kooma:Programa de Assistência aos Lavradores Pomeranos do Espírito Santo, 15 anos. Vitória (ES); Universidade Federal do Espírito Santo. Pró-Reitoria de Extensão; 2002.

Paschoal FM. Dermatoscopia, Microscopia de Superfície, Microscopia de Epiluminescência. GBM-Apoio ao diagnóstico. [serial on-line]2004.Disponível em <URL: http://www.gbm.org.br/ac_livre/apoio/art005.asp>[ 2004 set 8]. 
Pereira SM.Melanoma. GBM-Apoio ao diagnóstico. [serial on-line]2004. Disponível em <URL: http://www.gbm.org.br/ac_livre/apoio/art001.asp>[ 2004 ago 28].

Prado H Câncer de Pele. Piauí-1964-1984. I-Carcinoma basocelular. An bras Dermatol , Rio de Janeiro, 1987;62(3):143-146.

Prado H Câncer de Pele. Piauí-1964-1984. II-Carcinoma espinocelular. An bras Dermatol , Rio de Janeiro, 1987;62(3):147-150.

Projeto saber. Física para todos. [on-line]. Disponível em <URL:http://www.físicaparatodos.com.br>[2004 ago 30 ].

Rocha FP, Menezes AMB, Almeida Júnior HL e Tomazi E. Especificidade e sensibilidade de rastreamento para lesões cutâneas pré-malignas e malignas. Rev Saúde Pública 2002; 36(1): 101-6.

Rocha RCC. Pomeranos, sentindo na pele. Du kaft rina kooma: Programa de Assistência aos Lavradores Pomeranos do Espírito Santo, 15 anos. Vitória (ES); Universidade Federal do Espírito Santo. Pró-Reitoria de Extensão; 2002.

Rölke HR. Descobrindo raízes: aspectos geográficos, históricos e culturais da Pomerânia.Vitória (ES); Universidade Federal do Espírito Santo. Secretaria de Produção e Difusão Cultural; 1996.

Rölke HR. Quem são os pomeranos? Du kaft rina kooma: Programa de Assistência aos Lavradores Pomeranos do Espírito Santo, 15 anos. Vitória (ES); Universidade Federal do Espírito Santo. Pro-Reitoria de Extensão; 2002.

Santos Neves MCM. Além das aparências. Memória da dermatologia no Espírito Santo. Vitória (ES). Sociedade Brasileira de Dermatologia, regional Espírito Santo, 2003. 
Starfield B. Atenção primária: equilíbrio entre necessidades de saúde, serviços c tecnologia. Brasília: UNESCO, Ministério da Saúde; 2002.

Stenbeck KD, Balanda KP, Willians MJ, Ring IT, Maclennan R, Chick JE e Morton AP. Patterns of treated non-melanoma skin cancer in Queensland-the region with the highest incidence rates in the world. [on -line] 2004. Disponível em < URL: http://www.ciesin.org/docs/001-529/001-529.html > [2004 ago 23].

Stewart SL, King JB, Thompson TD, Friedman C, Wingo PA.Cancer Mortality Surveillance- United States, 1990-2000. Surveillance Summaries, MMWR 2004; $53: 1-112$.

Tressmann I. O convite e a participação do hochtijdsbirar na festa de casamento pomerano. Du kaft rina kooma:Programa de Assistência aos Lavradores Pomeranos do Espírito Santo, 15 anos. Vitória (ES); Universidade Federal do Espírito Santo. Pro-Reitoria de Extensão; 2002.

Universidade Federal do Espírito Santo.Pró-Reitoria de Extensão. Du kaft rina kooma: programa de assistência aos lavradores pomeranos do Espírito Santo, 15 anos.Vitória (ES); 2002.

Universidade Federal do Rio de Janeiro. $O$ que é o índice ultravioleta? Rio de Janeiro (RJ); 2003.Disponível em<URL:http://acd.ufrj.br/ indiceuv/oqueeiuv.html.> [2004 ago 29].

Universidade Federal do Rio de Janeiro. Identificação dos fototipos de pele.Rio de Janeiro(RJ);2003.Disponível

em<URL:http://www.indiceuv.ufrj.br/tipodepele.html[2003 out 13 ].

Vries E de, Tyczynski JE e Parkin DM. Cutaneous malignant melanoma in Europe. European Network of Câncer Registries. Internacional Agency for Research on 
Cancer.ENCR CANCER FACT SHEETS[serial on-line] 2003;4( ?).[ 4 screens]. Disponível em <URL:http://encr.com.fr./melanoma.factsheets.pdf > [2004 ago 10]

Wagemann E. A colonização alemã no Espírito Santo. Trad.de R Sant'anna. Rio de Janeiro.Boletim Geográfico; 1948-1949.

World Health Organization. WHO Câncer [ on line] 2004. Disponível em <URL: http: //www.who.int/cancer/en/> [ 2004 jul 25].

Zandonade E. Relatório de análise estastística-estudo descritivo sobre câncer de pele; Vitória (ES); 2000.

Zandonade E. Relatório de análise estastística-estudo descritivo sobre câncer de pele melanoma; Vitória (ES); 2000.

Zandonade E. Relatório de análise estastística-estudo descritivo sobre câncer de pele não melanoma; Vitória (ES); 2000. 


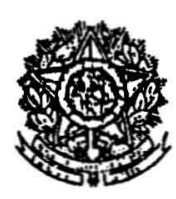

UNIVERSIDADE FEDERAL, DO ESPIRITO SANTO

CONVENIO QUIE ENTRLI SI CELTBRAM O MLINICÍPIO DE SANTA MARIA DE JEIIBA, A SECRETARIA DE FESTADO DA SAĹDI:, ATRAVES DO INSTTITIO ESTADLTAL DE SAĹTDE . PĹBLICA, A ASSOCIACCÃO ALBERGUIE MARTIM LUTERO E A UNIVIRSIDADE FEDERAL DO ESPIRTTO SANTO, ATRAVES DO HOSPIIAY, UNIVERSITÁRIO CAASSIANO ANTONIO DE MORAES, DO CENTRO BIOMEDICO E DA PRÓ-REITORIA DE IRXTENSÃO, OBJETIVANDO A VIABHLIZAÇÃO DO PROJETO DE EXTENSÃO "ASSISTENCLA DEIRMATOLÓGICA AOS LAYRADORES POMERANOS NO INTERIOR DO ESTADO DO ESPIRTIO SANTO.

O MUNICIPIO DE SANIIA MLARIA DE JETIBÁ, situada na rua Hemminu Miertschink, n* 488-A, Ceniro, Santa Marial de Jetibá - ES, CEP: 29645-100, inscrila no CGCAMF sob o no 36.388.445/0001-38, nesle alo rejeresentada pelo Prefeilo Murnicijual, Filário Rociphe, portador da

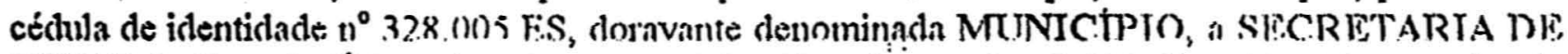
ESTADO DA SAOBN, inscrila nu CGCAMF sob," n" 27.080.605'0001-96, atraves du

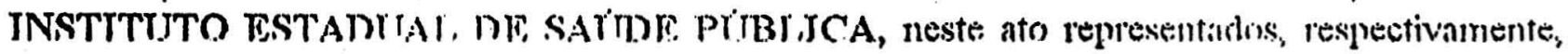
pelo seu Secretário e Direfor Presidenle, Dr. F́aldir Turini, carleira de ideulidade $n^{\circ} 1061753$ -

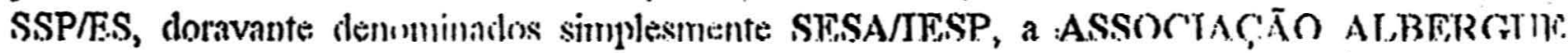

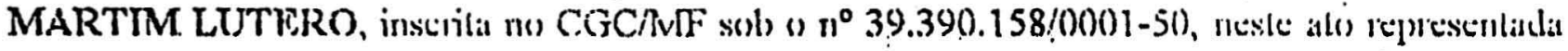

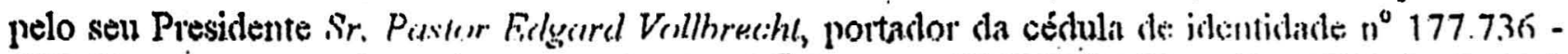

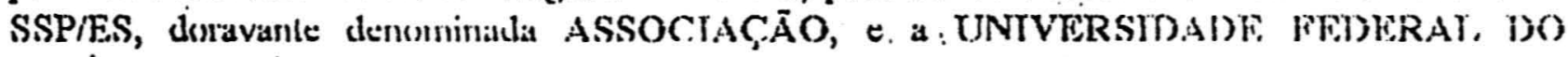
ESPIRITO SANTO, autaryuia educacional de regime especial, situadia na Av. Fomando Fomatri, $8 / 1^{\circ}$, Campus Universitirio, Guiabeiras, Vitúria, Espírito Santo, CEP 2906(i-900, insosita nu C.FC/MTF sol o $1^{\circ} \quad 32.479 .123 / 0001-43$, através do HOSPITAT, TINIVTRSTTÁRTO CASSIANO ANTONIO DE MORAES, do CENTRO BIOMÉDICO e da PRÓ-RETTORIA

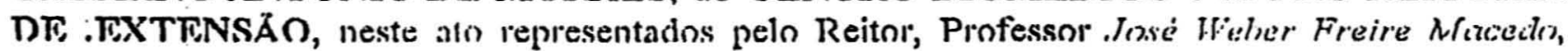

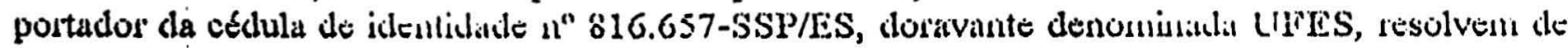
comum acordo celebrar o presente Convênio, conforme as seguintes cláusulis e condições:

\section{C.LÁUSULA 1 - DO OB.JliTOO}

1.1 - O presente Convêuic leın por objeto a realização do projeto de listensto Intitulado "ASSISTÉNCIA DFERMATOLÓGICA AOS. LAVRADORES POMERANOS NO INTFRIOR DO FETTAIDO DO F.SPIRITO SANTO", cujo projcto sc comatitui cm anc*o a este instrumento.
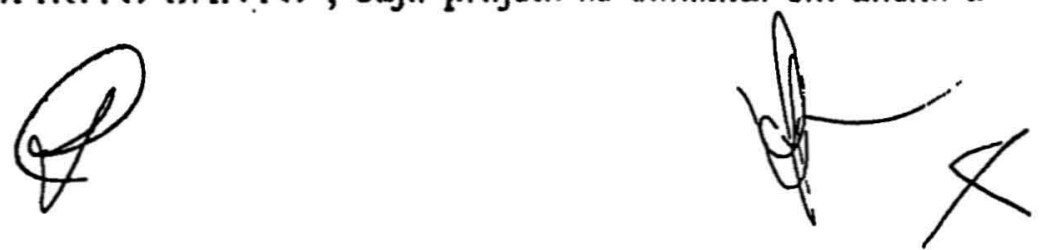
UNIVERSIDADE FEDERAI, DO ESPIRITO SANTO

CONVENIO QLIE ENTIRII SI CLILBRAM O MUINICÍPIO DE SANTA MARIA DE JETIBA, A SECRETARIA DE FSTADO DA SALTDIi, ATRAVÉS DO INSTITTIOO ESTADUTAL DE SAĹTDE PIBLICA, A ASSOCIACYÃO ALBERGLIE MIARTIM LUTERO E A UNTVERSIDADE FEDERAL. DO ESPIRITO SANTO, ATRAVÉS DO HOSPITAL UNIVERSITÁRIO CASSIANO ANTONIO DE MORAES, DO CENTRO BIOMIÉDICO E DA PRÓ-REITORIA DE EXTENSÃO, OBJETIVANDO A VHABILIZAÇÃO DO PROJETO DE EXTENSÃO "ASSISTENCIA DERMATOLÓGICA AOS LAVRADORES POMERANOS NO INTERIOR DO ESTADO DO ESPIRITO SANTO.

MUNICIPIO DE SANTA MLARIA DE JETIBA, situada na rua Hemainu Miertschink, $n^{\circ}$ 488-A, Cenlro, Sanla Maria de Jelibá - ES, CEP: 29645-000, inscrila no CGCMF sob o Il $^{\circ}$ 36.388.445/0001-38, neste alo vepresentadla pelo Prefeilo Municipal, Hilírio Rosephe, portador dat cédula de identidlade $n^{\circ} 328.100$ i ES, donvante dennminada MUINICIPTO, a STCCRETARTA DE,

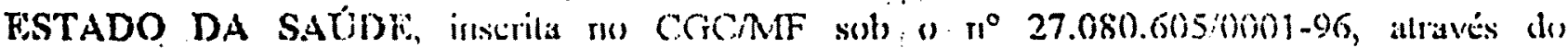
INSTITITTO ESTADITAI, MI. SAITDE PIIBI,JCA, neste ato replesentidns, respectivamente,

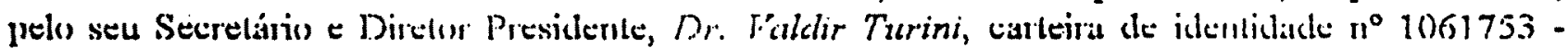

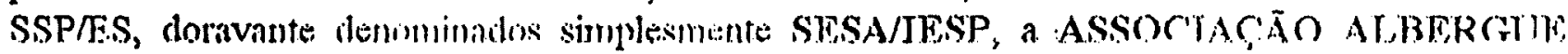

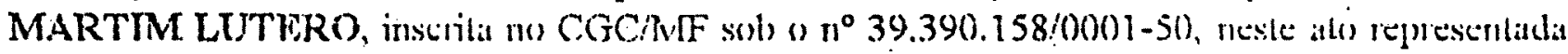

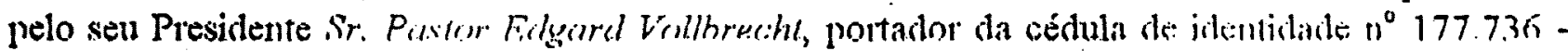

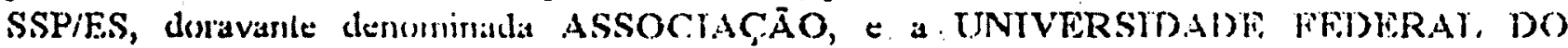
ESPIRITO SANTO, autarquia educaciomal de regime especial, sinuadi na Av. Fomando Fonati, $\$ / n^{\circ}$, Campus Universitirio, Guiabeinas, Vitúria, Espinto Santo, CEP 29000-900, inscrita no CFCAMF sol o $n^{n}$ 32.479.123/0001-43, através dn HOSPTTAT, TINTVFRSTTÁRTO CASSIANO ANTONIO DE MORAES, do CENTRO BIOMEDICO e da PRÓ-RETTORLA

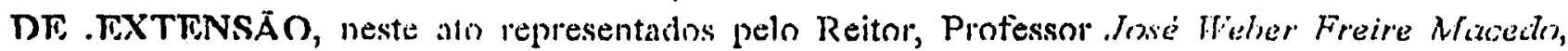
portador da cédula de idenlidale $\|^{\prime \prime} 816.657-$ SSP/ES, doravante denominada LIPES, resolven de comum acordo celebrar o presente Convênio, conforme as seguintes cláusulas e condições:

\section{CLÁUSUILA 1 - DO OB.JWTO}

1.1 - O presente Convêtuo ten pơ objeto a realização do Projeto de Extensão Intitulado "ASSISTENCIA IDFRMATOLOGICA AOS LAVRADORES IOMLERANOS NO DNTERIOR DO F.STADO DO FEPIRTTO SANTO", cujo projcti se comstitui em ancko a este instrumento.
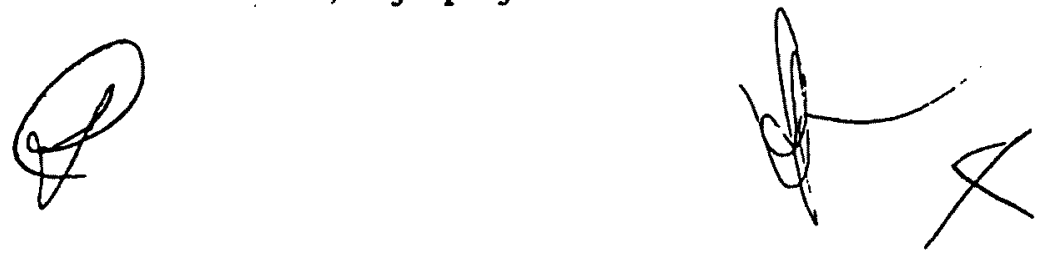


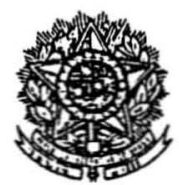 \\ UNIVERSIDADE FEDERAL DO ESPIRITO SANTO}

\section{CLÁUTSILA 2 - DIIS METAS}

2.1 - O presente convènio tem como meta principal atender à população pomerana de onze Municipios do Lestido do Espirito Sinto, no intuilo de prevenir ancilenciat de dincer de

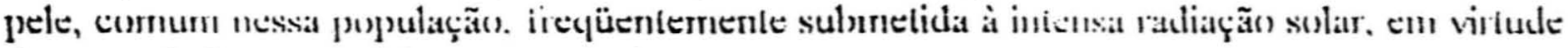
de seu traballo essencialmente agricola.

2.2 - O cronugrant. de alividales consiste de una viagem anual a cala un dos onze Mfunicipius, onde são feitos ciames clinicos, biópsia e pequenas cirurgias, yulando necessário, conforme projeto integrintic: deste instrumsto.

\section{CLAUISULA 3 - DAS ATRIBUTCOES DOS PARTICIPES}

3.1 - Compete à likits:

3.1.1 - Atraves da PliO_RFITORI.1 DF EXTENSÄO - PROFY.

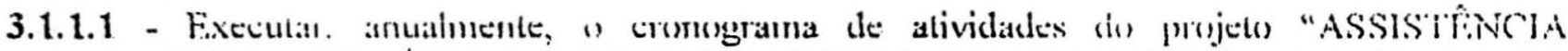
DFRNATTOIGGICA AOS IAAVADORES POMFRANOS NO INTERIOR DO ESTADO WO LSPIRTO SANTO";

3.1.1.2 - Assumir, atralvés dos professores envolvidos, a orientação técnico-cientifica dos acalenticos s medicos resictentes participantes do projeto:

3.1.1.3 - Promover reuniỗes de acomp̣anhamento e avaliação dals atividades:

3.1.1.4 - Fomecer erriticidos aos acirlêmicos e médicos residentes ai estagiários;

3.1.1.5 - Fornecer diáizass aus prolessores e ao restante da equipe ligada à UFES envolvidos no

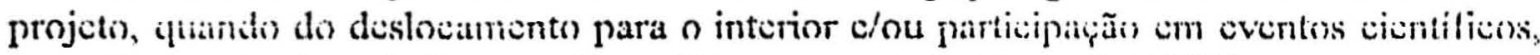

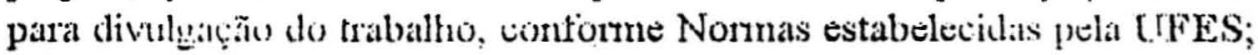

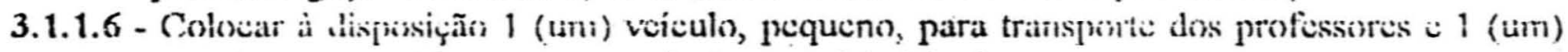
veiculo tipo kombi para transporte do material cirúrgico.

3.1.2 - Através do (TNTRO BIOMEDICO - CBM:

3.1.2.1 - Incluir cono atividade optativa na Residencia de Chinuci Médica e Cirúgica, a participaç̦īo no projelo de M.́ćdicos Residentes;

3.1.3 - Através dO IIOSPTTAT, TINIVRRSTTARIO CASSTANO ANTONIO DE NIORARS HUCAN:

3.1.3.1 - Fomecer malkial yrafico e cirurgico necessítio an projeto;

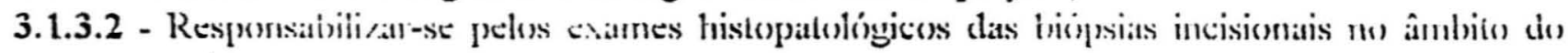
projeto.

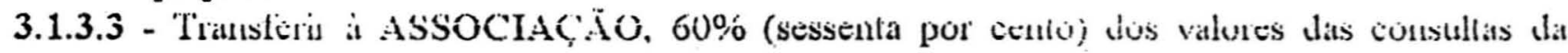
tabela SUS, e os valores correspondentes aos seniços protissionais das pequenas cirurgias, rualizatas nas ctajpas do projeto;

3.1.3.4 - Formecer dess seus quadros ou solicilar de oulras enlidades ligadas au SUS, que scja

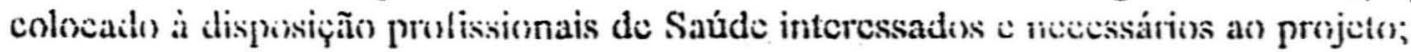

3.1.3.5 - Fomecer atrea para realização de atendimento ambulatorial de anoio às atividades extramuro do projelo;

3.1.3.6 - Apoiar, allaves do Centro de Estudos/HLCAM o preparo de trabalhos eientificos (slides, graficos, pain îis, ete), para apresentaçĩo em eventos cientifices a publicações.
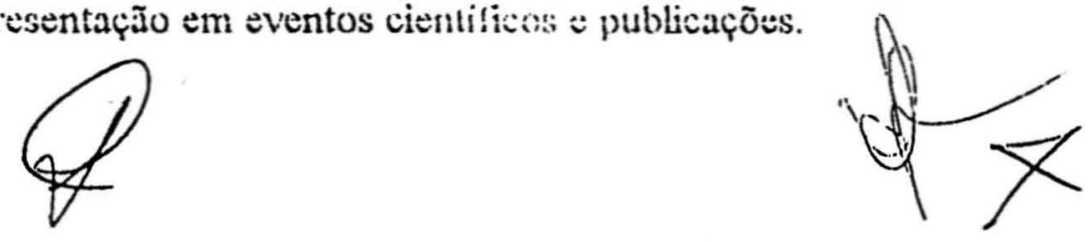


\section{UNIVERSIDADE FEDERAL DO ESPIRITO SANTO}

\section{2 : Compete a Slis vIISS:}

3.2.1 - Colocar parte da carga horária de profissionais de seus quadios, interessados e necessirios ao projeto, a disposiçĩo do IILCAM para esta finalidade;

3.22 - Fomecer 1 (um) veiculo, pequeno, para transporte dos seus protissionais, colocados à disposiçăo do 11 l ( AM, por ocasijo das etapas extra-muro do projeto;

3.2.3 - Fornecer 2 (ivois) veiculos, tipo Kombi, para o transporte dos acadénicos por ocasiño dals elapas exilral-muro do projelo.

3.2.4 - Fomecer medii:amenios para disisibuição aos pacienles alenuiicus pelo projelo.

\section{3 - Compete is issoiriciso:}

3.3.1 - Manler e proceder aclaplingöes das inslalações ulilizadlas pelo projelo nas 11 (onze) parcicquias, sede de posilos exlı a-murus;

3.3.2 - Guardar e \% lat pelos arquivos, móvejs e nutros utensilios, junto a tais ponstos;

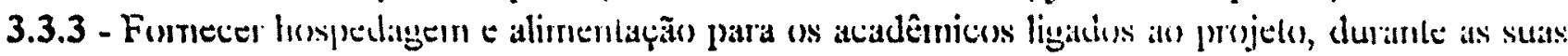
etapas extra-muros:

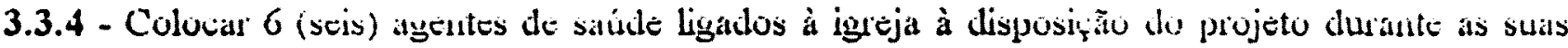
etapas extra-truros.

\section{4 - Compete an MllNICIPIO:}

3.4.1 - Cooperar coni as diretorias das respectivas paróquias, nö abojamento e alimentição dos acadêrnicos ligados a projelo;

3.4.2 - Fomecer mativial cirurgico complementar permanente e/ou desintiviol, necessário as ctapas do projeto enu selis municipios:

3.4.3 - Fomecer comblustivel para os veiculos utilizados no transporti da cquipe, em seu refimmo para Vitória:

3.4.4 - Colocar protissicmais da área de saúde, dos seus quadros, à disjosição do projeto, duante as etapas em seus municípios;

3.4.5 - Divulgar às atividades do projeto junto à população, e colocar transporte até o local de atcndimento;

3.4.6 - Colocar uma anbulincia à disposição do projeto, durante a ttapa um seus municipios para transporte de pilcientes idosos elou submetidos à cirurgia de maior porte.

\section{CLACISULA 4 - DUS RECURSOS WTNANCEIROS}

4.1 - Cabera a UTES o pagamento das diarias dos professores e técnicos-administrativos envolvidos no projelo, na lonte 0112 - rubrica 349014.

\section{CLÁUSULA S - DU PI ANO DE APIACAÇÃO E (CRONOGRANAA DE DESEMBOLSO}

5.1 - Us recursos para pagmento das diárias, por parte da UHLS, serĩo desembolsados uma vez por mês, durante orrze meses, na vigência do projeto.
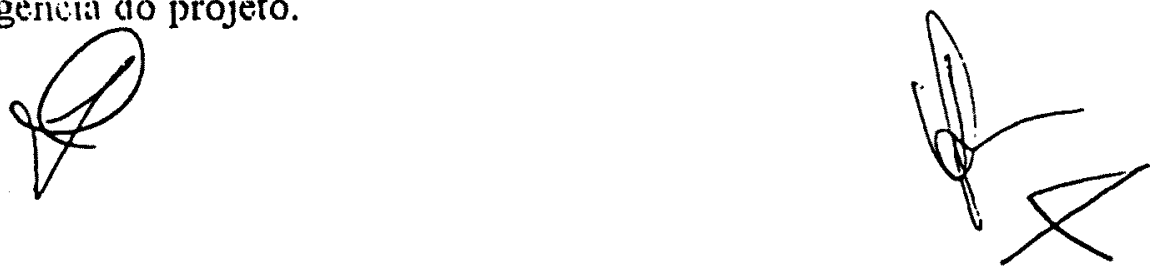


\section{CLÁLISCTLA G - DA VIGENCIA}

6.1 - O presente Convênio terá vigencia de 5 (cinco) anos, a contar da data de sua assinatura, podendo ser promogado, por intermedio de Termo Adilivo (T.A.), a criterio das partes signalairias.

\section{CLÁUISLLA 7 - DA RESCISÃO}

7.1 - O presente Comênio poderá ser denunciado por qualquer dos convenentes mediante comunicagãa expressia, resilido por múno acordo entre as convententes ou se houver a inadimplemento de qualiquer das cláusulas aqui pactuadas, mediante notiticação formal à outra parte, com antecedência mínima de 30 (trinta) dias, respeitadas as obrigações assumidas com terceiros e saldados os compromissos financeiros entre as partes.

\section{CLÁLISULA 8 - BO FORO}

8.1 - É compelunle o Foro da Jusliẹa Fudcral, seção judiciária do Espínilo Santo, para dirimir as questões decomentes di presente Convênio nu de sua cxecução, com reníncia expressa de qualquer outro, por mais privilegiado que seja.

E. pror eslisem assirn justus e acurdadus, leram e cunferinam " presente instrumenlo, que firmam on $n j$ (cinonj vias de igual teor e forma, para os mesmos efeitos, e na presença das testegnunhas abaixö.

Hilario Rocpk

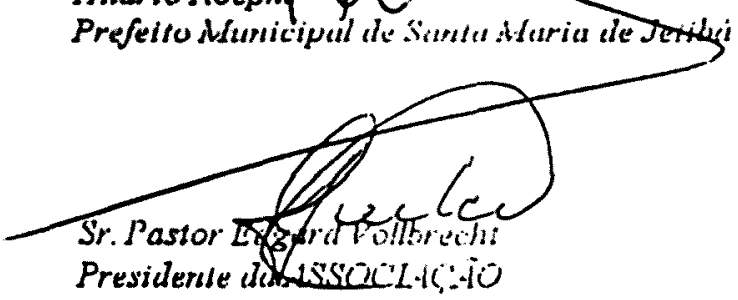

TESTEMUNHLLS:
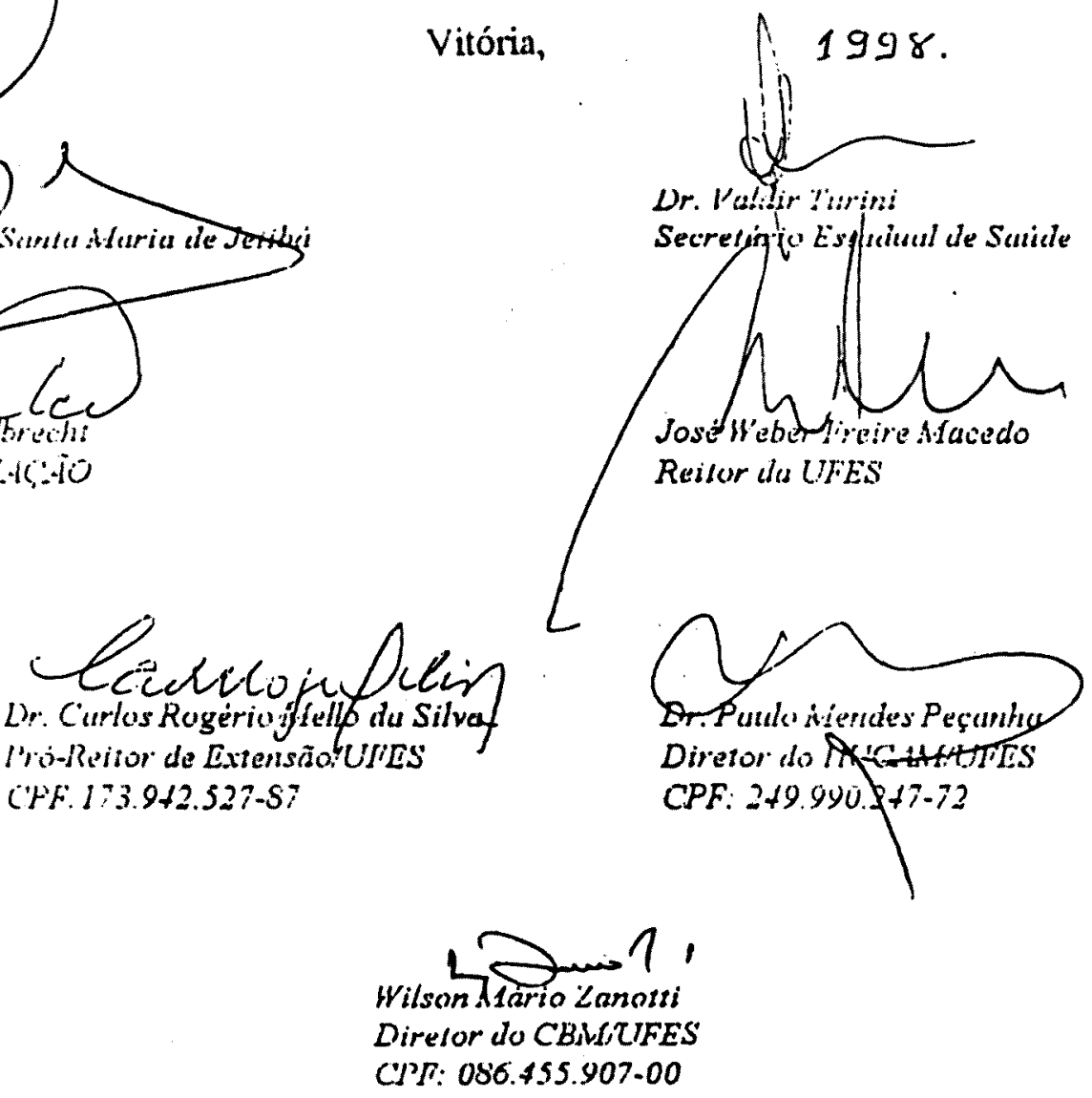

Obs: Pracesso $2658 / 98$ 


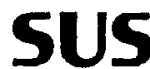

Sistema Ünico de Saüde

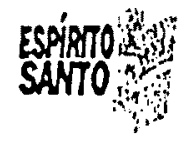

Instituto

Estadual de

Saúde Pública
Procuradoria Juridica

CONVÊNIO N०035/2.003

PROCESSO N० $24211427 / 2.003$

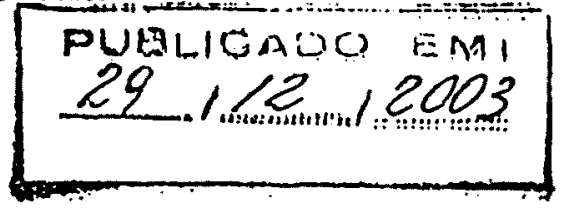

CONVENNIO QUE ENTRE SI CELEBRAM O INSTITUTO ESTADUAL DE SAUUDE PÜBLICA, A ASSOCIACCÃO ALBERGUE MARTIM LUTERO, A UNIVERSIDADE FEDERAL DO ESPIRITO SANTO, ATRAVÉS DO HOSPITAL UNIVERSITARIO CASSIANO ANTÔNIO DE MORAES, DO CENTRO BIOMÉDICO E DA PRÓ-REITORIA DE EXTENSAOO E OS MUNICIPIOS DE AFONSO CLAUDIO, ITARANA, SANTA MARIA DE JETIBA, DOMINGOS MARTINS, VILA PAVÃO. VILA VALÉRIO, LARANJA DA TERRA, BAIXO GUANDU. ITAGUAÇU, PANCAS E SAOO ROQUE DO CANAÁ, OBJETIVANDO A IIIABILIZAÇÃO DO PROJETO DE EXTENSAOO "PROGRAMA DE ASSISTENCIA DERMATOLÓGICA AOS LAVRADORES POMERANOS NO INTERIOR DO ESTADO DO ESPIRITO SANTO".

O INSTITUTO ESTADUAL DE SAÚDE PÚBLICA, pessoa juridica de direito público interno, inscrita no CNPJ(MF) sob o n⿳2 27.189.505/0001-00, sediada na Avenida Marechal Mascarenhas de Moraes, 2.025, Bento Ferreira, Vitória-ES, doravante denominado simplesmente IESP, neste ato representado pelo seu titular JOÃO FELÍCIO SCÁRDUA, brasileiro, casado, economista, inscrito no CRE sob o $n^{\circ} 668$, portador da Carteira de Identidade $n^{\circ} 119.090$ - SSP/ES, inscrito no CIC(MF) sob o $n^{\circ}$ 002.028.431-49, nomeado pelo Decreto $n^{\circ} 1.575$-S, de 28/07/03, publicado no DIO em 29/07/03, residente e domiciliado na Rua Desembargador Carlos Xavier Paes Barreto, 17, Mata da Praia, Vitória - ES, a ASSOCIAÇĀO ALBERGUE MARTIM LUTERO, con sede na Rua Francisco de Alvarenga Rabelo, 201, Maruipe, Vitória - ES, inscrita no CNPJ/MF sob o ${ }^{\circ}$ 39.390.158/0001-50, neste ato representada pelo seu Presidente, Sr. JOÃO PAULO AULER, portador da C. I. $n^{\circ} 7.005 .457 .564-R S$ e do CIC(MF) sob o $n^{\circ} 297.232 .560-53$, doravante denominada ASSOCIAÇÃO, e a UNIVERISDADE FEDERAL DO ESPÍRITO SANTO, autarquia educacional de regime especial, situada na Av. Fernando Ferrari, s/n $\mathrm{n}^{\circ}$, campus universitário, Goiabeiras, Vitória - ES, inscrita no CNPJ/MF sob o nº 32.479.123/0001-43, alravés do HOSPITAL UNIVERSITÁRIO CASSIANO ANTÔNIO DE MORAES, do CEN'TRO BIOMÉDICO e da PRÓ-REITORIA DE EXTENSÃO, neste ato representados pelo Reitor Professor JOSÉ UVEBER FREIRE MACÊDO, portador da C. I. n ${ }^{\circ}$ 816.657-SSP/ES, doravante denominada UFES e os municipios de AFONSO CLÁUDIO, situado na praça da Independēncia, $n^{\circ} 341$, centro, Afonso Cláudio - ES, inscrita no CNPJ/MF sob o $n^{\circ} 27.165 .562 / 0001-41$, neste ato representado pelo scu Prefcito Municipal, Sr. EDÉLIO FRANCISCO GUEDES, portador da C. 1. $n^{\circ}$ 162.355-ES e do CIC(MF) sob o $n^{\circ} 364.080 .007-97$; ITAGUAÇU, situado na Rua Vicente Peixoto Melo, 08, centro, Itaguaçu - ES, inscrito no CNPJ/MF sob o n ${ }^{\circ} 27.167 .451 / 0001-74$, neste ato representado pelo sell Prefeito Municipal, Sr. JOSÉ HAINSTEINREITER, portador da C. I. $n^{\circ}$ 243.407-ES e do CIC(MF) sob o $n^{\circ}$ 578.607.857-49; PANCAS, situado na Avenida Antônio Cabaline, 28, centro, Pancas - ES, inscrito no CNPJ/MF sob o $n^{\circ} 27.080 .605 / 0001-96$, neste ato representado pelo seu Prefeito Municipal, Sr. WALTER HAESE, portador da C. I. $n^{\circ} 176.184$-ES c do $\operatorname{CIC}(\mathrm{MF})$ sob o ${ }^{\circ}$ 416.395.967-04; ITARANA, situado na Run Elias Estevão Colnago, 65, centro, Itarana - ES, inscrito no CNPJ/MF sob o $n^{\circ} 27.104 .363 / 0001-23$, neste ato representado pelo seu Prefeito Municipal, Sr. GERALDO GALAZI, portador da C. I. $n^{\circ}$ 856.957-ES e do CIC(MF) sob $0 n^{\circ}$ 266.821.251-00; SANTA MARIA DE JETIBÁ, situado na Rua Hermann Micrtschink, 488-A, centro, Santa Maria de Jetibá - ES, inscrita no CNPJ/MF sob o $n^{\circ}$ 36.388.445/001-38, neste ato representado pelo sell Prefeito Municipal, Sr. IIELMaR POTRATZ, portador da C. I. $n^{\circ} 13555-R S$ e do CIC(MF) sob o ${ }^{\circ} 353.439 .667-72$; VILA PAVÃO, situado na Rua Travessa Pavão, 80, centro, Vila Pavão - ES, inscrito no CNPJ/MF sob o $\mathrm{n}^{0}$ 36.350.346/0001-67, neste ato representado pelo scu Prefeito Municipal, Sr. ERALDINO JANN TESCH, portador da C. I. $n^{\circ}$ 287.652-ES c do CIC(MF) solyo $n^{n} 416.079 .547-20$; VII VALérRIO; situado na Rua Lourenço de Martins, 80, centro, Vild Valério - ES, inscriyo no CNPJ/MF sob o $n^{\circ}$ 01.619.232/0001-95, neste ato representado pelo feu Prefeito Municjral, Sr.

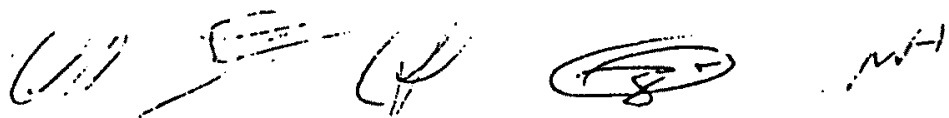


LUIZMAR MIELKE, portador da C. I. $n^{\circ}$ 643.363-ES e do CIC(MF) sob o n 975.066.757-91; LARANJA DA TERRA, situado na Avenida Luiz " Filho, 85, centro, Laranja da Terra - ES, inscrito no CNPJ/MF sob o $\mathrm{n}^{\circ} 31.796 .097 / 0001-14$, neste ato representado pelo seu Prefeito Municipal, Sr. CLÁUDIO PAGUNG, portador da C. I. $n^{\circ} 384.322-E S$ e do CIC(MF) sob o $n^{\circ}$ 479.017.997-49; BAIXO GUANDU, com sede na Rua Fritz Von Lutzon, 217, Centro, Baixo Guandu - ES, inscrito no CNPJ(MF) sob o $n^{\circ} 27.165 .737 / 0001-10$, neste ato representado pelo seu Prefeito, Sr. JOSÉ FRANCISCO DE BARROS, portador do CIC/MF n 125.329.597-20e do CIC(MF) n] 125.329.597-20; DOMINGOS MARTINS, inscrito no CNPJ/MF sob $0 n^{\circ}$ 27.150.556/0001-10, com sede na Rua Bernardino Montciro, 22, Centro, Domingos Martins - ES, neste ato representado pelo seu Prefeito, Sr. IVAN LUIZ PAGANINI, portador da C. I. $\mathrm{n}^{0}$ 380.280-ES e do CPF/MF no 716.788.917-20; SÄO ROQUE DO CANAĀ, situado na Rua Lourenço Roldi, 88, São Roquinho, São Roque do Canaã - ES, inscrito no CNPJ/MF sob o $n^{\circ}$ 01.612.865/0001-71, neste ato representado pelo seu Prefeito Municipal, Sr. MIGUEL DJALMA SALVALAIO, portador da C. I. $n^{\circ} 470.950$-ES e do CIC(MF) sob o $n^{\circ} 472.028 .587-20$, doravante denominados MUNICÍPIOS, resolvem de comum acordo celebrar o presente Convênio, conforme as seguintes cláusulas e condições:

\section{CLÁUSULA PRIMEIRA:} DO OBJETO

1.1 - O objetivo do presente Convênio é a realização do projeto de extensão intitulado 'PROGRAMA DE ASSISTÊNCIA DERMATOLÓGICA AOS LAVRADORES POMERANOS NO INTERIOR DO ESTADO DO ESPIRITO SANTO", cujo plano de trabalho será providenciado e aprovado pela SESAMESP, nos termos do $\S$ $1^{\circ}$ do art. 116 da Lei Federal $n^{\circ} 8.666 / 93$.

\section{CLÁUSULA SEGUNDA:}

\section{DAS METAS}

2.1 - O presente Convênio tem como meta principal atender à população pomerana de onze Municipios do Estado do Espirito Santo, no intuito de prevenir a incidência de câncer de pele, comum nessa população, frequilentemente submetida à intensa radiação solar, em virtude de seu trabalho essencialmente agricola.

2.2 - O cronograma de atividades consiste de uma viagem anual a cada um dos onze municipios, onde são feitos consultas, biópşias, cauterizações e cirurgias de pequeno e médio porte.

Parágrafó Único - Aos municipios de Itarana e São Roque do Canaã, a viagem anual estará condicionada à disponibilidade no calendário anual de mutirões. Fica assegurada, no entanto, a realização de uma viagem a cada dois anos.

\section{CLÁUSULA TERCEIRA: DAS ATRIBUICÕES DOS PARTÍCIPES}

\section{1 - Compete a UFES:}

\subsection{1 - Através da PRÓ-REITORIA DE EXTENSÃo - PROEX:}

3.1.1.1 - Executar, anualmente, o .cronograma de atividades do "PROGRAMA DE ASSITÊNCIA DERMATOLÓGICA AOS LAVRADORES POMERANOS NO INTERIOR DO ESTADO DO ESPÍRITO SANTO";

3.1.1.2 - Assumir, atravćs dos professorcs envolvidos, a orientação técnico-cientifica łos acadêmicos e médicos residentes participantes do programa;

\subsubsection{3 - Promover reuniões de acompanhamento e avaliação das atividades;}

3.1.1.4 - Fornecer certificados aos acadênicos e médicos residentes ou estagiários;
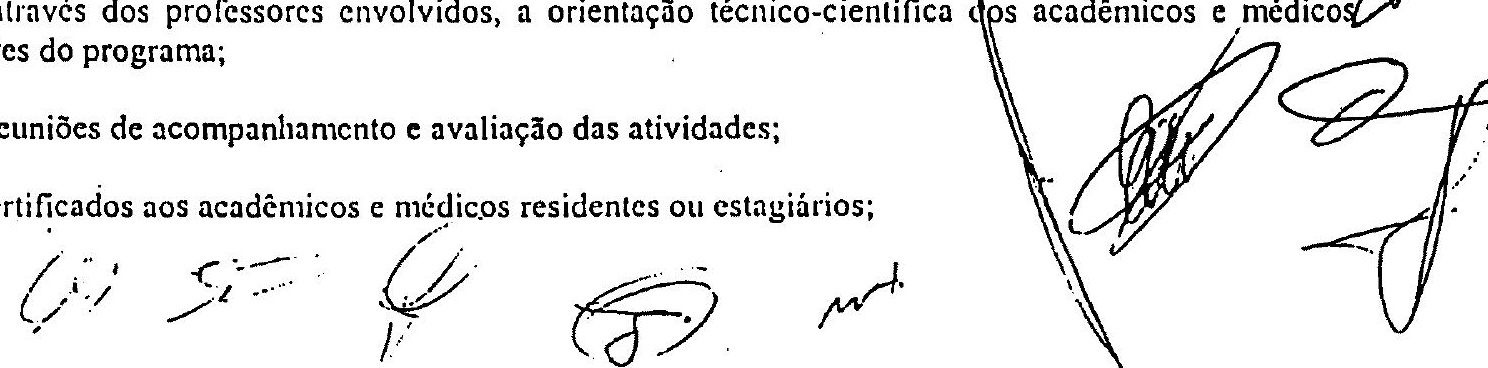
3.1.1.5 - Fomecer diárias aos professores e ao restante da equipe ligada à UFES envolvidos no projeto, quando do deslocamento para o interior e/ou participação em eventos cientificos, para divulgação do trabalho, conforme Normas estabelecidas pela UFES;

3.1.1.6 - Colocar à disposição 1 (um) veículo, pequeno, para transporte dos professores e 2 (dois) veiculos tipo Kombi para transporte do material cirúrgico e estudantes.

\subsection{2 - Através do CENTRO BIOMÉDICO - CBM:}

3.1.2.1 - Incluir como atividade optativa na Residência de Clinica Médica e Cirúrgica, a participação no projeto de médicos Residentes;

\subsection{3 - Através do HOSPITAL UNIVERSITÁRIO CASSIANO ANTÔNIO DE MORAES - HUCAM:}

3.1.3.1 - Fornecer material gráfico e material cirúrgico de consumo necessário ao programa;

3.1.3.2 - Responsabilizar-se pelos exames histopatológicos da biópsias no âmbito do programa;

3.1.3.3 - Transferir à Associação, $60 \%$ (sessenta por cento) dos valores das consultas e demais procedimentos, conforme tabela do SUS, realizadas nas etapas do programa;

3.1.3.4 - Fornecer dos seus quadros ou solicitar de outras entidades ligadas ao SUS, que seja colocado à disposição profissionais de saúde interessados e necessários ao programa;

3.1.3.5 - Fomecer área para realização de atendimento ambulatorial de apoio às atividades extra-muro do programa;

3.1.3.6 - Apoiar, através do Centro de Estudos/HUCAM o preparo de trabalhos cientificos (slides, gráficos, painéis, etc), para apresentação em eventos cientificos e publicações.

\section{2 - Compete no SESAIESP:}

3.2.1 - Colocar profissionais de scus quadros, interessados e necessários ao programa e/ou do HUCAM;

3.2.2 - Fornecer 2 (dois) ou mais veiculos, pequenos, para transporte dos seus profissionais, colocados à disposição do Programa e/ou do HUCAM, por ocasiảo das etapas extra-muro do programa;

3.2.3 - Fornecer 2 (dois) veículos, tipo kombi, para o transporte dos acadêmicos por ocasião das etapas extra-muro do programa;

3.2.4 - Computar, analisar e disponibilizar os dados epidemiológicos coletados durante o desenvolvimento programa.

\section{3 - Compete à ASSOCIAÇÃO:}

3.3.1 - Manter e proceder adaptações das instalações utilizadas pelo programa nas sedes de postos extra-muros;

3.3.2 - Guardas e zelar pelos arquivos, móvcis e outros utensilios, junto a tais postos;

3.3.3 - Fornecer hospedagem e alimentação para os acadêmicos ligados ao programa, durart muros;
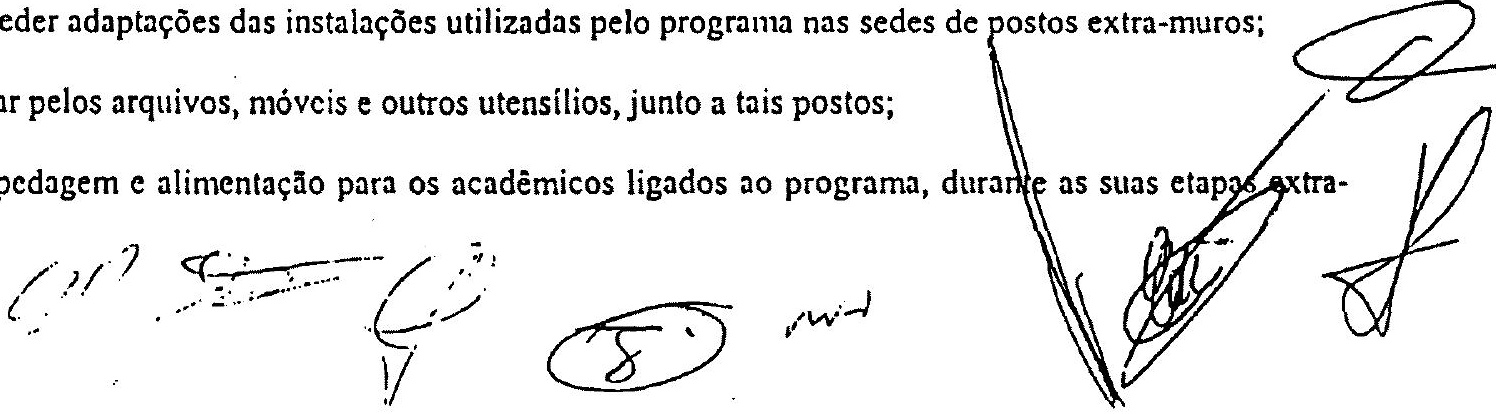
3.3.4 - Colocar voluntários ligados à igreja à disposição do programa durante as suas etapas extra-muros;

3.3.5 - Fornecer, zelar e manter cm condições de uso o material permanente utilizado pelo programa.

\section{4 - Compete aos MUNICİPIOS:}

3.4.1 - Cooperar con as diretorias das respectivas paróquias, no alojamento c alimentação dos acadêmicos ligados ao programa;

3.4.2 - Fomecer material cinírgico complementar permanente elou descartável, necessário às etapas do programa cm seus municipios;

3.4.3 - Fornecer combustivel para os veículos utilizados no transporte da equipe, em seu retorno para Vitória;

3.4.4 - Colocar profissionais da área da saude, especialmente médicos, dos seus quadros, á disposição do programa, durante as etapas em seus municipios;

3.4.5 - Divulgar as atividades do programa junto à população, e colocar transporte até o local de atendimento;

3.4.6 - Colocar uma ambulância à disposição do programa, durante a etapa em seus municipios para transporte de pacientes idosos e lou submetidos à cirurgia de maior porte;

3.4.7 - Fornecer medicamentos para distribuição aos pacientes atendidos pelo programa.

\section{CLÁUSULA QUARTA: DOS RECURSOS FINANCEIROS}

4.1 - Caberá à UFES o pagamento de diárias dos professores e técnicos-administrativos envolvidos no programa, na fontc 0112 - rubrica 349014 .

\section{CLÁUSULA OUINTA:}

\section{DO PLANO DE APLICACÃO E CRONOGRAMA DE DESEMBOLSO}

5.1 - Os recursos para pagamento das diárias, por parte da UFES, serão desembolsados uma vez por mês, durante onze meses, na vigência do programa.

\section{CLÁUSULA SEXTA: DA VIGÊNCIA}

6.1 - O presente convênio terá a vigência de 60 (sessenta) meses, a contar da data de sua assinatura, podendo ser prorrogado, por intermédio de Termo Aditivo (T. A), a critério das partes signatárias.

\section{CLÁUSULA SÉTIMA: DA RESCISÃO}

7.1 - O presente Convênio poderá ser denunciado por qualquer dos convenentes mediante comunicação expressa, residido por mútuo acordo entre os convenentes ou se houver o inadimpleniento de qualquer das cláusulas aqui pactuadas, mediante notificação formal à outra parte, com antecedência minima de 30 (trinta) dias, respeitadas as obrigações com terceiros e saldados os compromissos financeiros entre as partes.

\section{CLÁUSULA DÉCIMA: DO FORO}

S.1 - É competente o Foro da Justiça Federal, seção judiciária do Espirito Santo, para dirimir ał questöes decofrentes do presente Convênio ou de sua execução, com renúncia expressa de qualquer outro, por mais phivilegiado ghuçaja.
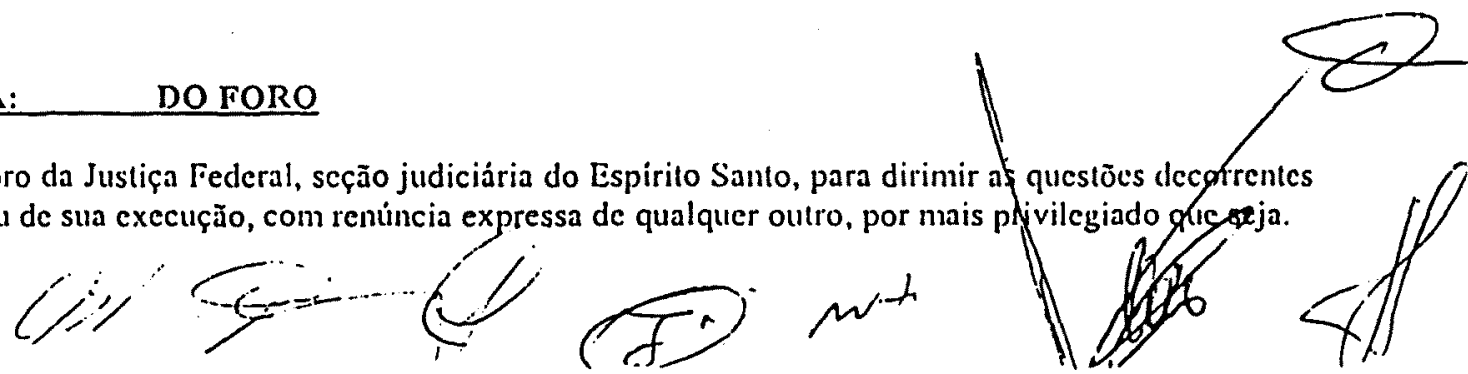
E, por estarem de pleno acordo e ajustados, depois de lido e achado conforme, assinam os participes o presente convênio em 05 (cinco) vias de igual teor e forma, na presença das testemunhas abaixo assinadas.

Vitória(ES), 30 de outubro de 2.003.

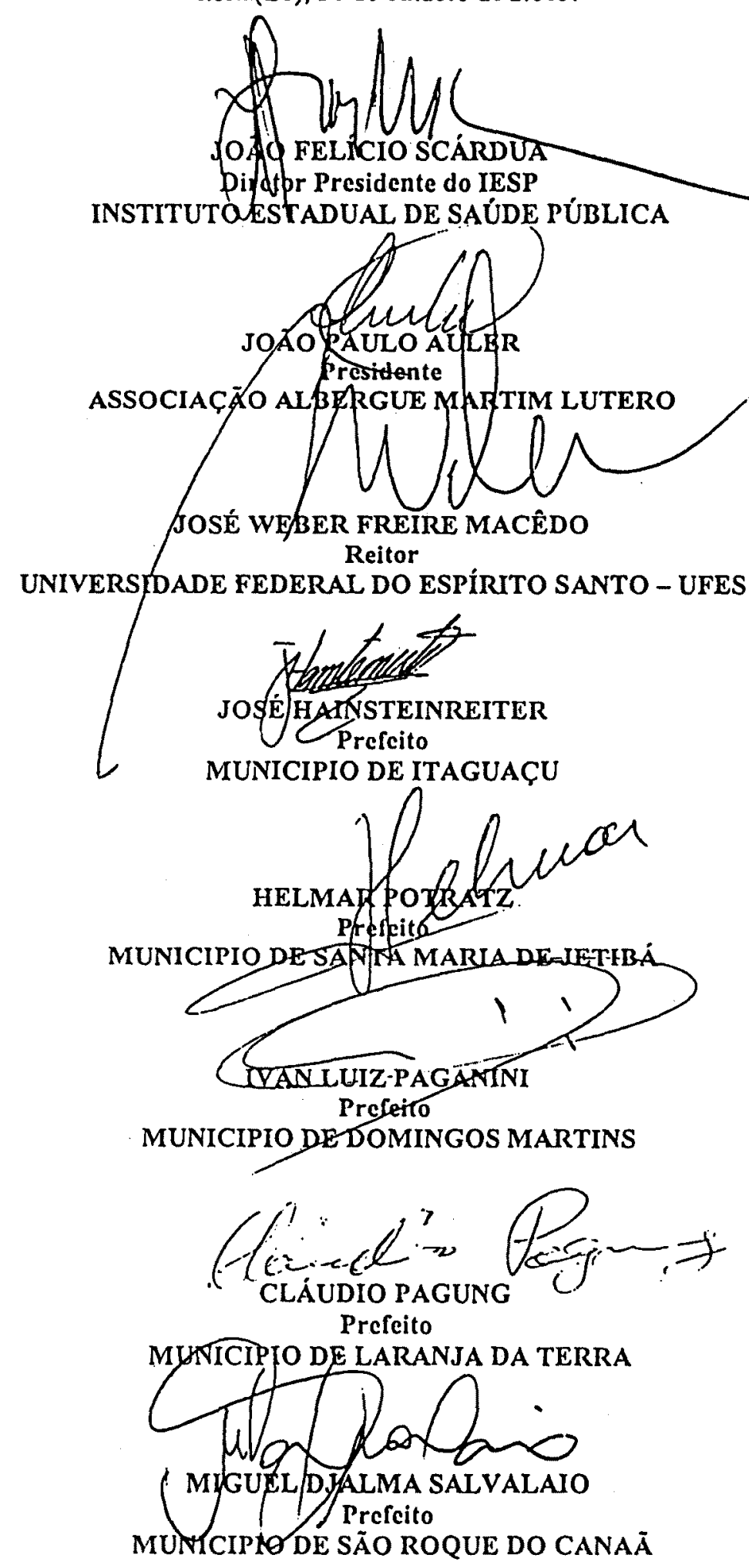




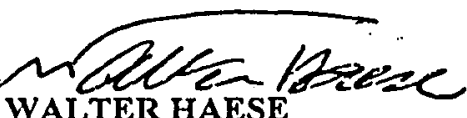

WALTER HAESE

Prefcito

MUNICIPIO DE PANCAS

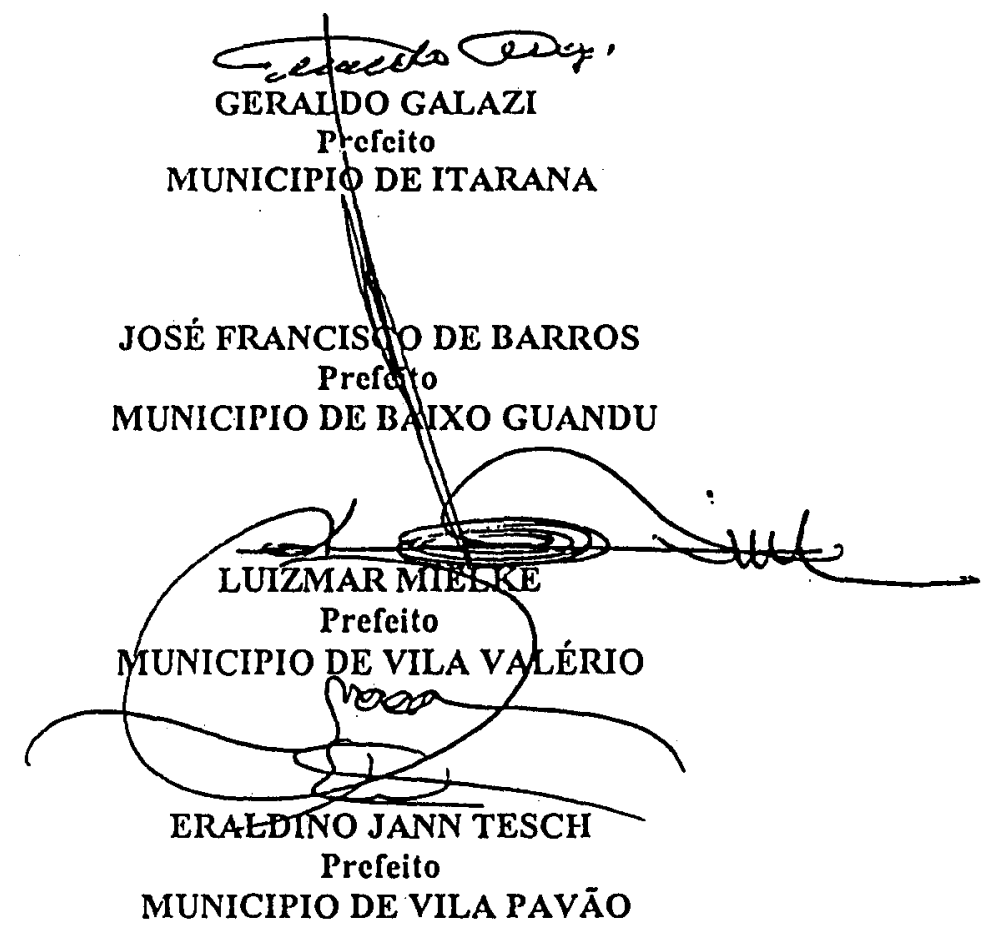

TESTEMUNHAS:

Dr. CARLOS ROGÉRIO MELLO DA SILVA

Pró-Reitor de Extensão/UFES

CPF: 173.942.527-87

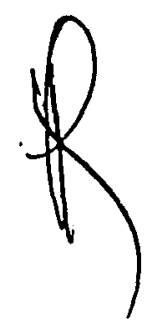

Dr. PAULO MENDES PEÇANHA

Diretor do HUCAM/UFES

CPF: 249.990.247-72

Sr. WLSON MÁRIO ZANETTI

Dirctor do CBM/UFES

CPF: 086.455.907-00 


\section{ANEXO 3}

PDR - Plano Diretor de Reglonalizaç5o 2003

$\triangle$ - POLO MACHORREGIONAL.

- polo microrregional

Macrorreglëo Norte - Colatina - Linhares:

○. SEDE DE Módulo Microrregiöes:

Sāo Mateus
Colatina
Linhares

Macrorregläo Centro - Vitórla Mierarregiöes:

O Serra-Santa Teresa

Q vitoria

Vila Velha - Venda Nova do Imigrante

Macrorreglä̌ Sul - C achoelro Microrregiöes:

Cachoeiro de Itapemirim

Guaqui

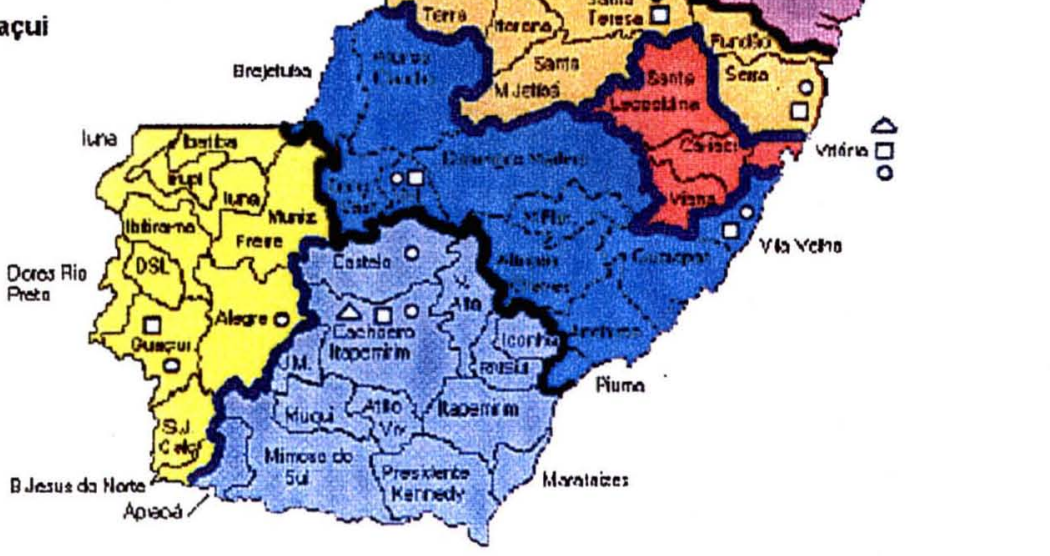




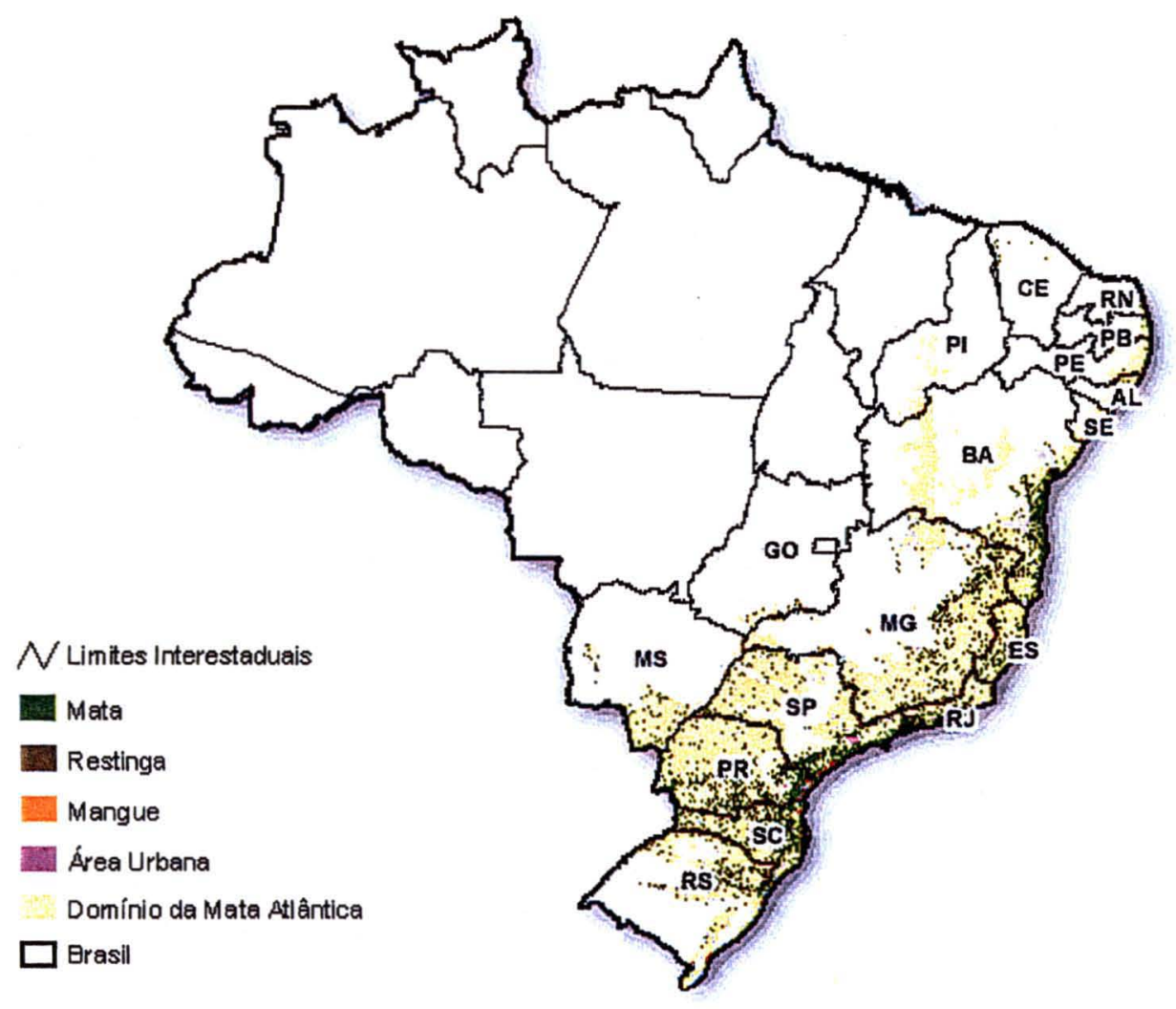


ANEXO 5 - ATLAS DA MATA ATLÂNTICA NO MUNICÍPIO DE SANTA MARIA DE JETIBÁ

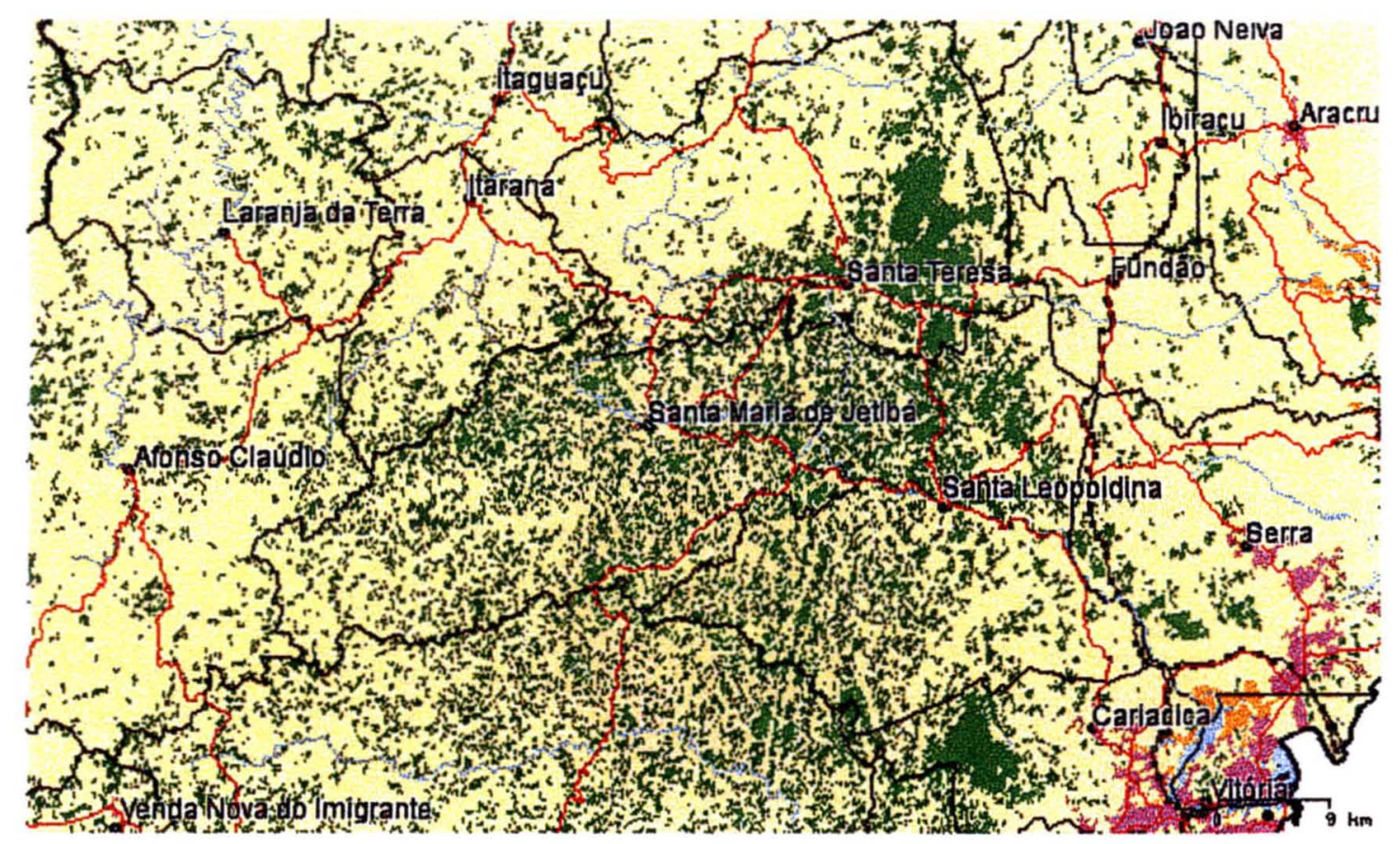




\section{ANEXO 6}

UNIVERSIDADE FEDERAL DO ESPIRITO SANTO-UFES/ASSOCIAÇÃO ALBERGUE MARTIN LUTERO-AAMUSECRETARIA ESTADUAL DE SAÚDE-SESA. PROGRAMA DE ASSISTÉNCIA DERMATOLÓGICA AOS LAVRADORES POMERANOS NO INTERIOR DO ESPÍRITO SANTO.

LOCAL DO ATENDIMENTO: Mês/Ano:

No Prontuário:

\section{DADOS PESSOAIS}

Nome:

Sexo: Cor: Estado Civil:

Local de nascimento: Data de nascimento:

Endereço atual:

Tempo de residência no endereço atual:

Atividade principal: Idade inicio de atividade:

Origem familiar: Materna Paterna

Tipo de pele:

( ) 2

( ) 3

( ) 4

( ) 5

Grau de distrofia solar: () Leve () Forte () Severa () Ausente () Pré-distrofico Número de horas de exposição ao sol no dia: ( ) $-9+14$ hs ( ) $+9-14$ hs () Ambas Uso de prot.contra o sol: ( ) chapéu ( ) manga compr. ( ) calça compr.( ) filtro solar $\begin{array}{llll}\text { História câncer de pele familia } & \text { ( ) } \operatorname{sim} & \text { ( ) não } & \text { ( ) ignorado }\end{array}$ $\begin{array}{llll}\text { História outro cânceres na família } & (\text { ) } \operatorname{sim} & \text { ( ) não } & \text { ( ) ignorado }\end{array}$

EVOLUCÃO CLINICA

Local da lesão

Hipótese diagnóstico clínico:

Biopsia: Tipo de tratamento:

Obs:

Local da lesão

Hipótese diagnóstico clínico:

Biopsia: Tipo de tratamento:

Obs: 